OPEN ACCESS

Edited by:

Tianzi Jiang,

Chinese Academy of Sciences, China

Reviewed by:

Michael E. Hasselmo, Boston University, United States

Baiying Lei,

Shenzhen University, China

*Correspondence:

Leon Stefanovsk

leon.stefanovski@charite.de

Petra Ritter

petra.ritter@charite.de

Received: 16 November 2020 Accepted: 08 March 2021 Published: 01 April 2021

Citation:

Stefanovski L, Meier JM, Pai RK Triebkorn P, Lett T, Martin L, Bülau K,

Hofmann-Apitius M, Solodkin A, Mclntosh AR and Ritter P (2021)

Bridging Scales in Alzheimer's

Disease: Biological Framework

for Brain Simulation With

The Virtual Brain.

Front. Neuroinform. 15:630172.

doi: 10.3389/fninf.2021.630172

\section{Bridging Scales in Alzheimer's Disease: Biological Framework for Brain Simulation With The Virtual Brain}

\author{
Leon Stefanovski ${ }^{1,2 *}$, Jil Mona Meier ${ }^{1,2}$, Roopa Kalsank Pai ${ }^{1,2,3}$, Paul Triebkorn 1,2,4, \\ Tristram Lett ${ }^{1,2}$, Leon Martin ${ }^{1,2}$, Konstantin Bülau ${ }^{1,2}$, Martin Hofmann-Apitius ${ }^{5}$, \\ Ana Solodkin ${ }^{6}$, Anthony Randal Mclntosh ${ }^{7}$ and Petra Ritter 1,2,3,8,9*
}

${ }^{1}$ Berlin Institute of Health at Charité - Universitätsmedizin Berlin, Berlin, Germany, ${ }^{2}$ Charité - Universitätsmedizin Berlin, Corporate Member of Freie Universität Berlin and Humboldt-Universität zu Berlin, Department of Neurology with Experimental Neurology, Brain Simulation Section, Berlin, Germany, ${ }^{3}$ Bernstein Center for Computational Neuroscience Berlin, Berlin, Germany, ${ }^{4}$ Institut de Neurosciences des Systèmes, Aix Marseille Université, Marseille, France, ${ }^{5}$ Fraunhofer Institute for Algorithms and Scientific Computing SCAI, Sankt Augustin, Germany, ${ }^{6}$ Behavioral and Brain Sciences, University of Texas at Dallas, Dallas, TX, United States, ${ }^{7}$ Baycrest Health Sciences, Rotman Research Institute, Toronto, ON, Canada, ${ }^{8}$ Einstein Center for Neuroscience Berlin, Berlin, Germany, ${ }^{9}$ Einstein Center Digital Future, Berlin, Germany

Despite the acceleration of knowledge and data accumulation in neuroscience over the last years, the highly prevalent neurodegenerative disease of $A D$ remains a growing problem. Alzheimer's Disease $(A D)$ is the most common cause of dementia and represents the most prevalent neurodegenerative disease. For $A D$, disease-modifying treatments are presently lacking, and the understanding of disease mechanisms continues to be incomplete. In the present review, we discuss candidate contributing factors leading to $A D$, and evaluate novel computational brain simulation methods to further disentangle their potential roles. We first present an overview of existing computational models for $A D$ that aim to provide a mechanistic understanding of the disease. Next, we outline the potential to link molecular aspects of neurodegeneration in $A D$ with large-scale brain network modeling using The Virtual Brain (www.thevirtualbrain.org), an open-source, multiscale, whole-brain simulation neuroinformatics platform. Finally, we discuss how this methodological approach may contribute to the understanding, improved diagnostics, and treatment optimization of AD.

Keywords: Alzheimer's disease, The Virtual Brain, brain simulation, multi-scale brain modeling, connectomics

\section{INTRODUCTION}

Every second senior with age above 90 years suffers from Alzheimer's disease (AD) or another dementia (Robinson et al., 2018a). The US's mortality rate for people with this neurodegenerative disease exceeds that of breast cancer and prostate cancer combined (Alzheimer's Association, 2019). Beyond the impact on patients' and their families' life circumstances, neurodegenerative diseases have an enormous economic impact and hence pose a massive societal burden. The Alzheimer's Association's latest report estimates the annual medical and care costs attributed to $\mathrm{AD}$ in the US at $\$ 290$ billion in 2019 (Alzheimer's Association, 2019). By 2050, this number is expected to 
rise as high as $\$ 1.1$ trillion (Alzheimer's Association, 2018). It is stated in the same report that early diagnosis at the stage of mild cognitive impairment (MCI) could save up to $\$ 7.9$ trillion in cumulated medical and care costs by the year 2050. While the prevalence of $\mathrm{AD}$, the most common type of neurodegenerative disease (Robinson et al., 2018a; Alzheimer's Association, 2019), increases, the underlying disease mechanisms are still not understood. No disease-modifying treatment exists for $\mathrm{AD}$.

Despite the collection of large data sets and major advances in high throughput computational methods, theoretical frameworks that link the many pieces of observations together can aim to infer novel insights about the underlying causes (Ritter et al., 2013; Schirner et al., 2018; Solodkin et al., 2018; McIntosh and Jirsa, 2019). The brain has multiple organization levels (e.g., molecular, cellular, ensemble- and region-level), including both feedback and feedforward interactions between and within those different levels (Solodkin et al., 2018). These dependencies are non-linear, leading to emergent phenomena-features of the system that cannot be understood by the simple "sum" of its parts (Ritter et al., 2013). Small perturbations in such non-linear systems can have enormous, widespread consequences. In the brain, interactions traverse many spatial and temporal scales, thus focusing on one scale can underestimate the emergent phenomena at other scales. Integrative brain modeling allows for the analysis of these multiple scales in parallel (Schirner et al., 2018), while computational neuroscience provides mathematical tools as the analysis of structured flows on manifolds (McIntosh and Jirsa, 2019) to understand the underlying dynamics.

A mechanistic understanding of AD could open new horizons for early diagnostics and cause-targeting treatments. Recent pharmacological clinical trials testing substances such as antiAmyloid-beta (Gilman et al., 2005; Lannfelt et al., 2008; Winblad et al., 2012; Farlow et al., 2015; Sevigny et al., 2016; Vandenberghe et al., 2017; Panza et al., 2019), tau-protein targeting (Yanamandra et al., 2015; Bachurin et al., 2017; Jadhav et al., 2019), and immune-modulating substances used for rheumatoid arthritis (Jaturapatporn et al., 2012; Chou et al., 2016) have experienced significant setbacks (Panza et al., 2019). The development of novel therapeutics would benefit from theoretical and computational approaches (Hofmann-Apitius et al., 2015; Selkoe and Hardy, 2016; Solodkin et al., 2018).

We hypothesize that an important contribution to understanding and curing $\mathrm{AD}$ lies in characterizing the features and processes that control emergent phenomena in the brain. A deep understanding of state-of-the-art biological research on $\mathrm{AD}$ and detailed knowledge of computational brain modeling tools are essential to reach this goal. In this review, we summarize current findings of $\mathrm{AD}$ pathogenesis from genomics to connectomics-describing the contribution of the classic hallmark proteins as well as current research on the Notch-1 pathway, neurotransmitters, polygenetic factors, neuroinflammation, and neuroplasticity. In the second part, we present various previous approaches to computational modeling of $\mathrm{AD}$ disease mechanisms and discuss their benefits and disadvantages. The last part describes The Virtual Brain (www.thevirtualbrain.org) as a multiscale brain simulation platform that enables linking molecular signaling cascades with large-scale brain simulation. An overview of the structure of this article is given by the flowchart in Figure 1.

\section{BACKGROUND}

\section{Historical Considerations}

While dementia is nowadays a descriptive term for (acquired) severely impaired cognitive function due to a brain disease, dementia has historically been understood as a mainly physiological loss of mental function in the elderly (Schorer, 1985). Psychiatrists had therefore contrasted cognitive disorders of young people ("dementia praecox"), classified today as schizophrenia, for example, with dementia in old people, "dementia senilis"-i.e., the classification of dementia was dependent on the age at which the cognitive impairment occurred (Kendler, 2009). A profound challenge to this concept was posted in 1907 by an observation of Alois Alzheimer. His patient, Auguste D., had characteristic psychopathology of dementia senilis rapidly progressing-at an early age of 56 years (Alzheimer, 1907, 1911). Based on his observations of an "unusual disease," a new neurologic and psychiatric research field emerged. Various mechanisms, risk factors, etiologic components (i.e., underlying causes such as neurotoxic proteins, risk-modifying genes, etc.), and comprehensive classifications of cognitive disorders were developed.

Interestingly much later in 2013 (Müller et al., 2013), it was shown that Auguste D. suffered from an early-onset variant of Alzheimer's dementia-a truly "unusual" and rare disease as one of the monogenetic forms with a mutation in the presenilin gene 1 (PSEN1) (Müller et al., 2013). Nevertheless, the primary cause of $\mathrm{AD}$ and also criteria for its diagnosis still remain unclear. Even the disease-defining biochemical findings of pathology in $\mathrm{AD}$, represented by Amyloid-beta ( $\mathrm{A} \beta 40$ and $\mathrm{A} \beta 42$, hereafter Abeta) and phosphorylation of Tau protein (TAU for tubulinassociated unit or by the Greek letter $\tau$, hereafter Tau; for a review, see Bloom, 2014), remain controversial as causative of disease trajectory and cognitive symptoms. Nevertheless, their presence during pathogenesis is undisputable (Jellinger, 1997; Hyman et al., 2012; Nelson et al., 2012).

\section{Definition and Diagnostic Criteria}

Nosology is the discipline of disease classification based on the underlying mechanisms. In this sense, a disease class can only be assigned if the respective disease's underlying etiology has been established. Otherwise, we speak of a "syndrome" or "disorder" (Jack et al., 2018). The dementia syndrome encompasses a broad array of different possible etiologies of cerebral or systemic origin (Wallesch and Förstl, 2012; Robinson et al., 2018a). Clinically it presents as a set of signs and symptoms. The affected neurocognitive domains are the higher cortical functions: memory, language, attentional processing, executive functions, and visuospatial domains. Different diagnostic criteria are currently used for the diagnosis of AD.

Among the most commonly used diagnostic criteria is the 1984 National Institute of Neurological and Communicative Disorders and Stroke and Alzheimer's Disease and Related 


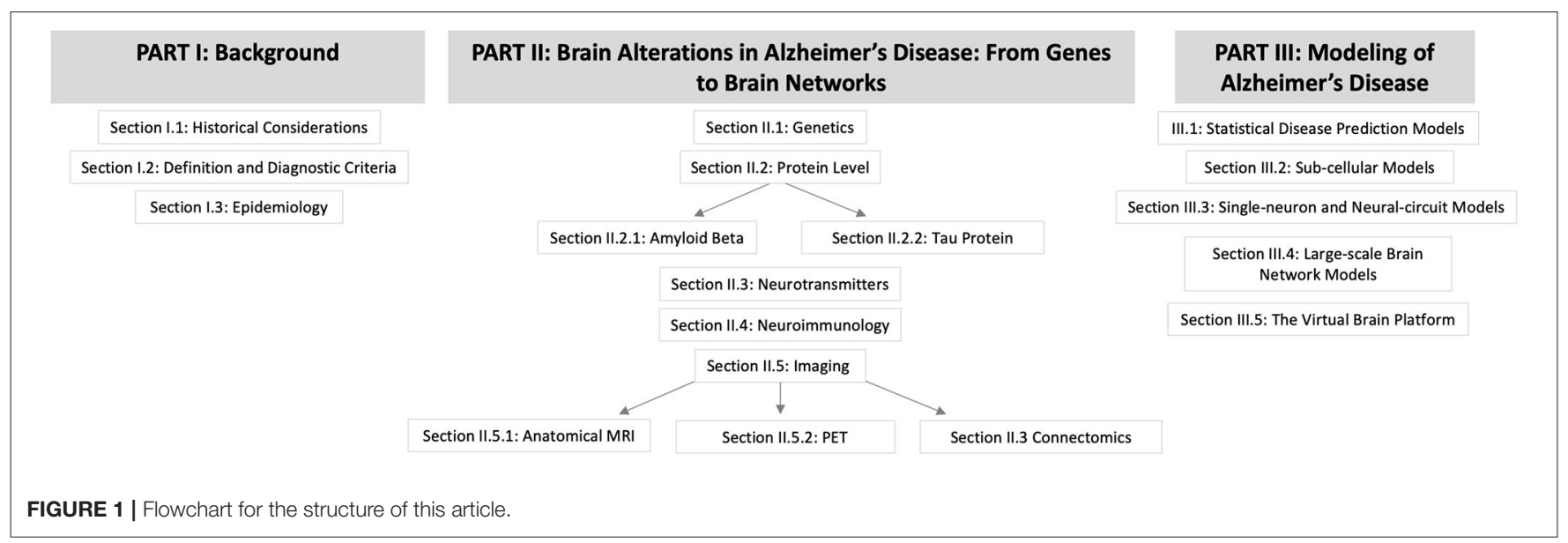

Disorders Association (NINCDS-ADRDA) definition of possible and probable $\mathrm{AD}$ purely by clinical (e.g., daily-life impairments) and neuropsychological criteria without further diagnostic evaluation by technical means (McKhann et al., 1984). At the core of this definition are the presence and slow progression of cognitive decline in two or more cognitive domains, including memory, and the absence of alternative causes of dementia. The 2011 revision of these criteria further specified that impairment in activities of daily living is necessary for the diagnosis of dementia (McKhann et al., 2011).

In clinical practice, a diagnosis is mainly made based on the definition of probable AD according to NINCDS-ADRDA and by excluding possible other causes of dementia (Blennow et al., 2006). A challenge with this purely symptomatic definition is posed by the various phenomenological forms of $\mathrm{AD}$ (Wallesch and Förstl, 2012). Clinical symptoms and neurodegeneration occur on a continuum. They can vary tremendously between patients. The most common phenotype of $\mathrm{AD}$ is the slowly progressive amnestic variant. However, it is not uncommon for language disorders, disorientation, apraxia, or neuropsychiatric signs such as affective symptoms to appear first, while memory deficits do not seem to be predominant. This heterogeneity in phenotypes can have various causes, such as educational and social factors, the individual brain's structural vulnerability, or the patient's cognitive "reserve" (Stern, 2012).

The clinical definition of $\mathrm{AD}$ is further complicated by the overlap of symptoms with those of other dementias and comorbidities that can influence the clinical presentation. For example, if the patient also suffers from depression, possibly caused by beginning cognitive decline, this mood disorder itself can impact memory. And if patients also have Parkinson's disease-do they then necessarily have so-called Parkinson's dementia? Or do they suffer from $\mathrm{AD}$ and Parkinson's disease at the same time? Or has the neurodegeneration caused by Parkinson's disease diminished the cognitive reserve, which leads to the clinical onset of $\mathrm{AD}$ ?

Unlike the original NINCDS-ADRDA classification, the current 2018 National Institute of Aging and Alzheimer's
Association (NIA-AA) diagnostic definition is based on the presence of Abeta and Tau proteins in cerebrospinal fluid or positron emission tomography (PET) and atrophy indicating neurodegeneration in brain imaging. The NIA-AA definition introduces the so-called $\mathrm{AT}(\mathrm{N})$ classification to standardize biomarker findings in $\mathrm{AD}$ : therein $\mathrm{A}$ stands for positive Abeta biomarkers, $\mathrm{T}$ for phospho-Tau biomarkers, and $\mathrm{N}$ for Neurodegeneration markers in cerebrospinal fluid (total Tau burden) or atrophy shown in magnetic resonance imaging (MRI). Positive biomarkers are marked with a "+"-sign. As neurodegeneration is not specific for $\mathrm{AD}, \mathrm{N}$ is usually placed in parentheses. The disease's cognitive dimension is defined separately and can be added to the classification as the letter C in its extension $\operatorname{AT}(\mathrm{N})(\mathrm{C})$. This definition is primarily intended for research and not used in routine clinical practice (Jack et al., 2018). It is debated whether this definition may prevent shifting scientific attention to other relevant candidate factors contributing to $\mathrm{AD}$ - which might lead to missing mechanistic cascades beyond Abeta and Tau proteins (Gauthier et al., 2018).

While the NINCDS-ADRDA definition only considers cognitive symptoms, the NIA-AA definition does not consider cognitive symptoms in their core AT(N) classification (Jack et al., 2018). Therefore, possible, more specific classifications could be "Alzheimer's disease with dementia" or "Alzheimer's disease with mild cognitive impairment" instead of the currently used term "Alzheimer's dementia," which merges both $\mathrm{AD}$ pathologic changes and dementia syndromes (Jack et al., 2018).

Even though clinical classification for probable AD (McKhann et al., 1984) and research frameworks as the definition of $\mathrm{AD}$ by dementia with $\mathrm{A}+\mathrm{T}+\mathrm{N}+$ biomarkers exist (Jack et al., 2018), only examination of invasively obtained tissue samples either from living individuals by biopsy or post-mortem at autopsy can provide a definitive diagnosis of $\mathrm{AD}$-by proving the presence of neuritic plaques (with Abeta) or neurofibrillary tangles (with Tau). Autopsy is preferred to highly invasive in vivo interventions for a definitive diagnosis of $\mathrm{AD}$, due to the lack of causal disease-modifying treatment options. The confirmation rate of 
clinically diagnosed AD by autopsy was calculated in a metaanalysis with a sensitivity of $85.4 \%$ and specificity of $77.7 \%$ (Cure et al., 2014). However, even neuropathological examination of brain tissue as the state-of-the-art gold standard method for AD diagnosis often reveals several protein-related pathologies, i.e., those representing the typical picture for $\mathrm{AD}$ plus others that have been associated with different neurodegenerative diseases (Robinson et al., 2018b).

Possible prodromal stages of dementia, e.g., mild cognitive impairment (MCI) and subjective cognitive decline, do not meet clinical criteria for a dementia syndrome because patients do not have deficits in their activities of daily living. In MCI, cognitive deficits are measurable but still do not affect activities of daily living (Petersen et al., 2014). In the case of subjective cognitive decline, it is not possible to objectively measure the deficits in neuropsychological examinations, but patients notice cognitive deficits themselves (Rabin et al., 2015). These states may in some cases be phase transitions of disease progression to dementia. In combination with other factors, they may help to assess an individual's risk of developing manifest dementia (Cheng et al., 2017).

Diagnosis is often an important question for patients and their families-even without helpful therapeutic interventions because it provides more certainty regarding the prognosis of the disease and the development of care plans. However, it is often unclear to what extent distinct types of dementia and related disorders contribute to cognitive impairment (Ashraf et al., 2016; Leyhe et al., 2017).

\section{Epidemiology}

Neurodegeneration is a continuum where several factors, such as proteinopathies, vascular and immunological changes, are likely to interact (Robinson et al., 2018b). Within the spectrum of dementias, the most common dementia is due to $\mathrm{AD}$, followed by vascular dementia and mixed dementia which is a combination of $\mathrm{AD}$ and vascular dementia (American Psychiatric Association, 2013) (Figure 2, data from Robinson et al., 2018a). Frontotemporal dementias and Parkinsonian syndromes, particularly Lewy-body dementia and Parkinson's dementia, occur with lower prevalence than AD (Robinson et al., 2018a). A systematic overview of the most common and clinically important dementias is presented in Figure 3. Dementias can occur due to primary neurodegenerative diseases, i.e., $\mathrm{AD}$, mixed dementia, frontotemporal and Lewy-body dementia, and due to secondary dementias linked to vascular changes, immunology, infections, and other diseases (Figure 3). Nevertheless, this differentiation is a simplification, as many secondary dementias arise from neurodegenerative processes during the disease course of primarily non-neurodegenerative diseases. A well-known example is the neurodegenerative course in late stages of multiple sclerosis (Bermel, 2017).

The relevance of a correct diagnosis of the specific form of dementia results from the different treatment strategies and prognoses related to different types of dementia. Some possible causes of dementia are curable, such as normal pressure hydrocephalus, metabolic disorders, and immunologic or infectious causes. While presently no disease-modifying therapy for any primary neurodegenerative disease exists (Alzheimer's Association, 2019), future therapies, as well as ongoing symptomatic and more experimental studies, may benefit from a careful patient stratification. This is particularly important for approaches that aim to model $\mathrm{AD}$ mechanisms with patient data, as the resulting model will only be as specific to $\mathrm{AD}$ as the patients' assigned correct (and strict) diagnosis. An overview of the experimental therapies that are in development for AD can be found in Table 1. For the established treatments for other dementia causes, we refer to Table 2.

The population over 80 years of age is the group in which the prevalence of dementia is increasing most rapidly (Fiest et al., 2016). While different pathogenic pathways have been hypothesized for $\mathrm{AD}$ and vascular dementia, it is increasingly acknowledged that both diseases share many risk factors (Love and Miners, 2016). However, interactions of Abeta in AD with vascular factors [e.g., altered blood-brain barrier permeability caused both by microvascular changes and Abeta deposition (Santos et al., 2017)] can be differentiated from cerebral amyloid angiopathy (Banerjee et al., 2020), a distinct vascular disease caused by amyloid, which we will not discuss further here.

An increased rate of cerebrovascular disease manifestations and thus a higher incidence of vascular dementia correlates with lifestyle and atherogenic risk factors such as physical activity (Lindsay et al., 2002; Larson et al., 2006), diabetes mellitus (Pasquier et al., 2006), and hypercholesterinemia (Shepardson et al., 2011a,b), which are also risk factors for AD (Reitz et al., 2011; Love and Miners, 2016). However, mechanisms whereby these factors mediate their impact, have been debated (Santos et al., 2017). One hypothesis is that microvascular lesions remain undiscovered, leading to a failure to diagnose vascular or mixed dementia. Another possibility is the involvement of metabolic pathways in the pathogenesis. Notably, the most important genetic risk factor in the general population is apolipoprotein E (APOE) E4 hetero- or monozygotic, an allele of a metabolic gene that also modulates atherosclerotic risk (Suri et al., 2013; Mahley, 2016). Especially in the elderly, the prevalence of both atherosclerosis and neurodegeneration increases exponentially and could likely affect the same individuals (Rohn, 2014). Although the role of metabolic factors is not clear, epidemiological approaches have shown that up to one-third of cases attributed to $\mathrm{AD}$ might be preventable by addressing these modifiable risk factors (Norton et al., 2014). However, this evidence comes from a mere observational method using the population-attributable risk. This statistical method describes the fraction of the incidence of a disease attributed to one particular risk factor. While this index allows an estimation of the effect that might follow removing the risk factor, as a result of an observational study, it precludes establishing a clear causal relation between observed risk factors and the disease (Siegerink and Rohmann, 2018). For example, if the definition of AD in the underlying observational study is inconsistent and therefore contains also other disease entities as mixed dementia, the population-attributable risk would be related to mixed dementia as well as to AD itself. Therefore, reducing atherosclerotic risk factors might affect the mixed dementia patients instead of "pure" $\mathrm{AD}$ cases. 

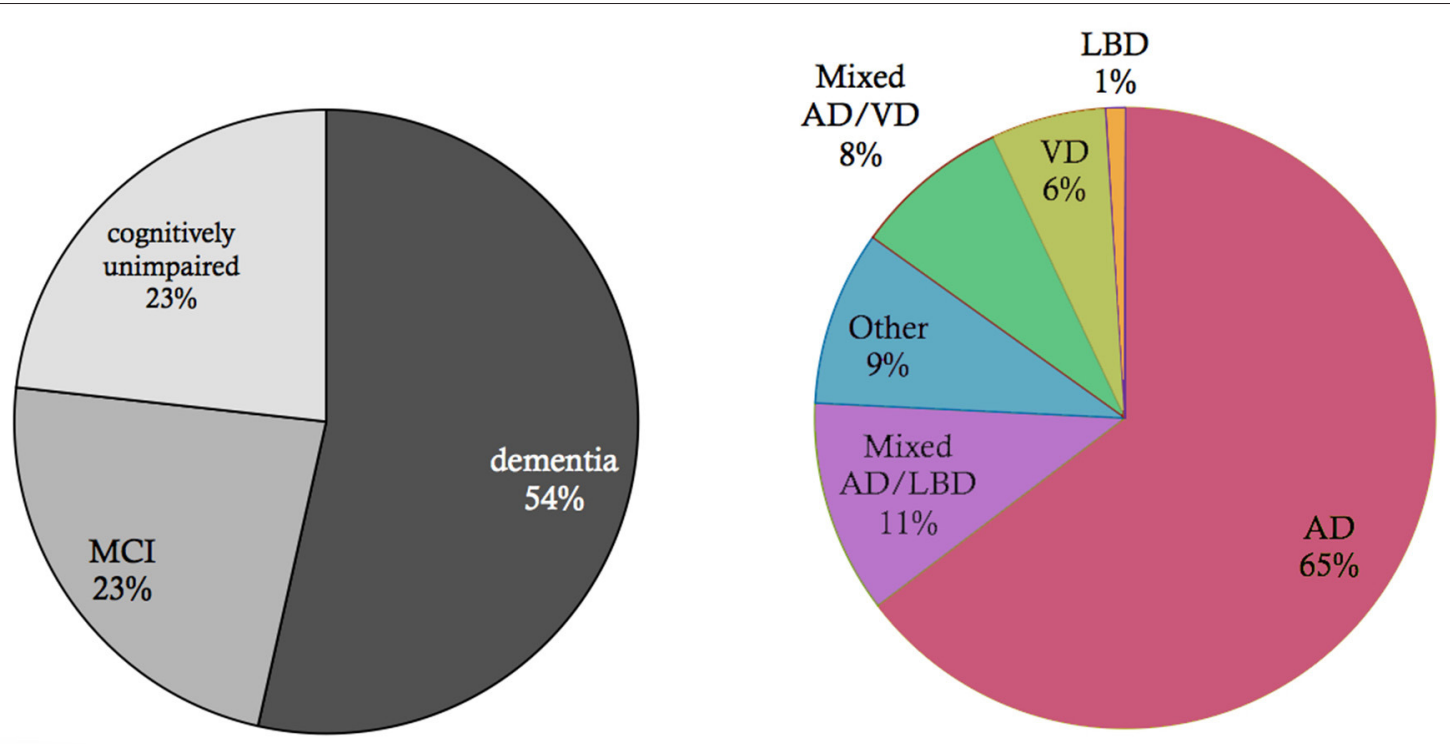

FIGURE 2 | Basic epidemiology of different types of dementia. Data and $p$-values from Robinson et al. (2018a). Shown is an elderly cohort ( $n=185$ ) with a mean age of 97.7 years in an autopsy study. On the left, we see the prevalence of the cognitive states within this cohort at the time of death. More than half of the people suffered from dementia in this age group, while a quarter suffered from mild cognitive impairment (MCl), and another quarter had no cognitive disturbances. On the right, the clinical diagnosis (ante mortem) for the subpopulation that suffered from dementia is shown. Alzheimer's Disease (AD) is the most prevalent form of dementia; however, mixed forms and other primary neurodegenerative dementias as synucleinopathies or frontotemporal lobar degeneration (FTLD) spectrum also play a role as well as vascular dementia (VD). In the post mortem analysis, the full cohort showed at least partial AD-related pathologic changes: $100 \%$ had neurofibrillary tangles of at least Braak stage I, and $63 \%$ had neuritic plaques. The mean Braak stage was in the dementia group 4.1 , in the non-dementia group 3.2 ( $p$ $<0.001)$. However, the dementia group also showed a significant higher Lewy-body pathology $(p=0.018)$ and transactive response DNA-binding protein 43 kDa (TDP-43) pathology $(p<0.001)$ as well as a higher rate of definitive cerebrovascular disease $(p=0.016)$. These findings indicate that in particular in the "super old," different neuropathologic changes are probably concomitant and contribute to the development of cognitive decline in dementia-in contrast to the concept of "pure" $\mathrm{AD}$ as an isolated neurodegenerative disease.

\section{BRAIN ALTERATIONS IN ALZHEIMER'S DISEASE: FROM GENES TO BRAIN NETWORKS}

\section{Genetics}

Early-onset $\mathrm{AD}$ can be a familial disease with rare structural variants or copy number variants in genes that regulate Abeta production and clearance. For example, structural variants in the Amyloid beta precursor protein gene $(A P P)$ affect posttranslational processing of APP by secretases leading to excess Abeta in early-onset AD. The presenilin 1 (PSEN1) and presenilin 2 (PSEN2) genes form the active component of the $\gamma$-secretase complex. It is critical for processing APP and other type-I integral membrane proteins, including members of the Notch signaling pathway and receptor tyrosine-protein kinase erbB-4 (ERBB4) (Sannerud et al., 2016). Autosomal dominant mutations of PSEN1 and PSEN2 affect endopeptidase and carboxypeptidase activity, leading to longer and more toxic forms of Abeta peptides (Ertekin-Taner, 2007; Lanoiselée et al., 2017). Other environmental and genetic factors may contribute to the etiology of early-onset AD (Sun et al., 2017).

In contrast, late-onset $\mathrm{AD}$ is a complex genetic disease in which rare structural variants and common variants, mostly identified by genome-wide association studies, play an influential role in etiology. The heritability of late-onset $\mathrm{AD}$ is estimated to be high, with $\sim 50 \%$ (Pedersen et al., 2004; Ridge et al., 2016)_yet environmental factors are likely to be additionally important (Grant et al., 2002; Wainaina et al., 2014). The single nucleotide polymorphism based heritability estimates are usually high in AD, at 25-30\% (Cuyvers and Sleegers, 2016), compared to other complex genetic brain disorders (Speed et al., 2017; Visscher et al., 2017). APOE E2/E4 polymorphisms alone explain $\sim 25 \%$ of the single nucleotide polymorphism-based heritability, while common single nucleotide polymorphisms explain the remaining 5-7\% (Cuyvers and Sleegers, 2016; Ridge et al., 2016; Kunkle et al., 2019). The most recent three genomewide association studies have identified 40 independent risk loci (Marioni et al., 2018; Jansen et al., 2019; Kunkle et al., 2019). The majority of these loci have functions in three main pathways: lipid metabolism, microglial activation, and APP processing (Andrews et al., 2020). Notably, many of these loci contain functionally relevant single nucleotide polymorphisms that impact expression in $\mathrm{AD}$-associated cortical tissues and correlate with the so-called expression of quantitative trait loci (Kunkle et al., 2019).

\section{Protein Level}

Two of the most relevant proteins associated with the pathogenesis of $\mathrm{AD}$ are Abeta and phosphorylated Tau. Abeta is a human protein that-due to an abnormally cleaved 


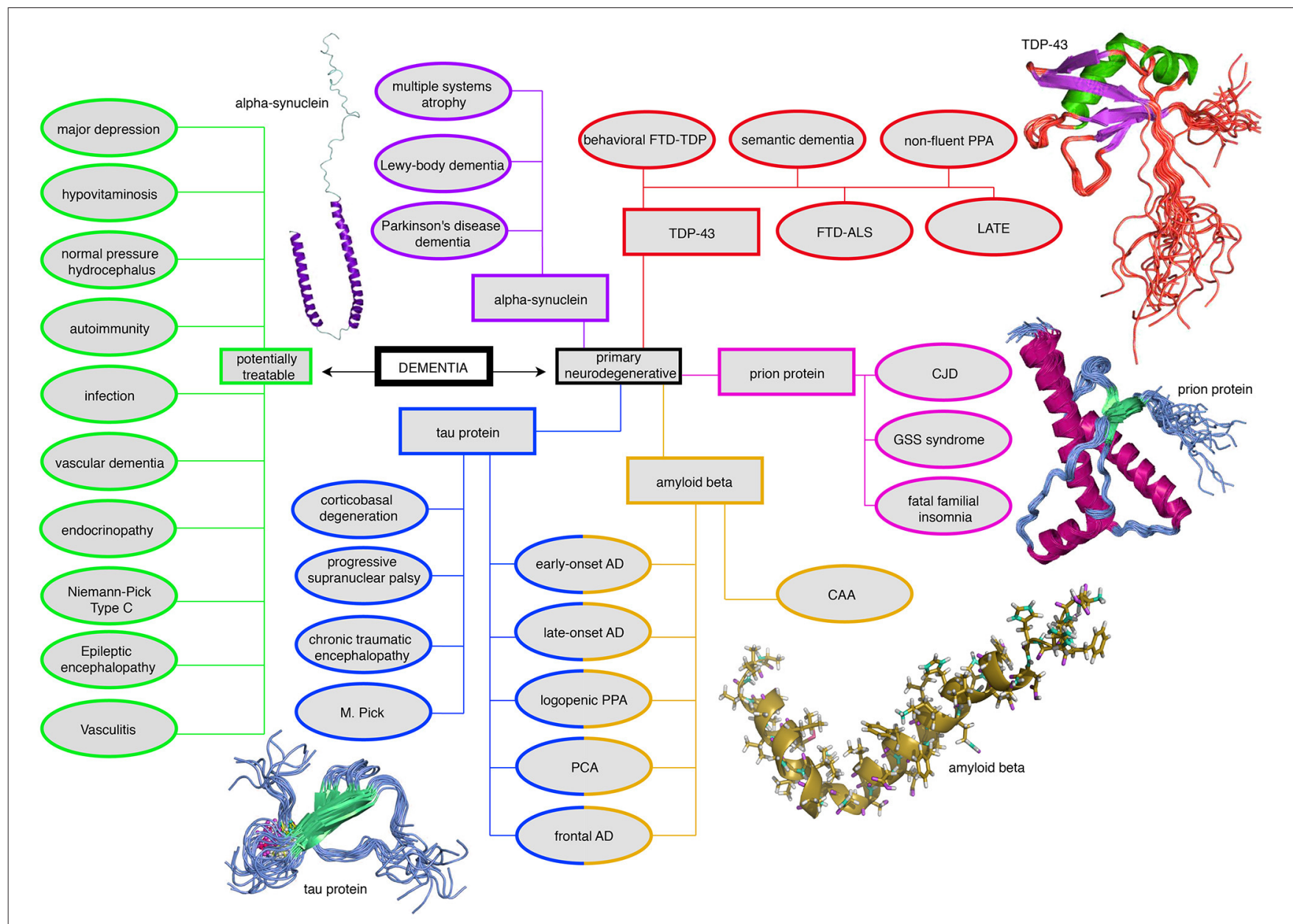

FIGURE 3 | Mind map of the dementia syndrome and its differential diagnoses. The possible etiologies are widely spread across cerebral and systemic diseases. It is important to mention that Alzheimer's Disease (AD) is the most common form of dementia, but AD is not trivial to diagnose, in particular, if it requires to forgo some invasive tests in the elderly. However, the exact diagnosis is of enormous relevance because some possible causes of dementia are curable, such as normal pressure hydrocephalus, metabolic disorders, and immunologic or infectious causes. In the clinic, most patients are diagnosed with AD, vascular dementia, Lewy-body dementia, frontotemporal dementia, or a mixed form thereof (Figure 2). None of the primary neurodegenerative diseases can be treated in a causal and disease-modifying way, besides the treatment of vascular dementia with general atherosclerosis therapy. Their leading proteinopathy sorts the neurodegenerative diseases - caused by Abeta, Tau, prion protein, transactive response DNA binding protein $43 \mathrm{kDa}$ (TDP-43), and alpha-synuclein (Wallesch and Förstl, 2012). Protein images modified from http://www.ebi.ac.uk/. FTD-TDP, frontotemporal degeneration caused by TDP-43; PPA, primary progressive aphasia; FTD-ALS, frontotemporal degeneration with amyotrophic lateral sclerosis; LATE, limbic-predominant age-related TDP-43 encephalopathy; CJD, Creutzfeldt-Jakob's disease; GSS,

Gerstmann-Sträußler-Scheinker (syndrome); CAA, cerebral amyloid angiopathy; PCA, posterior cortical atrophy; M. Pick, Pick's Disease.

configuration-aggregates in neuritic plaques leading to its (neuro-)toxic effects (Klunk et al., 2007; Jack et al., 2009; Villemagne et al., 2009). It can be found both intra- and extracellularly (Hardy and Selkoe, 2002; Walsh and Selkoe, 2007; Selkoe and Hardy, 2016). It has been suggested that the hyperphosphorylation of Tau protein develops as a consequence of the aggregation of Abeta (Blennow et al., 2006). However, phosphorylated Tau is also present in other neurodegenerative diseases not associated with Abeta deposition (Kovacs, 2015). Immunohistochemical analysis of brain tissue, which is more sensitive than standard microscopical tissue examination, reveals up to $92-100 \%$ of Tau in people who died with neurodegenerative disorders at a mean age of 71 years, in contrast to Abeta with 20-57\% (Robinson et al., 2018b). All subjects who met the official clinicopathological criteria for AD [ADNPC, defined as the presence of Abeta plaques, neurofibrillary tangles, and neuritic plaques (Montine et al., 2012)] in standard microscopy also showed Abeta and Tau in immunohistochemistry (Robinson et al., 2018b). However, in the same group of patients, two other protein pathologies were measured: alpha-synuclein (SNCA, associated with several diseases of the Parkinson spectrum) was present in $41-55 \%$ and transactive response DNA-binding protein $43 \mathrm{kDa}$ (TDP-43, associated with amyotrophic lateral sclerosis and frontotemporal dementia) in $33-40 \%$ of patients (Figure 3) (Robinson et al., 2018b). Therefore, "pure" AD was a rare case in this cohort as $65-70 \%$ of confirmed AD patients suffered at least from one other neurodegenerative comorbidity (Robinson et al., 2018b). 
TABLE 1 | Ongoing developments for AD treatment and therapies.

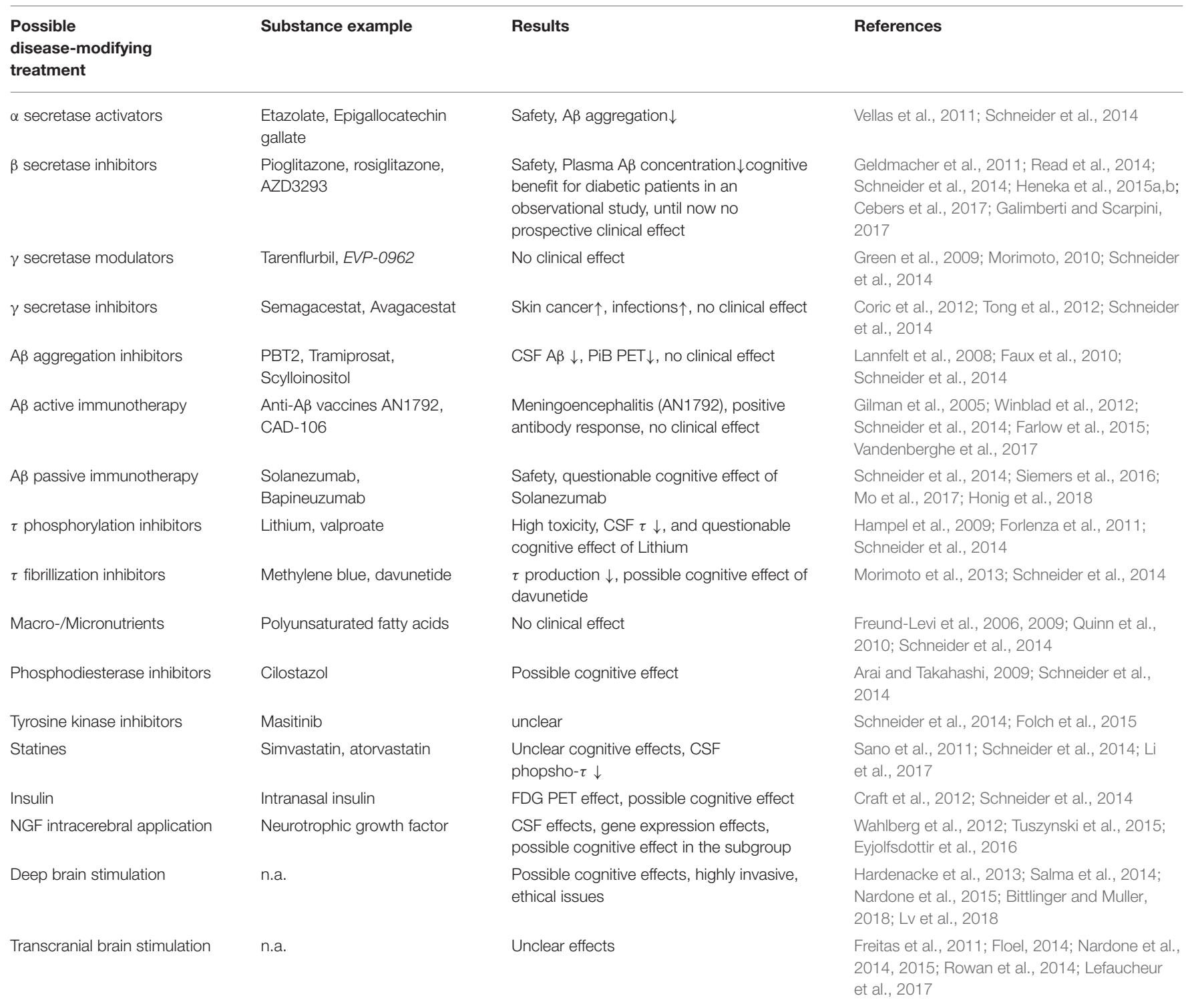

Parts of the table are modified from Schneider et al. (2014), Oertel (2017), and Young et al. (2018). AB, amyloid beta protein; CSF, cerebrospinal fluid; PiB PET/FDG PET, Pittsburgh Compound B/fluordeoxyglucose positron emission tomography; $\tau$, tau protein.

\section{Amyloid-Beta}

The deposition of Abeta typically follows a particular spatiotemporal pattern in the progression of $\mathrm{AD}$. An illustration of this distribution, initially described by Braak and Braak (1991), can be seen in Figure 4. The course can be divided into three general stages (Braak and Braak, 1991, 1997; Taylor and Probst, 2008). Stage A develops along the perirhinal and entorhinal cortices. Stage B involves the hippocampus proper and neighboring regions like the posterior gyrus parahippocampalis. Stage $\mathrm{C}$ also encompasses a wide distribution of neocortical areas. Table 3 lists the brain regions that are specific to each amyloid stage.

One possible explanation of the pathogenic deposition of Abeta is a maladaptive change in its processing, regulated by a group of secretases and other enzymes. We give only a brief overview here. APP is a transmembrane protein whose function has been associated with neural development and synaptic plasticity (Korte, 2019). It can be processed into different subdomains. One possible way is the subsequent procession by the $\alpha$-secretase and the $\gamma$-secretase, called the non-amyloidogenic pathway (Blennow et al., 2006). This "physiological" pathway does not lead to Abeta fragments (with $\beta$-helix), which can later aggregate to plaques, but APP is transformed into a protein subdomain with $\alpha$-helix configuration (Blennow et al., 2006). In another "pathological" pathway, APP is processed to soluble Abeta with a $\beta$-helix configuration by the $\beta$ secretase (and afterwards again by the $\gamma$-secretase). The $\beta$ helices allow molecules to aggregate into Abeta oligomers and 
TABLE 2 | Potentially curable causes of dementia syndromes (Wallesch and Förstl, 2012; Day, 2019).

\begin{tabular}{|c|c|c|}
\hline Curable dementia cause & Diagnostic tool & Therapy \\
\hline Major depression & Clinical & Psychotherapy, anti-depressive pharmacotherapy \\
\hline Nutritive deficiency (Vitamine B12, D, folic acid) & Blood & Substitution \\
\hline Infections (lues, borreliosis, viral) & CSF, Blood, clinical, imaging & Anti-infectious \\
\hline Normal-pressure hydrocephalus & Imaging, tab test & Ventriculoperitoneal shunt \\
\hline Autoimmune encephalitis & CSF, imaging & Immunosuppression, plasmapheresis \\
\hline Vasculitis & CSF, imaging, angiography & Immunosuppression \\
\hline Macroangiopathy & Imaging & Risk factor management, thrombendarteriectomy \\
\hline Microangiopathy & Imaging & Risk factor management \\
\hline Hypothyreosis & Blood & Substitution \\
\hline Niemann-Pick type C & Blood (genetics, oxysterols) & Enzyme substitution \\
\hline Epileptic encephalopathy & EEG, ex juvantibus & Anticonvulsive drugs \\
\hline
\end{tabular}

CSF, cerebrospinal fluid; EEG, electroencephalography.

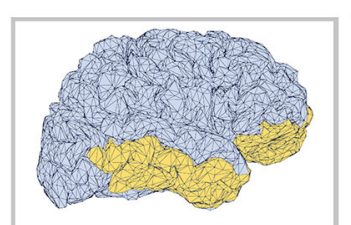

Amyloid stage A
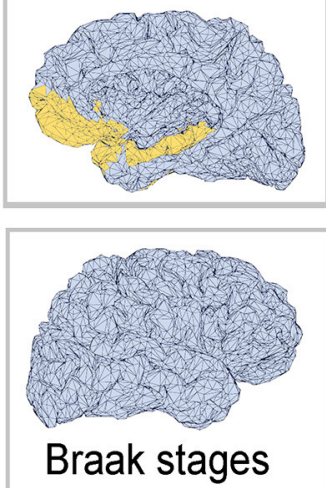

I+II

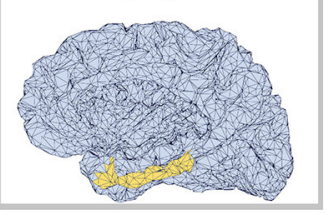

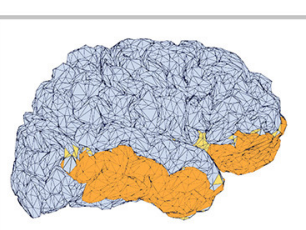
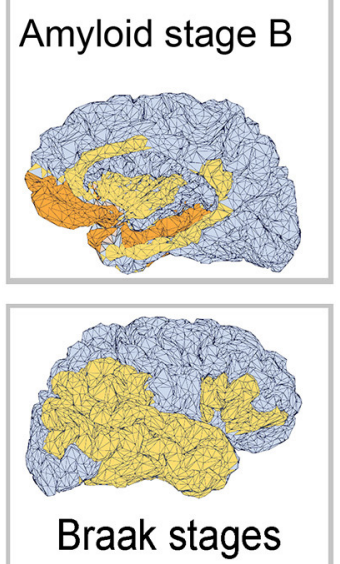

III+IV

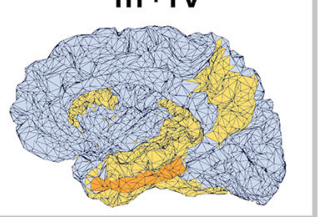

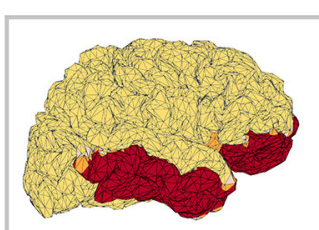
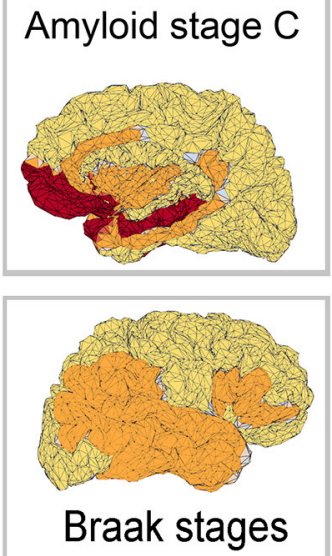

$\mathrm{V}+\mathrm{VI}$

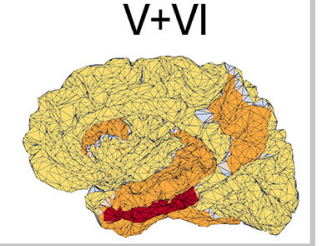

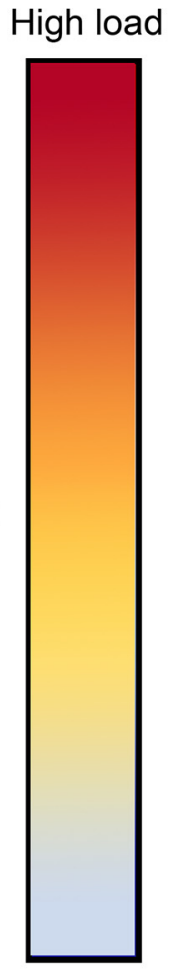

Low load

FIGURE 4 | Visual representation of Abeta and Tau stages according to Braak and Braak (1991, 1997), and Braak et al. (2006). The darker color indicates a higher load of this protein in the respective brain area. The regions are listed in Tables $\mathbf{3}, \mathbf{4}$.

afterwards polymers which become insoluble and deposit in the extracellular space, forming the so-called Abeta plaques. This pathway's activation leads to decreased Abeta concentration in cerebrospinal fluid because its insoluble configuration cannot be measured therein (Blennow et al., 2006; Olsson et al., 2016). The imbalance between these two pathways, represented by the activity of $\alpha$ - and the $\beta$-secretase, is suggested to play a major role in the pathogenesis of $\mathrm{AD}$ and is currently the target of various experimental treatment strategies (Coric et al., 2012; Tong et al., 2012; Ortega et al., 2013; Hsiao et al., 2019; Xia, 2019) (Table 1 and Figure 5).

Another important feature, linked not only to the protein metabolism of Abeta but also to neural development, is the notch receptor 1 (NOTCH1) pathway (Pierfelice et al., 2011; Brai 
TABLE 3 | Stages of amyloid deposition (Braak and Braak, 1991, 1997; Braak et al., 2006).

\begin{tabular}{lll}
\hline $\begin{array}{l}\text { Amyloid deposition - } \\
\text { Stage A }\end{array}$ & Stage B & Stage C \\
\hline $\begin{array}{l}\text { Polar and orbitofrontal } \\
\text { prefrontal cortex; polar, } \\
\text { inferior, central, and } \\
\text { ventral temporal cortex }\end{array}$ & $\begin{array}{l}\text { As stage A, additional: } \\
\text { hippocampus and gyrus } \\
\text { parahippocampalis, } \\
\text { amygdala, posterior and } \\
\text { anterior insula, subgenual } \\
\text { and retrosplenial cingulum, } \\
\text { ventrolateral prefrontal } \\
\text { cortex }\end{array}$ & $\begin{array}{l}\text { As stage B, additional } \\
\text { global neocortical } \\
\text { dissemination }\end{array}$ \\
&
\end{tabular}

et al., 2015; Marathe and Alberi, 2015). NOTCH1 is a membrane protein that plays a major role as the transcription factor for both its intracellular- and extracellular domain (Brai et al., 2016). The processing of NOTCH1 to its subdomains is performed by the $\gamma$-secretase-the same secretase involved in the amyloidogenic and non-amyloidogenic pathway of APP processing (Brai et al., 2016). APP and NOTCH1 are co-substrates in the extracellular domain of the $\gamma$-secretase (Marathe and Alberi, 2015; Brai et al., 2016). NOTCH1 is found in Abeta plaques, and its intracellular signaling is reduced in AD (Brai et al., 2016).

\section{Tau Protein}

In the absence of any additional neuropathological factors in several dementias, phosphorylated Tau may play a major role in the degenerative process of so-called primary tauopathies. This group includes, e.g., progressive supranuclear palsy (Cope et al., 2018), corticobasal degeneration, and the spectrum of frontotemporal dementia (including Pick's disease) (Kovacs, 2015). In contrast, in secondary tauopathies, Tau seems to be involved in the pathogenesis only when other factors are present, as, e.g., in prion diseases and chronic traumatic encephalopathy (Kovacs, 2015) (Figure 3). From this point of view, $\mathrm{AD}$ has a unique context because it is neither classified as a primary tauopathy (due to the concomitant presence of Abeta) nor is the amyloid pathology ultimately linked to Tau's hyperphosphorylation. However, phosphorylated Tau density correlates better with the severity of cognitive decline than the accumulation of Abeta itself (Riley et al., 2002; Bennett et al., 2005). Hence, there is controversy about the role of Tau protein in $\mathrm{AD}$ as either an independent disease factor or an indicator of general neurodegeneration derived from the neurotoxic effects of amyloid deposition. Clinical trials, based on anti-Tau-antibodies and -vaccines, modulators of Tau aggregation, and antisense oligonucleotides targeting its gene the microtubule associated protein tau (MAPT), are currently ongoing for $\mathrm{AD}$ patients (Yanamandra et al., 2015; Jadhav et al., 2019) (Table 1).

Tau protein pathology is complex and involved in several neurodegenerative processes (Kovacs, 2015; Guo et al., 2017; Cope et al., 2018). Different forms of neurodegeneration lead to the deposition of Tau (Spires-Jones et al., 2017), which can be measured in the cerebrospinal fluid (Ossenkoppele et al., 2015). In general, the phosphorylation homeostasis of the Tau protein is maintained by a series of kinases. A turn of this equilibrium toward hyperphosphorylation of Tau protein shows two consequential effects: first, Tau loses its natural function of microtubule stabilization followed by disturbed axonal transportation of vesicles, leading to disturbed axonal signal transmission. Second, the hyperphosphorylated Tau protein polymerizes to insoluble filaments and big tubular aggregates, the so-called neurofibrillary tangles. The brain's clearance system is unable to eliminate these aggregates leading to inflammatory processes and, eventually, neuronal death (Blennow et al., 2006). These phenomena have been observed using three methods: (i) microscopy of neuronal tissue with neurofibrillary tangles, (ii) an increased concentration of the hyperphosphorylated Tau section in the cerebrospinal fluid, and (iii) non-invasive nuclear imaging methods that trace Tau protein (flortaucipir PET) (Cope et al., 2018). Because of its two main effects, namely neuronal death and axonal dysfunction, Tau leads to a disconnection of the affected regions in the brain network. This has been measured in regions with high binding of flortaucipir PET tracing the Tau protein (Cope et al., 2018). However, the Tau protein is a better marker in diagnostics for the severity of cognitive dysfunction than Abeta in AD (Degerman Gunnarsson et al., 2014). The local neurotoxic effects of Tau can be linked to network disruption and an increased clinical score of apathy symptoms (Kitamura et al., 2018).

The stages of Tau deposition (defined by post mortem histopathological criteria), similar to Abeta stages, are called Braak Tau deposition stages (Braak and Braak, 1991, 1997; Braak et al., 2006), and show a characteristic spatiotemporal pattern formation in the course of typical AD. The patterns of post mortem neuropathological and nuclear imaging findings are illustrated in Table 4. For this reason, most patients with "typical" AD show early Tau depositions years before the onset of symptoms in the medial temporal lobe. The so-called transentorhinal stage consists of stages I and II and concerns the transentorhinal cortex in the ventromedial temporal lobe, and later the entorhinal cortex in the lamina granularis externa (Lamina II). This prodromal stage is followed by a further spreading into the limbic lobule (stages III and IV, involving mainly the hippocampus and the temporal allocortex) and finally into the neocortex (stages V and VI) (Braak and Braak, 1991, 1997; Braak et al., 2006). The six stages of this dissemination process of Tau deposition fall into three functional stages (i.e., transentorhinal/entorhinal, limbic, and neocortical), and have a high correlation to the cognitive decline of an individual AD patient (Riley et al., 2002; Bennett et al., 2005). Only a few amyloid plaques and often no clinical symptoms can be observed in this first functional category. In detail, the non-obligatory prodromal stage of AD is characterized by an MCI, which often converts to the full clinical presentation of dementia and has, thus, a significant correlation to higher Braak Tau deposition stages (Riley et al., 2002; Bennett et al., 2005). In the limbic stage, the Tau deposition is strongly associated with clinical symptoms of MCI stage (e.g., memory function, verbal fluency, impairments of daily life activities) (Riley et al., 2002). In the highest functional stage, which concerns the neocortex, most patients have amnestic impairment (Braak and Braak, 1991, 1997; 
TABLE 4 | Braak stages of Tau deposition (Braak and Braak, 1991, 1997; Taylor and Probst, 2008).

\begin{tabular}{|c|c|c|c|c|}
\hline \multicolumn{2}{|c|}{ Tau deposition stage } & \multirow{2}{*}{$\begin{array}{l}\text { Anatomic region } \\
\text { Transentorhinal cortex, perirhinal cortex (medial temporal } \\
\text { lobe) }\end{array}$} & \multirow{2}{*}{$\begin{array}{l}{ }^{18} \text { F-AV-1451 PET } \\
\text { Entorhinal cortex, Hippocampus, Parahippocampal } \\
\text { cortex (Cho et al., 2016) }\end{array}$} & \multirow{2}{*}{$\begin{array}{l}\text { Diagnosis (PET) } \\
\mathrm{MCl}\end{array}$} \\
\hline I & Trans-entorhinal & & & \\
\hline$\|$ & & Entorhinal cortex (lamina II) & & \\
\hline III & limbic & Hippocampus, temporal allocortex & & \\
\hline IV & & Neocortical association fields next to the hippocampus & $\begin{array}{l}\text { Isocortical spreading, particular differences to } \mathrm{MCl} \text { in the } \\
\text { precuneus, prefrontal, temporal, and inferior parietal } \\
\text { cortex (Cho et al., 2016) }\end{array}$ & $A D$ \\
\hline V & Isocortical & Neocortex, spreading to dorsolateral & & \\
\hline $\mathrm{VI}$ & & Primary sensory and motor areas & & \\
\hline
\end{tabular}

${ }^{18} \mathrm{~F}$-AV-1451 PET, ${ }^{18} \mathrm{~F}$-flortaucipir positron emission tomography; $\mathrm{MCl}$, mild cognitive impairment.

Taylor and Probst, 2008). Similarly, the Tau protein deposition traced by flortaucipir PET correlates with the clinical presence of $\mathrm{MCI}$ as well as with $\mathrm{AD}$ and with cognitive performance (Cho et al., 2016).

There seems to be a high correlation in general of Tau and amyloid deposition patterns described above; however, it is worth mentioning that the three stages of amyloid deposition described by Braak and Braak (Braak and Braak, 1991, 1997; Taylor and Probst, 2008), A, B, and C, do not strictly coincide with the Tau deposition stages I-VI. The six stages of Tau deposition follow a stricter distribution course and show some overlap with the amyloid deposition stages, in particular, within the ventromedial temporal allocortices and pro-isocortices and later temporoparietal neocortices (Tables 3, 4 and Figure 4). The effects of both pathologies differ to a larger extend, for instance, in the specificity to $\mathrm{AD}$, to neurodegeneration in general, or to cognitive functions (Van Hoesen and Solodkin, 1994). However, the "macro sequence" of archicortex-mesiotemporal cortex-temporoparietal neocortex is the same, and the impaired cognitive domains in $\mathrm{AD}$ (memory and visuoconstruction) are associated with those regions.

\section{Neurotransmitters}

Of interest in $\mathrm{AD}$ pathogenesis are especially two transmitter systems: the cholinergic and the glutamatergic systems. Acetylcholine is one of the essential neurotransmitters in the brain. Its functions are pleiotropic: acetylcholine is a fundamental transmitter in the peripheral vegetative nervous system and neuromuscular transmission. In the brain, acetylcholine is involved in many functional systems but particularly involved in the modulation of synaptic signaling (Van der Zee et al., 2011). The dysfunction of the cholinergic system is relevant in the pathogenesis of $\mathrm{AD}$, as acetylcholine is essential for memory consolidation (Ferreira-Vieira et al., 2016). Anti-dementia drugs work as inhibitors of the acetylcholine esterase, increasing the concentration of acetylcholine in the synaptic gap, leading to slightly improved memory function (Ferreira-Vieira et al., 2016). Cholinergic effects have been shown to be involved in learning processes in the hippocampal formation by the enhancement of synaptic modification and selective presynaptic inhibition of synaptic transmission in different regions and layers (Hasselmo and Schnell, 1994). The beneficial effect of acetylcholine on memory encoding is probably mediated by strengthened synaptic modification, afferent input and spiking behavior (Hasselmo, 2006). On a functional level, cholinergic modulation has been linked to working memory for novel stimuli (Hasselmo and Stern, 2006). It has been hypothesized that synaptic connections exist for previously familiar stimuli (such as words or numbers) (Hasselmo and Stern, 2006), which makes working memory of these stimuli independent of cholinergic modulation (Crow and Grove-White, 1973; Broks et al., 1988). Moreover, acetylcholine is involved in excitability modulation in AD. While memory performance during task functional MRI can be correlated with activation of medial temporal lobe regions as the hippocampus and gyrus parahippocampalis, it was shown that stronger recruitment of those regions is associated with cognitive decline in MCI patients (Dickerson et al., 2004). The underlying hypothesis stated that hyperactivation could be seen as a compensatory effect due to hippocampal atrophy (Dickerson et al., 2004). Similarly, task functional MRI in cognitively still unimpaired PSEN1 mutation carriers revealed increased activation of the right anterior hippocampus compared to non-carrier controls, many years before the estimated disease onset of familial AD (Quiroz et al., 2010). This can be brought into context with the role of cholinergic suppression in learning and $\mathrm{AD}$. Runaway synaptic modification describes the phenomenon of exponential gain in synaptic connection strength, caused by activity evolving across already strengthened connections (Hasselmo, 1994). It can be seen as a natural consequence of Hebbian rules (Morris, 1999), but it interferes with learning processes, wherein only a selective subset of connections should be strengthened (the pattern to learn), while other existing strong connections should remain stable (Hasselmo, 1994). Cholinergic presynaptic inhibition of transmission along associative fibers offers a mechanism to protect from runaway synaptic modification during learning (Hasselmo and Bower, 1992). However, when hyperactivity in $\mathrm{AD}$ is introduced, it leads to more runaway synaptic modification, while vice versa, the strengthening of undesired networks can lead to more hyperactivity in a vicious circle (Hasselmo, 1994). The continuous presence of hyperactivation can further lead to excitotoxic effects (Hynd et al., 2004). Excitotoxicity refers to calcium-mediated toxic effects due to a sudden increase in glutamatergic transmission. Ashford and Jarvik hypothesized already in $1985 \mathrm{a}$ preferential affection of 


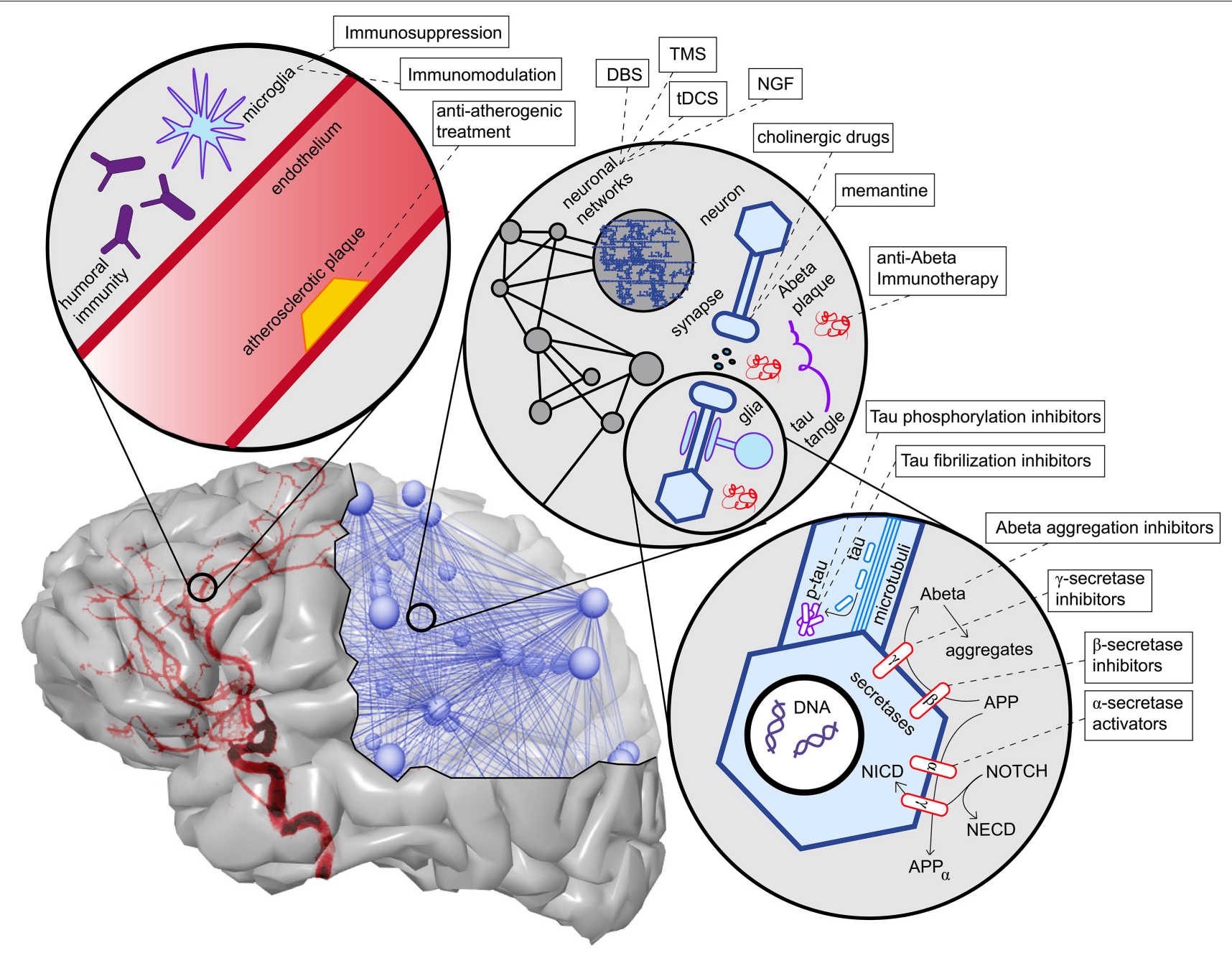

FIGURE 5 | Overview of contributing factors in AD and potential intervention strategies. Shown are only the most important factors, which are also described in more detail in this article's main text. In the upper left corner, we see the neurovascular system. Both characteristics of blood vessels (e.g., atherosclerosis and endothelial dysfunction) (Love and Miners, 2016), as well as aspects of the blood-brain barrier (Sweeney et al., 2018), play a role in AD. A particular aspect here is the role of neural immunity, both with the brain-own microglia cells and the effect of systemic immune cells, e.g., mediated by antibodies (Heneka et al., 2015a,c). On the upper right corner, we see an illustration of the multiscale network structure of the brain. Stimulation approaches as deep brain stimulation (DBS), transcranial magnetic stimulation (TMS), and transcranial direct current stimulation (tDCS) act on the larger scale of a network-level; nevertheless, the actual changes happen on the level of synapses. Also, transmitter interventions develop their effects mainly at the micro-scale of synapses. In the lower right corner, basic molecular pathways in the extraand intracellular space of a neuron are shown. We focused here on the processing of the two hallmark proteins Abeta and Tau, as well as the Notch-1 pathway, which is involved in memory (Marathe and Alberi, 2015) and plasticity (Brai et al., 2015). We illustrate the APP procession by the amyloidogenic or non-amyloidogenic way and its interaction with Notch-1 processing and, second, in the axon, the hyperphosphorylation and aggregation of Tau. A more detailed description of the named treatment strategies presently under development is provided in Table 1. NGF, nerve growth factor; Abeta, amyloid-beta; p-tau, phosphorylized Tau protein; APP, amyloid precursor protein; APP $\alpha$, APP in alpha-helix configuration; NECD, Notch extracellular domain; NICD, Notch intracellular domain.

highly neuroplastic connections with neurofibrillary tangles (Ashford and Jarvik, 1985), which has been further supported by a wide range of genetic and environmental AD risk factors that are associated with increased plasticity (Mesulam, 2000).

The concept of excitotoxicity is moreover essential for other transmitter systems as glutamate. Anti-dementia drugs that are no inhibitors of the acetylcholine esterase-mainly the N-methylD-aspartate (NMDA) receptor antagonist memantine-decrease glutamatergic transmission in the synaptic cleft. Glutamatergic dysfunction is also related to neuroinflammation and plasticity.

\section{Neuroimmunology}

Besides the cascades of Abeta and Tau, another important hallmark in $\mathrm{AD}$ pathogenesis is the role of neuroinflammation and autoimmunity. One of the difficulties in understanding $\mathrm{AD}$ pathogenesis is that intrinsic proteinopathic dysfunction alone does not necessarily lead to neurodegeneration and cognitive decline. Such impairments are more likely to be caused by various toxic intermediate mechanisms, as discussed before. One potentially important but poorly understood mechanism is neuroinflammation. Neuroinflammation is a relevant factor in the pathogenesis of dementia because it 
is always the last part of the pathogenic cascade and leads directly to neuronal death (Heneka et al., 2015a). However, it is not clear how the modulation of inflammation can affect the process of neurodegeneration. Clinical trials have shown contradictory results. For instance, the long-term administration of non-steroidal anti-inflammatory drugs showed positive preventive effects and can hence reduce the a priori risk for $\mathrm{AD}$ (Wang et al., 2015). However, in contrast to those observational studies, prospective trials with steroids and other immunosuppressive drugs have not shown significant effects, and neither have randomized controlled studies with non-steroidal anti-inflammatory drugs (Jaturapatporn et al., 2012). A casecontrol study in patients with rheumatoid arthritis (who have a slightly higher risk for $\mathrm{AD}$ ) showed a significant reduction of $\mathrm{AD}$ incidence by $70 \%$ (adjusted Odds ratio of $0.30, p=0.02$ ) if the patients were treated with the tumor necrosis factor $\alpha$ inhibitor etanercept (Chou et al., 2016), as long as it was well tolerable (Butchart et al., 2015). As the etiology and differential diagnosis of dementia is often unclear, the label of $\mathrm{AD}$ could cover up a relevant percentage of autoimmunological neural phenomena that could be treated with high-dose and long-time corticosteroid therapies (Pruss and Lennox, 2016). Cerebral immunology is complex, as it involves the organ-specific immunological cell type of microglia. An appropriate discussion would go beyond this review's scope, and we would like to refer the interested reader to the following review on neuroimmunology and AD (Heneka et al., 2015c).

\section{Imaging}

\section{Anatomical Magnetic Resonance Imaging}

MRI offers a commonly used technique to screen for biomarkers in vivo. As described, the pathogenetic pattern of $\mathrm{AD}$ consists of the accumulation of amyloid plaques and neurofibrillary tangles. Volumetric assessment of gray matter loss in MRI has been identified to correlate with the distribution and degree of neurofibrillary tangle accumulation (Csernansky et al., 2004; Whitwell et al., 2008). Therefore, volumetric MRI can provide a proxy measurement for regional neurofibrillary tangle load (Persson et al., 2017).

$\mathrm{AD}$ patients have consistently been found to have atrophy of memory-related structures, including the hippocampus and other mesiotemporal regions, as well as the precuneus, cingulate, and the prefrontal areas (Braak and Braak, 1991; Frisoni et al., 2002; Karas et al., 2004; Shiino et al., 2006; Rosenbloom et al., 2011). However, non-amnestic symptoms like aphasia, visuospatial problems, or behavior-predominant dysfunction are initially present in up to $30 \%$ of $\mathrm{AD}$ patients (Koedam et al., 2010; Dickerson et al., 2017). The distribution of neurofibrillary tangles in those patients with an atypical clinical presentation is either limbic-predominant, hippocampal-sparing, or not reported, which is also referred to as the no-atrophy or minimalatrophy AD variant (Murray et al., 2011; Persson et al., 2017). A correlation between these phenomenological subtypes of $\mathrm{AD}$ and volumetric MRI has already been demonstrated (Whitwell et al., 2012). Multiple studies explored MRI as an in vivo marker of these AD subtypes (Byun et al., 2015; Hwang et al., 2016; Ferreira et al., 2017; Persson et al., 2017). Besides the atrophy patterns of syndrome variants in $\mathrm{AD}$ morphology, a few single-regionbased volume reductions have also been identified as potential biomarkers for AD. A detailed overview of these features is provided in Table 5 .

As a non-invasive in vivo measurement, MRI opens up the possibility of longitudinal tracking of atrophy and disease progression of $\mathrm{AD}$. Recent studies investigated volume loss in $\mathrm{AD}$ patients longitudinally (Harrison et al., 2019; Pontecorvo et al., 2019; Sintini et al., 2019). Regions with reduced baseline gray matter volume also tend to show more atrophy over time and the highest atrophy rates are in the temporoparietal regions (Sintini et al., 2019).

Besides gray matter atrophy, white matter hyperintensities, which appear on T2-weighted or fluid-attenuated inversion recovery MRI scans, have a high prevalence among AD patients (Brickman, 2013). White matter hyperintensities, in general, can be morphological correlates of microvascular lesions as well as inflammatory or unspecific changes in aging. Increased overall hyperintensity volume has been observed 6-22 years before estimated symptom onset of AD (Lee et al., 2016). The relationship between white matter hyperintensities and AD pathology is still an active research field (Graff-Radford et al., 2019).

\section{Positron Emission Tomography}

Nuclear imaging methods allow in vivo acquisition of metabolic features of the brain by using various radioactively marked tracer molecules, so-called radionuclides. PET offers a remarkable possibility of different functional assessments of the brain. The underlying procedure makes use of $\beta^{+}$-emitters: the emitted positrons of $\beta$-decay react with electrons of the tissue in a socalled annihilation. This leads to the emission of photons, which can be measured by specific sensors (Phelps, 2000).

Both Abeta and Tau deposits can be detected indirectly by PET and correspond well to the underlying pathologic changes at autopsy (Clark et al., 2011; Schöll et al., 2016). Tau tracer binding in $\mathrm{AD}$ is not only increased in regions that are known to be affected in early Braak stages (Cho et al., 2016; Schöll et al., 2016; Kitamura et al., 2018; Gordon et al., 2019; Harrison et al., 2019), but also globally heightened in the cortex (Cho et al., 2016; Pontecorvo et al., 2019). However, Tau binding is also present in healthy controls, predominantly located in areas with atrophic changes (Harrison et al., 2019). Similarly, Abeta tracers show increased global deposition in the whole brain (Clark et al., 2011; de Wilde et al., 2018) and in early Braak stage regions (Murray et al., 2015) (Alongi et al., 2019). However, the percentage of "Abeta-positive" healthy controls seems higher than for Tau (Jack et al., 2014; Jansen et al., 2015; Song et al., 2015).

Another important PET measurement is the assessment of energy metabolism by the usage of marked glucose molecules. Multiple studies suggest temporoparietal hypometabolism in AD (Meltzer et al., 1996; Langbaum et al., 2010; Morbelli et al., 2010; Fukai et al., 2018; Ou et al., 2019), which is already an established marker for unclear cases of other dementias in clinical practice. Interestingly, similar to atrophy patterns (Csernansky et al., 2004; Whitwell et al., 2008), hypometabolism has a strong association with Tau deposits (Adams et al., 2018). The usage of glucose PET 
TABLE 5 | Overview of brain imaging studies and their results in Alzheimer's disease for different modalities.

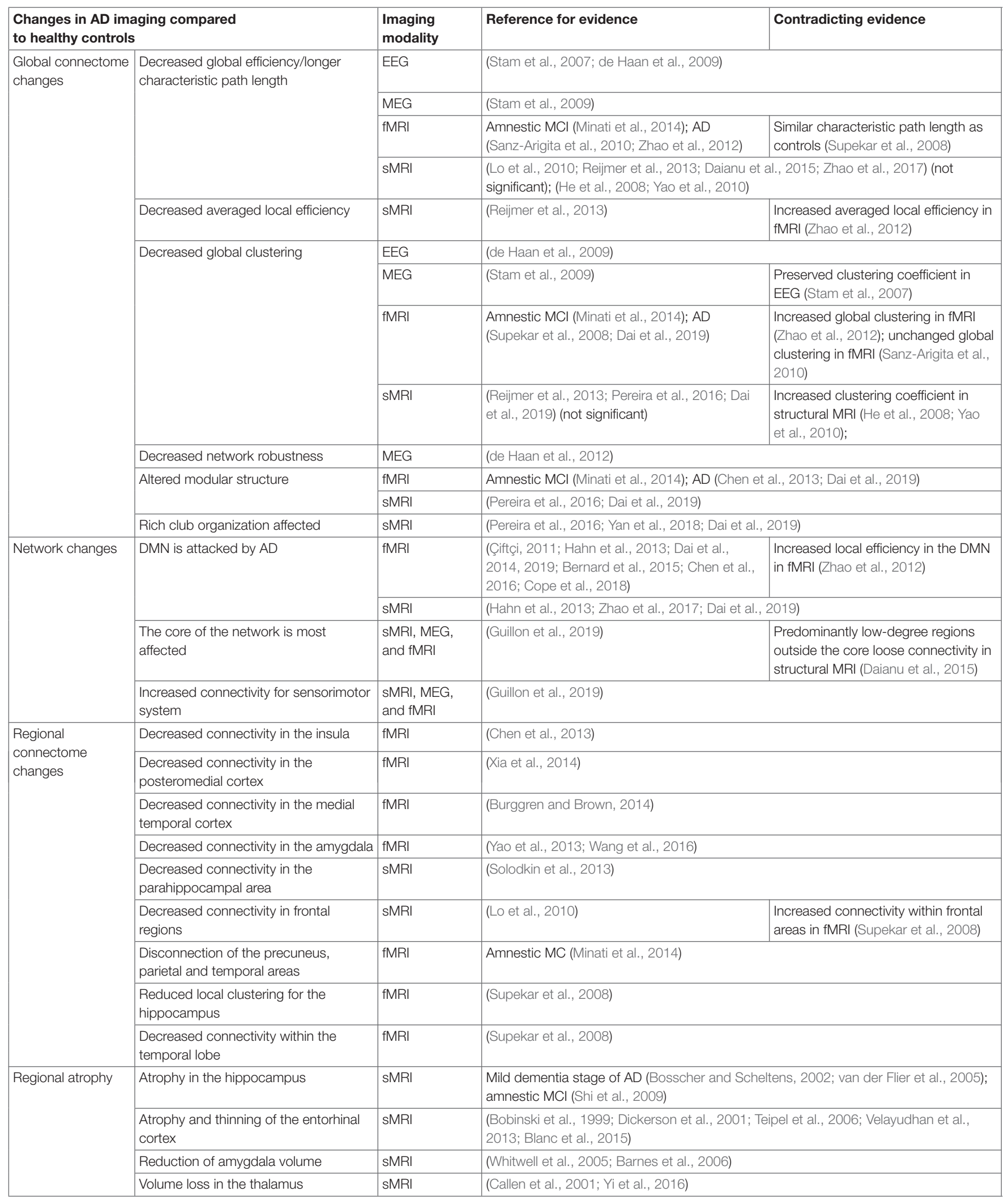


TABLE 5 | Continued

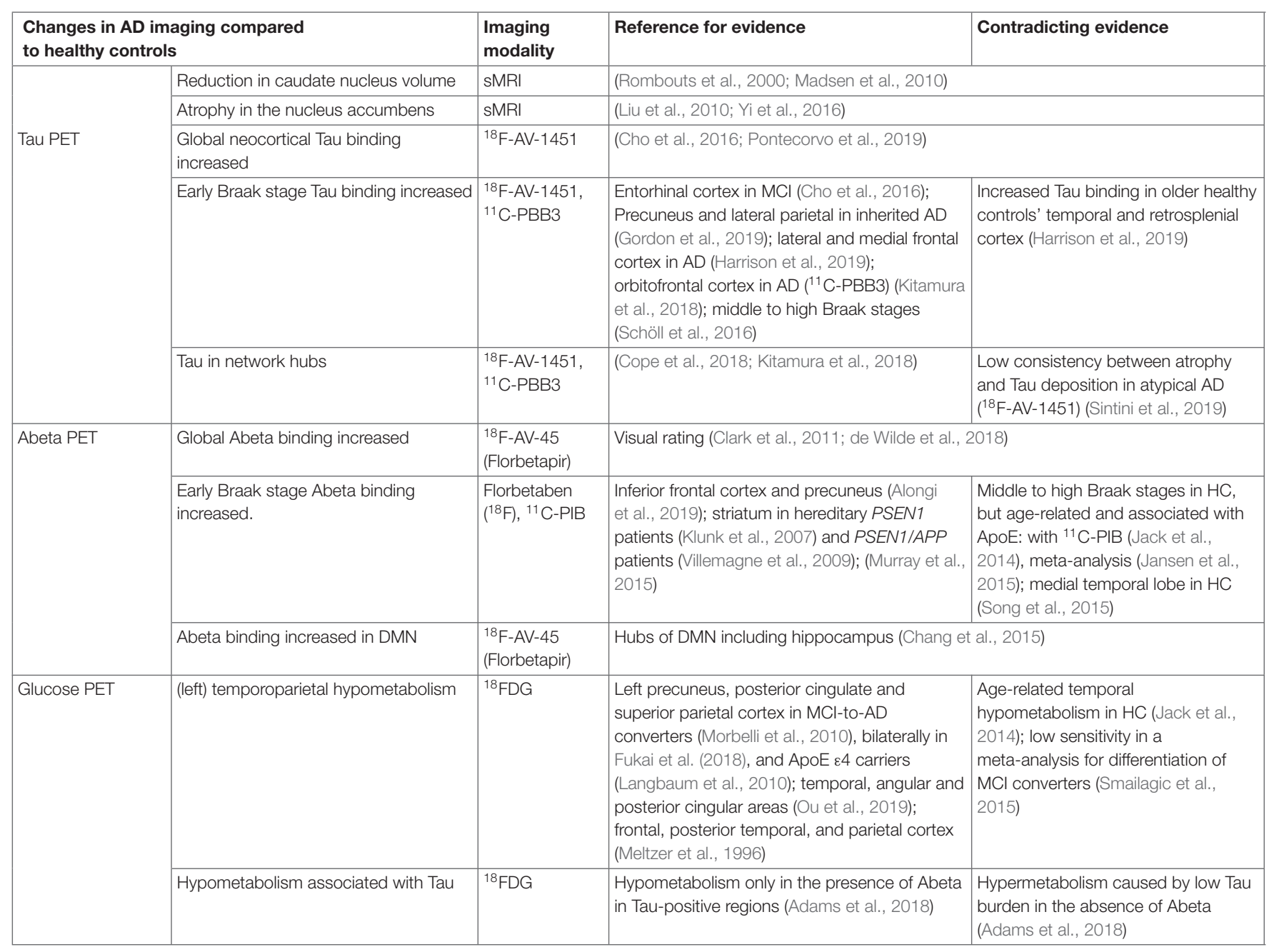

EEG, electroencephalography; MEG, magnetoencephalography; fMRI/SMRI, functional/structural magnetic resonance imaging; PET, positron emission tomography; DMN, default mode network; $A D$, Alzheimer's Disease; $M C l$, mild cognitive impairment.

in clinical routine is limited by its high costs, exposure to ionizing radiation, and low sensitivity in detecting MCI patients that will convert to AD (Smailagic et al., 2015).

An overview of PET findings in AD is provided in Table 5.

\section{Connectomics}

After discussing the recent advances researching the microscopic molecular level in $\mathrm{AD}$, we consider a whole-brain perspective at the macroscopic brain region level. The connectomic approach is a neuroscientific discipline that analyzes, describes, and uses (axonal) connectivity measures of the brain (Fornito et al., 2015). It provides an overview of the disease effects in $\mathrm{AD}$ and identifies global phenomena beyond the impairment of single regions.

In the general framework of brain networks, regions are represented by nodes, and connections between them (either structural or functional) are denoted as links or edges (Figure 6 shows an abstract example network). At this level of abstraction, it is possible to calculate graph-theoretic measures for the connectome, so-called network metrics (Bullmore and Sporns, 2009). A plethora of different-partly interdependent-metrics shows changes in AD networks compared to healthy controls. An overview of these findings is provided in Table 5. Heterogenous findings for different measurement modalities exist, pointing toward a widely spanned network disruption in $\mathrm{AD}$ on different scales (Dennis and Thompson, 2014; Stam, 2014). This heterogeneity can also be explained by different methodological choices for network construction, e.g., setting different thresholds for filtering out the most essential connections (van Wijk et al., 2010; Tijms et al., 2013; van den Heuvel et al., 2017). In general, however, converging evidence suggests aberrant functional connectivity (measured by functional MRI) and abnormal white matter structural connectivity in AD compared to healthy aging. We review and align the recent literature on this topic showing multiple local network changes resulting in 


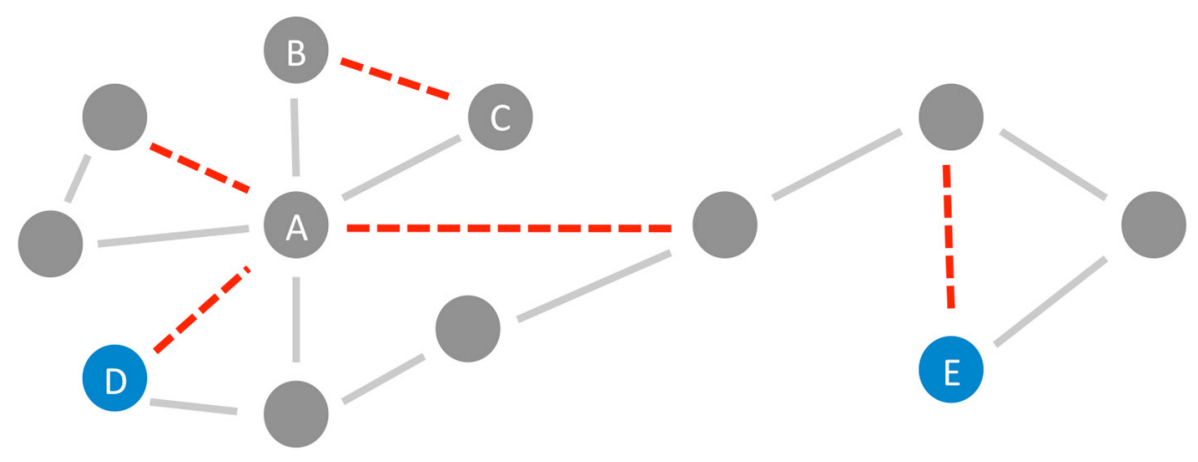

FIGURE 6 | Neurodegeneration in Alzheimer's Disease (AD) from a network perspective. In this schematic example network, the red links (edges) are being weakened and progressively disconnected by AD. Preferentially, edges attached to nodes with high degree (hubs) are being targeted (here node A) (Stam et al., 2009; Lo et al., 2010; Yan et al., 2018). Besides, lower clustering in AD has repeatedly been observed (Brier et al., 2014b; Minati et al., 2014; Pereira et al., 2016; Dai et al., 2019), i.e., links involved in triangles are broken off (here, e.g., the link between nodes B and C forming the triangle A-B-C). These two "attacks" of AD on the network lead not only to a lower clustering coefficient but also evoke a lower efficiency, defined here as the inverse of the global path length. This lower efficiency is demonstrated in the example network by the shortest path length between the blue nodes $D$ and $E$ before and after the deletion of the red links (before: 4 links, after: 6 links).

the global phenomena of less efficient network communication for AD patients compared to healthy controls.

Connectomic research provides an important perspective for understanding the development of cognition and its decline in dementia. There are various hypotheses about the network changes in dementia highlighting different aspects of neurodegeneration (Dennis and Thompson, 2014). One line of research refers to dementia as a disconnection syndrome (Brier et al., 2014a), where the loss of neurons and smallscale connectivity influences the macro-scale in the form of (structurally and functionally) disconnected brain areas (Delbeuck et al., 2003; Stam, 2014). This disconnection correlated with the cognitive and behavioral decline (Stam, 2014) and white matter pathology in certain areas could be used as a biomarker for disease progression (Solodkin et al., 2013). This view on AD as a disconnection syndrome was able to bridge multiple scales of disease pathology in a coherent way. In recent years, however, network science studies on $\mathrm{AD}$ patients expanded this picture: widespread increases and decreases of connectivity within the brain network were observed, pointing toward compensatory mechanisms or reactions of the network beyond disconnection (Stam, 2014). Even an early but seminal study conveying the importance of "small networks studies," especially related to the initial disease stages, showed isolation of the hippocampus from its cortical network connections through initial entorhinal cortex degeneration via the perforant pathway (Hyman et al., 1984).

In network science, brain regions with high connectivity to other regions are called hubs. For both structural and functional connectivity studies, hub regions have consistently been identified as the most affected areas by AD (Stam et al., 2009; Lo et al., 2010; Yan et al., 2018). De Brier et al. showed that even in preclinical stages of $\mathrm{AD}$, hubs are disrupted, where hubs were defined here as nodes with the highest betweenness centrality (a measure for involvement in important pathways) and the highest participation coefficient (in how far the node is connected to different modules or subnetworks) (Brier et al., 2014b). This vulnerability of hubs correlates with a higher Abeta burden in these hub regions (Cope et al., 2018). A focus of the disconnection in $\mathrm{AD}$ lies on the default mode network, a largescale network of regions strongly interconnected in resting state (Çiftçi, 2011; Hahn et al., 2013; Dai et al., 2014, 2019; Bernard et al., 2015; Chen et al., 2016; Cope et al., 2018). Although this phenomenon is also observed in aging (Perry et al., 2015), the degree of default mode network disruption allows in parts the distinction between healthy aging and $\mathrm{AD}$ (Greicius et al., 2004). Regarding the functional network, especially the default mode network is targeted by the AD-caused neurodegeneration (Çiftçi, 2011; Hahn et al., 2013; Dai et al., 2014, 2019; Bernard et al., 2015; Chen et al., 2016), where the highest Abeta deposition is also located. The extent of hub disruption correlates significantly with the cognitive status of a patient (Dai et al., 2014). Thus, it can be hypothesized that hubs - with their high Abeta deposition and central role in the overall information flow of the brain network-facilitate the spreading of the pathological cascade within the brains of AD patients (Buckner et al., 2009). Aberrant or decreased functional connectivity has also been observed in the insula (Chen et al., 2013), posteromedial cortex (Xia et al., 2014), medial temporal cortex (Burggren and Brown, 2014), and amygdala (Yao et al., 2013; Wang et al., 2016).

Next to the vulnerability of hubs, a decreased global clustering coefficient has been reported, showing a loss of connectedness and important redundancy structures for brain communication in FC, which consequently also alters the modular structure of AD patients (Brier et al., 2014b; Minati et al., 2014; Pereira et al., 2016; Dai et al., 2019). Probably as a global effect of these "local attacks" on the network (Figure 6), decreased global efficiency in structural connectivity as well as functional connectivity networks is often observed in $\mathrm{AD}$ patients, which correlates with cognitive and behavioral decline (Lo et al., 2010; Reijmer et al., 2013; Dai et al., 2019). Global efficiency is in network science defined as the inverse of the characteristic path length-with 
shorter pathways between the nodes, the information flow within the network is more efficient. A less efficient network can still provide connections between nodes, but they are longer and with more nodes and edges in-between (Bullmore and Sporns, 2009).

Recent work analyzed a multimodal perspective on $\mathrm{AD}$, combining diffusion tensor imaging, functional MRI, and magnetoencephalography measurements in a multilayer network (Guillon et al., 2019). They found that the core of this multilayer network, which is likely to contain the hubs, has been most affected, which establishes hubs' vulnerability across modalities. Together, these changes were able to predict the cognitive and memory impairment of patients (Guillon et al., 2019).

Emerging evidence suggests that in the preclinical stage of $\mathrm{AD}$, network changes are present in the form of disconnection on a large scale (Brier et al., 2014b; Daianu et al., 2015; Zhao et al., 2017). Indeed, functional connectivity and structural connectivity are now being investigated to better differentiate $\mathrm{AD}$ patients, MCI, and controls, moving toward the goal of identifying prodromal $\mathrm{AD}$ patients and the possibility of developing early intervention strategies (Phillips et al., 2015; Pereira et al., 2016; de Vos et al., 2018; Ye et al., 2019). A recent study suggests altered functional connectivity corresponding to accelerated aging in preclinical $\mathrm{AD}$ (Gonneaud et al., 2020).

To sum up, both altered global and local connectivity have been associated with $\mathrm{AD}$. Converging evidence from white matter diffusion tensor imaging and resting-state functional MRI studies point toward less efficient network communication in $\mathrm{AD}$ patients compared to healthy aging, especially in the default mode network.

\section{MODELING OF ALZHEIMER'S DISEASE}

As $\mathrm{AD}$ is a complex disease that takes place on various scales, a wide range of models have been developed for its analysis, e.g., animal disease models (Saito et al., 2014; Weintraub et al., 2014), cognitive models (Sevush et al., 2003), or disease progression and classification models (Bhagwat et al., 2018; Khanna et al., 2018; Koval et al., 2018; Pellegrini et al., 2018; Golriz Khatami et al., 2019). Mathematical modeling is an adaptive and creative scientific concept and a core technique of computational neuroscience. In general, one can differentiate between approaches focusing on single aspects of the disease, e.g., biochemical Abeta modeling (George and Howlett, 1999), and integrative models incorporating several biomarkers while using multiple scales simultaneously (Khanna et al., 2018). The latter might provide a more comprehensive, multimodal view on the disease with its interacting mechanisms and might be more suitable to reflect disease pathogenesis. This multiscale approach-also called "integrative disease modeling" (Younesi and Hofmann-Apitius, 2013)—can combine functional and structural neuroimaging techniques, cerebrospinal fluid sampling, and genomic data and analyzes their intercorrelations with computational algorithms (Golriz Khatami et al., 2019).
A comprehensive understanding of both the underlying biological processes of $\mathrm{AD}$ and the computational framework of high-performance modeling approaches is necessary to develop novel models for $\mathrm{AD}$ that integrate multiple scales, modalities, and research disciplines. With increasing technical possibilities for high-performance computing and growing hierarchically organized knowledge architectures, this crossdisciplinary approach holds the potential to overcome some of the enigmas in $\mathrm{AD}$ pathogenesis that might not be revealed on a single scale applying a single method.

Therefore, in the following sections, we describe existing computational (brain) models of different scales and outline how far they can be linked to the biological concepts presented before.

\section{Statistical Disease Prediction Models}

Statistical prediction models are mainly descriptive when used in linear classification tasks. Subjects are assigned to a diagnostic category (HC, MCI, or AD) based on the input data. But beyond their practical translational usage as diagnostic tools, prediction models provide certain decision criteria that can also be of interest in understanding the underlying disease mechanisms (Jack and Holtzman, 2013). In addition to those rather simplistic linear models there are methods such as machine learning (Moradi et al., 2015; Pellegrini et al., 2018) or Bayesian modeling (Khanna et al., 2018). All exhibit individual challenges and advantages regarding data analysis and model interpretation (Poil et al., 2013).

Machine learning approaches are applied to predict disease trajectories (predictive modeling) or classify subjects into groups with highly similar data points (discriminative modeling or clustering). The latter goal can be reached by supervised $a$ priori labeling of the training data (e.g., as two classes $\mathrm{AD}$ and non$\mathrm{AD}$, or as a three-class problem with $\mathrm{AD}, \mathrm{MCI}$, and healthy controls) or by unsupervised clustering without labeling (Golriz Khatami et al., 2019). Those unsupervised discriminative models cluster subjects based on the degree of (dis-)similarity between parameters. This can be quantitatively expressed by statistical proximity measures (Bock, 2005; Golriz Khatami et al., 2019).

Structural T1-weighted MRI, in conjunction with other biomarkers, has been considered as a feature for classic machine learning techniques, such as support vector machines-often combined with linear discrimination analysis. Pellegrini et al. (2018) reported in a review that, while patients with AD could successfully be differentiated from controls, the classification of subjects with MCI remained unsatisfactory (Pellegrini et al., 2018). This held also true for the risk prediction of conversion from MCI to AD. Thus, the classifiers' clinical relevance remains relatively low, given that-in practice-it is already possible to distinguish between controls and $\mathrm{AD}$ based on cognitive performance. A diagnosis before clinically-noticed AD onset is therefore still missing.

Attempts of facilitating early $\mathrm{AD}$ prediction are therefore building biologically informed models that develop "mechanistic biomarkers" by aiming at a deeper understanding of $\mathrm{AD}$ pathomechanisms (Selkoe, 2004). To achieve that, a complex disease knowledge system (i.e., ontology) can be built from different data sources, and biologically plausible predictors are 
deduced. This contrasts the approaches described above in which the selection of biomarkers is mainly based on statistical dependence (e.g., correlations). Mechanistic biomarkers however resemble biologically plausible concepts instead of merely relating to the disease by correlation.

Using this approach, biological mechanisms of the transition from asymptomatic stages or MCI to $\mathrm{AD}$ have been computationally reconstructed to achieve a more accurate risk prediction (Khanna et al., 2018). By using a predictive time-to-event model that incorporates multimodal data ranging from genetic variants to neuroimaging and neuropsychological assessments, several biological risk factors and their interaction could be extracted (Khanna et al., 2018). As the model makes use of a graph-like Bayesian network organization (Khanna et al., 2018), it opens up new possibilities for the integration of multiscale and multimodal information to discover more possible mechanistic biomarkers.

Additionally, information about disease progression can be extracted from longitudinal patient data to increase the accuracy of subsequent predictions. For example, Bhagwat et al. (2018) have modeled AD disease trajectories of patients with varying cognitive performance at baseline by combining longitudinal data of MRI brain volumetry (cortical thickness) and clinical assessments with genetic information (ApoE $\varepsilon 4$ status). Comparing different algorithms trained on multimodal data from two time points, a longitudinal predictive neural-network showed the highest performance, even after validation with a second untrained data set (Bhagwat et al., 2018).

This longitudinal and multimodal approach of predicting the individual risk and disease trajectories could thus represent promising new paths in personalized medicine. Modeling structural and metabolic changes in different brain areas concerning the decline in cognitive functions can yield more sophisticated information about disease progression and its influencing factors on an individual level (Koval et al., 2018). Future approaches could also incorporate a broader range of data modalities from different sources, like the graphtheoretically-organized database European Brain Research Infrastructures (EBRAINS) of the Human Brain Project (https:// ebrains.eu, Markram et al., 2011). EBRAINS hosts detailed data for many brain areas from a variety of modalities, such as receptor densities (Palomero-Gallagher and Zilles, 2018) or gene expressions (Yetman et al., 2016). Besides that, the Multimodal Mechanistic Signatures Database for Neurodegenerative Diseases (NeuroMMSig, https://neurommsig.scai.fraunhofer. de, Domingo-Fernández et al., 2017) poses great potential for mechanistic models. NeuroMMSig, a hierarchically organized ontology, integrates chemical compounds, genes, proteins, medical terms, and imaging features into a mechanistic pathway representation of $\mathrm{AD}$. These pathways (i.e., cause-and-effect chains of biological concepts or processes) were retrieved by methods of literature mining and condensed into 125 sub-networks that play a distinct role in the pathophysiology of AD (Domingo-Fernández et al., 2017). By integrating big databases like those described, promising new approaches for the predictions of individual disease trajectories with mechanistic cause-and-effect models are posed.

\section{Sub-cellular Models}

Brain simulation can occur on many different scales, as the complex topological hierarchy of the brain consists of many essential components: cortical and subcortical regions, networks, columns, ensembles, circuits, neurons, synapses, vesicles, molecules, and genes (compare Figure 5).

Sub-cellular features of $\mathrm{AD}$ provide promising input for computational modeling based on protein interaction and gene expression. Early AD modeling approaches have focused e.g., on the deposition process of Abeta (Jarrett et al., 1993; Lomakin et al., 1997; Pallitto and Murphy, 2001; Ortega et al., 2013). Moreover, biochemical models account for the interaction between numerous factors like Abeta, Tau, inflammation, and different proteases, as well as possible interventions during the disease course (Proctor and Gray, 2010; Anastasio, 2013, 2014; Kyrtsos and Baras, 2013; Proctor et al., 2013).

Early studies have used computational modeling to assess aggregation kinetics for synthetic Abeta-like peptides (Tomski and Murphy, 1992). Comparably simple biochemical models allowed a mathematical description of the aggregation processas the temporal evolution of Abeta in the form of monomers, micelles, and fibrils (Lomakin et al., 1997). Subsequently, the Abeta aggregation theory was enhanced by including more detailed interactions between different forms of Abeta fibrils and fitting the model to empirical data (Pallitto and Murphy, 2001). As experimental evidence on Abeta's toxicity increased, a particular model was developed that describes disrupted $\mathrm{Ca}^{2+}$ homeostasis and Abeta aggregation as a positive feedback loop and their interaction in a vicious circle (De Caluwé and Dupont, 2013). Over the last decade, more specific models have included associations of $\mathrm{AD}$ to important gene transcription factors as p53 (Proctor and Gray, 2010), possible intervention strategies (Proctor et al., 2013), and genetic risk factors (Kyrtsos and Baras, 2013).

Concepts of sub-cellular modeling are valuable for integrating multiscale models as they describe the molecular hallmarks of AD in a computationally accessible manner. Molecular pathways can be "coded" as a network of relations by employing computational linguistics and semantic frameworks. One possible tool for this approach is the Biological Expression Language (BEL), which makes it possible to describe the interaction between proteins, genes, and other chemical compounds with means of first-order logic (Madan et al., 2019).

\section{Single-Neuron and Neural-Circuit Models}

Besides the subcellular scope, AD models span over different microscopic scales, ranging from single-cell models (Morse et al., 2010; Romani et al., 2013; Bianchi et al., 2014; Perez et al., 2016) to neural circuits (Zou et al., 2011; Abuhassan et al., 2012; Bianchi et al., 2014; Rowan et al., 2014).

Single-neuron models are often inspired by an experimental approach, such as a patch-clamp experiment (Chen, 2005), in the effort of reproducing the observed data (Morse et al., 2010). Underlying mathematics for those single-cell simulations may refer to general formulations for neural oscillation models, as it is the case for Hodgkin-Huxley model (Hodgkin and Huxley, 1952). Hodgkin and Huxley delivered the first impactful 
mathematical description of electric conductances in a neuron model in 1952 (Hodgkin and Huxley, 1952). The HodgkinHuxley model is based on experimental recordings on squid axons: By defining the phospholipid membrane's capacitance and the conductance of leak and voltage-gated ion channels, it enables a realistic approximation of membrane potentials over time (Hodgkin and Huxley, 1952). However, the model is computationally expensive, qualifying it mainly for simulations with either few neurons or small simulation length (Izhikevich, 2004). There seems to be a dilemma between biologically plausible but comparably inefficient models (e.g., Hodgkin and Huxley, 1952; Morris and Lecar, 1981; Rose and Hindmarsh, 1989; Wilson, 1999) and very efficient models that lack plausibility as they show a limited range of possible behaviors (e.g., the integrate-and-fire or integrate-and-fire-or-burst model; Smith et al., 2000; Izhikevich, 2004). A possible solution was supposed by Izhikevich, providing a computationally efficient model with the ability to produce emergent biological phenomena as tonic and phasic spiking and bursting, frequency adaptation, and accommodation (Izhikevich, 2003, 2004).

The mean-field theory can integrate complex systems of a large number of neurons (Spiegler et al., 2011). The simplification of the mean field has its origin in physics to describe fluid or gas behavior without considering individual molecules. In the brain, it allows simplifying the behavior of a spatially distinct group of neurons with a similar function (Liley et al., 2002). This group of neurons is called a neural mass and can be defined on various scales-e.g., as a brain region, a column, or a neuronal ensemble. Neural mass models (Wilson and Cowan, 1972; Zetterberg et al., 1978; Hindmarsh and Rose, 1984; Jansen and Rit, 1995; Wong and Wang, 2006; Stefanescu and Jirsa, 2008; Sanz-Leon et al., 2015) have been widely used to define local dynamics in a large-scale brain network model.

\section{Large-Scale Brain Network Models}

The evolution of large-scale computational brain modeling has accelerated over the past decade. de Haan et al. (2012) built a model to test the hypothesis that excessive neural activity leads to neurodegeneration. This model is a largescale brain network derived from diffusion MRI, where each network node holds a neural mass model by Zetterberg et al. (1978) as its local dynamic model. De Haan and colleagues simplified the synaptic strength as a function of neural activity over time (de Haan et al., 2012). As a result, those connections transmitting higher activity became weakened after a certain time period. The purpose of implementing this specific mechanism was to describe a form of excitotoxicity that leads to degeneration. Here, after a certain period, one could consecutively observe degeneration in the functional and structural network topology using graph-theoretical measures. The authors also observed a loss of spectral power and an increased sensitivity of hubs, defined as highly connected brain regions (incoming and outgoing ties) (de Haan et al., 2012). The authors observed an increase in brain activity and functional connectivity in the model, similar to empirical findings in MCI or mild AD stages (de Haan et al., 2012). A subsequent study by de Haan et al. (2017) tested different "therapeutic" strategies, like increasing or decreasing the excitability of excitatory and inhibitory subpopulations of the neural masses to prevent neurodegeneration in the excitotoxic model. The most convincing strategy, which could maintain healthy network features over a long time, was increasing excitability of excitatory neurons followed by increasing inhibition of inhibitory neurons. At first glance, this might seem contradictory, but it suggests the reversal of hyperexcitability by either more excitation or less inhibition. The authors suggested that the reason for this phenomenon might be in the network topology. The best strategies suppress the network hub activities, which in return may lead to decreased disease propagation. According to this prediction, neurodegeneration spreads along the network infrastructure as a kind of "pro-degenerative" signaling pattern. This can be related to an earlier description of Hasselmo in 1994. This model (Hasselmo, 1994) provides a descriptive model of runaway synaptic modification, learning, and cholinergic suppression that can explain essential findings of $\mathrm{AD}$ : the spatiotemporal pattern of disease progression along substantial fiber tracts, early memory deficits, and neurodegeneration due to excessive demands on synaptic plasticity rather than excitotoxicity. In contrast to the work by de Haan et al. (2012), which assumes neurodegeneration as a consequence of hyperactivation, the Hasselmo model (Hasselmo, 1994) explains an earlier part of the same process, wherein hyperactivation induces undesired neuroplasticity by extensive runaway synaptic modification and through this mechanism causes neurodegeneration and interferes with learning mechanisms.

Pons and colleagues used another brain network model for AD (Pons et al., 2010), using the neural mass model of Jansen and Rit (1995) at each cortical network node, which is related to the Zetterberg model (Zetterberg et al., 1978). The authors used electroencephalography recordings that showed a slowing of the alpha rhythm and an increase in functional connectivity (using phase lag index) in MCI patients with age, i.e., the functional connectivity increased from young to old subjects. Pons et al. were able to describe these observations by decreasing the maximum postsynaptic potential and increasing the thalamocortical SCs during simulations.

In another recent modeling study, Demirtaş and colleagues investigated the blood-oxygen-level-dependent (BOLD) signal changes due to AD (Demirtaş et al., 2017). This study included 109 subjects from different groups (healthy controls, preclinical $\mathrm{AD}, \mathrm{MCI}$, and $\mathrm{AD}$ ). Regarding their empirical BOLD signal, one could observe a decrease in global interactions of $\mathrm{AD}$ patients evaluating first-order circular statistics, that is in the Kuramoto order parameter, as well as regional differences in the functional connectivity strengths, compared to the controls (Demirtaş et al., 2017). Further, functional connectivity differences were correlated to cerebrospinal fluid biomarkers like Abeta, total Tau, and phospho-Tau (Demirtaş et al., 2017). Estimating individual effective connectivity from subjectspecific structural connectivity and functional connectivity with a heuristic approach, the brain model could replicate these observed changes (Demirtaş et al., 2017). A supercritical Andronov-Hopf bifurcation described its local dynamics. In an 
in silico experiment using brain network models based on healthy subjects' effective connectivity, Demirtaş et al. systematically varied the order parameter of the model (Demirtaş et al., 2017). In this way, they were able to observe the progress of functional connectivity degeneration. An optimal order parameter was individually found for each disease stage and group, replicating best the empirical observed degeneration. This study showed how changes in regional dynamics could lead to the disintegration of activity within the anatomical large-scale brain network. Concurrently, simulations also replicated the finding that the interaction (measured by Kuramoto order parameter) between BOLD signals declines with disease progression.

\section{The Virtual Brain Platform}

In the following, we focus on The Virtual Brain, a multimodal and multiscale virtual brain simulation framework (Ritter et al., 2013; Sanz Leon et al., 2013; Sanz-Leon et al., 2015; Stefanovski et al., 2016; Solodkin et al., 2018) that holds the potential to combine different modeling scales of $\mathrm{AD}$ research. The open-source platform of The Virtual Brain is available under www.thevirtualbrain.org. The Virtual Brain is a standardized and an established framework that enables large-scale modeling approaches (as mentioned in the previous section Large-scale Brain Network Models) on individual patient data including a wide range of underlying dynamics.

The Virtual Brain uses the structural connectome as its underlying basis (Sanz-Leon et al., 2015). Most of the neural mass models (representing the regional activity) implemented in The Virtual Brain had their origin as a network model for smaller, distinct networks. But with the development of connectomics, the networks included were more complex and elaborate (Dipasquale and Cercignani, 2016). Likewise, the local dynamic models used in The Virtual Brain were, in principle, composed of smaller or even single-neuron systems (Wilson and Cowan, 1972; Zetterberg et al., 1978; Hindmarsh and Rose, 1984; Jansen and Rit, 1995; Wong and Wang, 2006; Stefanescu and Jirsa, 2008; Sanz-Leon et al., 2015). The Virtual Brain was designed to simulate whole-brain network dynamics, but it can also model and simulate separate subnetworks ranging from a regional level to a few neurons (see Spiegler and Jirsa, 2013 for the integration hierarchy of The Virtual Brain).

The second important feature of The Virtual Brain that can assist in $\mathrm{AD}$ research is the multiscale character. This term has been coined to describe the fluid transition of brain scales, ranging from the macroscale, at which brain regions interact intra- and inter-hemispherically via long-range connections, to the microscale of myriads of single neurons, where we have the knowledge on their electrophysiological properties, receptors, transmitters, position and wiring in cortical layers, etc. In vivo measurement techniques at the macroscale offer information about individual brains, whereas measurements at the microscale are more specific to cell membranes and structures but cannot sample an entire individual brain. The concept of The Virtual Brain addresses both scales: on the one hand, the structural connectivity of the whole brain is the scaffold of The Virtual Brain, and, on the other hand, the characteristics on the neural level are represented in the local dynamic models and their biophysiological parameters (e.g., the Jansen-Rit model). Modeling the large-scale brain alone may not comprise microscopical elements, as well as modeling the entire brain based on every single neuron may be computationally infeasible.

For this reason, the mesoscale has been established (Deco et al., 2008; Wright and Liley, 2010) and comprises different components. First, the direct electromagnetic fields between neighboring regions directly influence each other. In addition, neural masses, which can cover the anatomical extent of a functional region or cover the neural mass in a voxel sampled by an MRI scanner. Depending on the neural mass model, they can refer to excitatory and inhibitory populations interacting with each other and through the large-scale network, the connectome, with distant regions. The interplay of this local circuitry in the large-scale brain network can produce physiologically plausible brain activity on a large scale (Honey et al., 2007; Ghosh et al., 2008; Sotero and Trujillo-Barreto, 2008; Bojak et al., 2010; Jirsa et al., 2010; Ritter et al., 2013; Sanz-Leon et al., 2015; Kunze et al., 2016).

The prospect of The Virtual Brain as an interdisciplinary research framework is that clinical applications and ensuing technologies may benefit and build on theoretical and computational predictions, as it has already shown success in epileptic surgery (Jirsa et al., 2017; Proix et al., 2017). The Virtual Brain has already been used in a wide range of research topics, from the modeling of physiological brain phenomena in healthy participants (Ritter et al., 2013; Sanz Leon et al., 2013; Spiegler and Jirsa, 2013; Roy et al., 2014), mouse brain models (Melozzi et al., 2017), to clinical approaches of $\mathrm{AD}$ (Zimmermann et al., 2018; Stefanovski et al., 2019), stroke (Falcon et al., 2015, 2016), and brain tumors (Aerts et al., 2018).

A study by Zimmermann et al. modeled AD using The Virtual Brain (Zimmermann et al., 2018). By fitting the model to predict individual functional connectivity from the underlying structural connectivity, the authors could show a significant correlation between the cognitive state of $\mathrm{AD}$ patients and the fitted model parameters of The Virtual Brain (Zimmermann et al., 2018). As the parameters are surrogates of biophysically relevant entities such as long-range coupling factors and local interactions between inhibitory and excitatory neuronal populations, this enables the non-invasive estimation of intrinsic brain features.

For the field of $\mathrm{AD}$, multimodal data could include, e.g., anatomical MRI, the structural connectivity out of diffusion tensor imaging, and PET imaging data of Glucose metabolism, Amyloid, and Tau. Our previous study (Stefanovski et al., 2019) used one of these features, namely Abeta PET, to explore the mechanisms behind another prominent phenomenon in $\mathrm{AD}$ : the slowing of electroencephalography (Stefanovski et al., 2019). As a pilot study in the field of molecular-driven large-scale brain simulations, we modeled local Abeta-mediated hyperexcitability using brain network modeling with The Virtual Brain, where regional Abeta burden was derived from PET data. By defining the local excitation-inhibition balance as a function of local Abeta burden from PET, fundamental differences between the $\mathrm{AD}$ patients and controls were observed. We showed that a few regions with moderate or high Abeta burden are transferred into an altered dynamic state, wherein their activity oscillations 
slowed down. This slowing is mainly presented as a shift from alpha to theta rhythm. It was propagated throughout the network and focused on the hubs. Interestingly, local hyperexcitation took also place in the central parts of the network. Therefore, with this approach, we were able to reveal a possible pathomechanism behind electroencephalographic slowing in $\mathrm{AD}$ (Stefanovski et al., 2019).

\section{CONCLUSIONS AND FUTURE DIRECTIONS}

Although our knowledge about the contributing factors in $\mathrm{AD}$ pathogenesis grows, it is still a major challenge in neuroscience to understand their distinct meaning and interaction. Moreover, the translation to clinical research is lagging behind. Rather than exploring isolated mechanisms, the goal should be to integrate multiscale datasets to reveal complex interactions underlying $\mathrm{AD}$ (Hofmann-Apitius et al., 2015; Iyappan et al., 2016) (Figure 7).

The main reasons for the development of precise and early diagnosis tools for AD can be summarized as follows:

1. Future treatments. When a disease-modifying treatment for degenerative dementia will be available, it probably needs to be performed many years before the clinical and behavioral manifestation of the disease. This is because pathway changes in the brain begin decades before the onset of dementia and lead to irreversible neuronal death. However, one has to expect that such a treatment has to be taken for many years and might have severe adverse reactions. Therefore, high sensitivity for the screening and high specificity of the diagnosis will be of crucial importance. Moreover, future trends of personalized treatments can only be performed with personalized biomarker-profiled patient 'fingerprints'. For example, a recent analysis has shown that the multimodal dataset from the Alzheimer's Disease Neuroimaging Database (ADNI) can predict the gene expression pattern (as a potential individualized treatment target) better than the clinical presentation does (Iturria-Medina et al., 2018).

2. Differential diagnosis. A more precise diagnosis of $\mathrm{AD}$ will lead to the possibility to clarify seemingly atypical cases. Some etiologies could be identified with prospective treatments. Moreover, in the future, subtypes of disease entities could be established, which are currently subsumed under $\mathrm{AD}$, and assessed by a specific treatment, e.g., autoimmunity phenomena with immunosuppression or early-onset $\mathrm{AD}$ with anti-Abeta drugs.

3. Patient stratification. It is necessary to identify the right population to test new treatments. If the diagnosis is not clear enough, possible effects could be overlaid because of too many patients with other disease causes, in which the treatment does not show an effect.

4. Study monitoring. Because the disease's clinical trajectories are slow and not easy to measure objectively, it is beneficial to use biomarkers to monitor drug effects in study settings.

Using computational models for multiscale brain simulations in future research may lead to improved diagnostics in the early

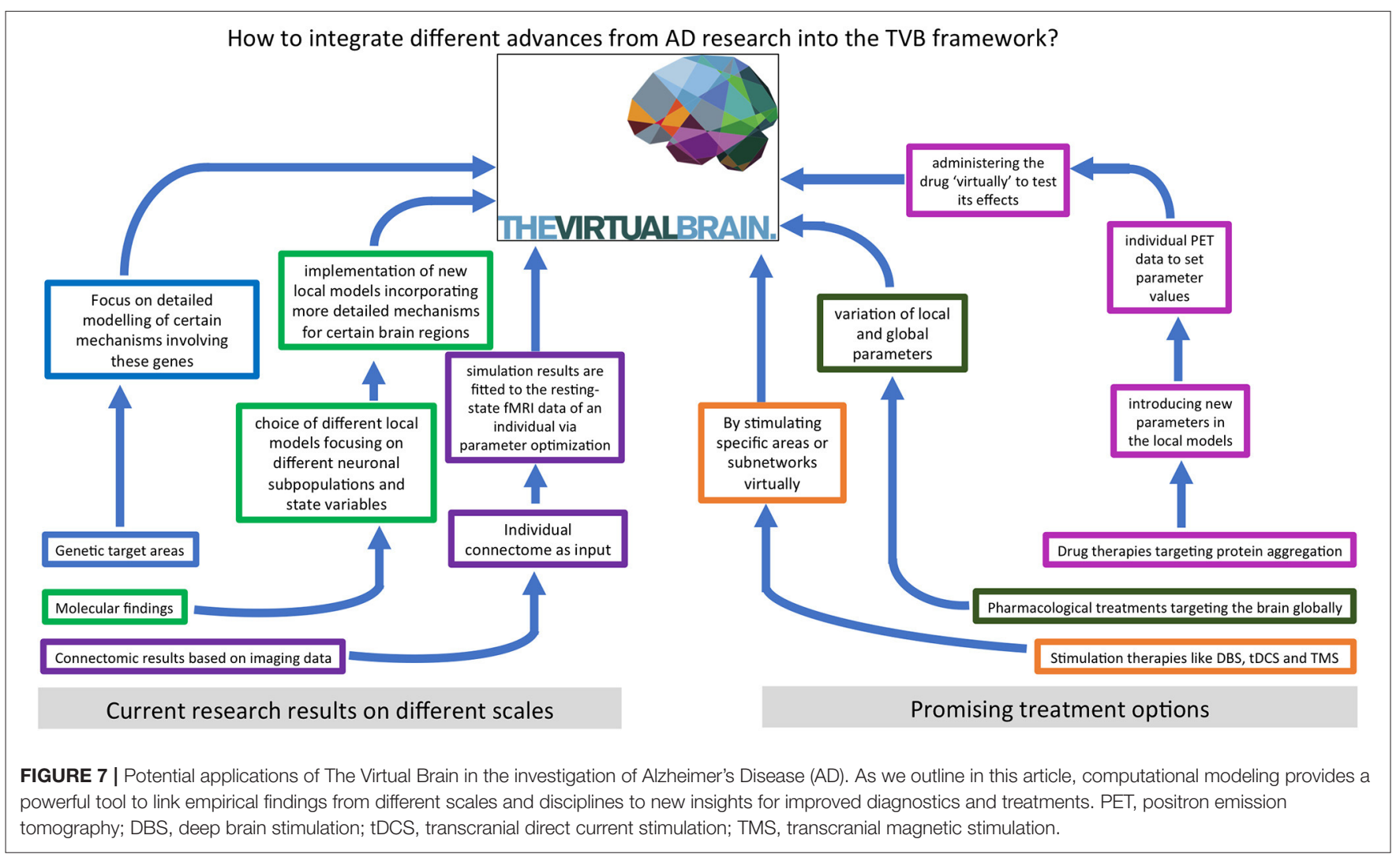


stages of dementia, to a more precise prognostic prediction and differential diagnosis which are the fundamentals of rational medical treatment of $\mathrm{AD}$ patients.

\section{AUTHOR CONTRIBUTIONS}

LS and PR developed the idea and concept for this article. LS wrote the manuscript with the contribution of JM, RP, PT, TL, LM, KB, and PR. LS, JM, and PT developed the figures. MH-A, $\mathrm{AS}, \mathrm{AM}$, and PR contributed to the interpretation of the results, figure development, and revision of the manuscript. All authors have made substantial intellectual contributions to this work and approved it for publication.

\section{REFERENCES}

Abuhassan, K., Coyle, D., and Maguire, L. P. (2012). Investigating the neural correlates of pathological cortical networks in Alzheimer's disease using heterogeneous neuronal models. IEEE Trans. Bio Med. Eng. 59, 890-896. doi: 10.1109/TBME.2011.2181843

Adams, J. N., Lockhart, S. N., Li, L., and Jagust, W. J. (2018). Relationships between tau and glucose metabolism reflect Alzheimer's disease pathology in cognitively normal older adults. Cereb. Cortex. 29, 1997-2009. doi: 10.1093/cercor/ bhy078

Aerts, H., Schirner, M., Jeurissen, B., Van Roost, D., Achten, E., Ritter, P., et al. (2018). Modeling brain dynamics in brain tumor patients using the virtual brain. eNeuro 5, 1-15. doi: 10.1523/ENEURO.0083-18.2018

Alongi, P., Sardina, D. S., Coppola, R., Scalisi, S., Puglisi, V., Arnone, A., et al. (2019). 18F-florbetaben PET/CT to assess Alzheimer's disease: a new analysis method for regional amyloid quantification. J. Neuroimaging. 29, 383-393. doi: 10.1111/jon.12601

Alzheimer, A. (1907). Über eine eigenartige Erkrankung der Hirnrinde. Centralblatt Nervenheilkunde Psychiatrie 18, 177-179.

Alzheimer, A. (1911). Über eigenartige Krankheitsfälle des späteren Alters. Zeitschrift Gesamte Neurol. Psychiatrie 4, 356-385. doi: 10.1007/BF02866241

Alzheimer's Association (2018). 2018 Alzheimer's disease facts and figures. Alzheimer Dement. 14, 367-429. doi: 10.1016/j.jalz.2018.02.001

Alzheimer's Association (2019). 2019 Alzheimer's disease facts and figures. Alzheimer Dement. 15, 321-87. doi: 10.1016/j.jalz.2019.01.010

American Psychiatric Association (2013). Diagnostic and Statistical Manual of Mental Disorders, 5th Edn. Washington, DC.

Anastasio, T. J. (2013). Exploring the contribution of estrogen to amyloid-beta regulation: a novel multifactorial computational modeling approach. Front. Pharmacol. 4:16. doi: 10.3389/fphar.2013.00016

Anastasio, T. J. (2014). Computational identification of potential multitarget treatments for ameliorating the adverse effects of amyloid- $\beta$ on synaptic plasticity. Front. Pharmacol. 5:85. doi: 10.3389/fphar.2014.00085

Andrews, S. J., Fulton-Howard, B., and Goate, A. (2020). Interpretation of risk loci from genome-wide association studies of Alzheimer's disease. Lancet Neurol. 19, 326-335. doi: 10.1016/S1474-4422(19)30435-1

Arai, H., and Takahashi, T. (2009). A combination therapy of donepezil and cilostazol for patients with moderate Alzheimer disease: pilot follow-up study. Am. J. Geriatr. Psychiatry 17, 353-354. doi: 10.1097/JGP.0b013e31819431ea

Ashford, J. W., and Jarvik, L. (1985). Alzheimer's disease: does neuron plasticity predispose to axonal neurofibrillary degeneration? N. Engl. J. Med. 313, 388-389. doi: 10.1056/NEJM198508083130616

Ashraf, G. M., Chibber, S., Mohammad, Zaidi, S. K., Tabrez, S., Ahmad, A., et al. (2016). Recent updates on the association between Alzheimer's disease and vascular dementia. Med. Chem. 12, 226-237. doi: 10.2174/1573406411666151030111820

Bachurin, S. O., Bovina, E. V., and Ustyugov, A. A. (2017). Drugs in clinical trials for Alzheimer's disease: the major trends. Med. Res. Rev. 37, 1186-1225. doi: $10.1002 /$ med.21434

\section{FUNDING}

PR acknowledges support by EU H2020 Virtual Brain Cloud 826421, Human Brain Project SGA2 785907; Human Brain Project SGA3 945539, ERC Consolidator 683049; German Research Foundation SFB 1436 (project ID 425899996); SFB 1315 (project ID 327654276); SFB 936 (project ID 178316478; SFB-TRR 295 (project ID 424778381); SPP Computational Connectomics RI 2073/6-1, RI 2073/10-2, RI 2073/9-1; Berlin Institute of Health \& Foundation Charité, Johanna Quandt Excellence Initiative. We acknowledge support from the German Research Foundation (DFG) and the Open Access Publication Fund of Charité-Universitätsmedizin Berlin.

Banerjee, G., Ambler, G., Keshavan, A., Paterson, R. W., Foiani, M. S., Toombs, J., et al. (2020). Cerebrospinal fluid biomarkers in cerebral amyloid angiopathy. J. Alzheimer Dis. 74, 1189-1201. doi: 10.3233/JAD-191254

Barnes, J., Whitwell, J. L., Frost, C., Josephs, K. A., Rossor, M., and Fox, N. C. (2006). Measurements of the amygdala and hippocampus in pathologically confirmed Alzheimer disease and frontotemporal lobar degeneration. Arch. Neurol. 63, 1434-1439. doi: 10.1001/archneur.63.10.1434

Bennett, D. A., Schneider, J. A., Bienias, J. L., Evans, D. A., and Wilson, R. S. (2005). Mild cognitive impairment is related to Alzheimer disease pathology and cerebral infarctions. Neurology 64, 834-841. doi: 10.1212/01.WNL.0000152982.47274.9E

Bermel, R. A. (2017). Unravelling neurodegeneration in multiple sclerosis. Lancet Neurol. 16, 764-766. doi: 10.1016/S1474-4422(17)30302-2

Bernard, C., Dilharreguy, B., Helmer, C., Chanraud, S., Amieva, H., Dartigues, J.-F., et al. (2015). PCC characteristics at rest in 10-year memory decliners. Neurobiol. Aging 36, 2812-2820. doi: 10.1016/j.neurobiolaging.2015.07.002

Bhagwat, N., Viviano, J. D., Voineskos, A. N., Chakravarty, M. M., and Alzheimer's Disease Neuroimaging Initiative (2018). Modeling and prediction of clinical symptom trajectories in Alzheimer's disease using longitudinal data. PLoS Comput. Biol. 14:e1006376. doi: 10.1371/journal.pcbi.1006376

Bianchi, D., De Michele, P., Marchetti, C., Tirozzi, B., Cuomo, S., Marie, H., et al. (2014). Effects of increasing CREB-dependent transcription on the storage and recall processes in a hippocampal CA1 microcircuit. Hippocampus 24, 165-177. doi: 10.1002/hipo. 22212

Bittlinger, M., and Muller, S. (2018). Opening the debate on deep brain stimulation for Alzheimer disease - a critical evaluation of rationale, shortcomings, and ethical justification. BMC Med. Ethics 19:41. doi: 10.1186/s12910-018-0275-4

Blanc, F., Colloby, S. J., Philippi, N., de Pétigny, X., Jung, B., Demuynck, C., et al. (2015). Cortical thickness in dementia with lewy bodies and Alzheimer's disease: a comparison of prodromal and dementia stages. PLoS ONE 10:e0127396. doi: 10.1371/journal.pone.0127396

Blennow, K., de Leon, M. J., and Zetterberg, H. (2006). Alzheimer's disease. Lancet 368, 387-403. doi: 10.1016/S0140-6736(06)69113-7

Bloom, G. S. (2014). Amyloid- $\beta$ and tau: the trigger and bullet in Alzheimer disease pathogenesis. JAMA Neurol. 71, 505-508. doi: 10.1001/jamaneurol.2013.5847

Bobinski, M., de Leon, M. J., Convit, A., Santi, S. D., Wegiel, J., Tarshish, C. Y., et al. (1999). MRI of entorhinal cortex in mild Alzheimer's disease. Lancet 353, 38-40. doi: 10.1016/S0140-6736(05)74869-8

Bock, H.-H. (2005). Proximity Measures. Encyclopedia of Statistics in Behavioral Science, Vol. 3, eds B. S. Everitt, and D. C. Howell (New York, NY: Wiley), 1621-1628. doi: 10.1002/0470013192.bsa510

Bojak, I., Oostendorp, T. F., Reid, A. T., and Kötter, R. (2010). Connecting mean field models of neural activity to EEG and fMRI data. Brain Topogr. 23, 139-149. doi: 10.1007/s10548-010-0140-3

Bosscher, L., and Scheltens, P. (2002). II. 4.7 MRI of the medial temporal lobe for the diagnosis of Alzheimer's disease. Evid. Based Dement. Prac. 154. doi: $10.1002 / 9780470752340$

Braak, H., Alafuzoff, I., Arzberger, T., Kretzschmar, H., and Del Tredici, K. (2006). Staging of Alzheimer disease-associated neurofibrillary pathology using 
paraffin sections and immunocytochemistry. Acta Neuropathol. 112, 389-404. doi: 10.1007/s00401-006-0127-z

Braak, H., and Braak, E. (1991). Neuropathological stageing of Alzheimer-related changes. Acta Neuropathol. 82, 239-259. doi: 10.1007/BF00308809

Braak, H., and Braak, E. (1997). Frequency of stages of Alzheimer-related lesions in different age categories. Neurobiol. Aging 18, 351-357. doi: 10.1016/S0197-4580(97)00056-0

Brai, E., Alina Raio, N., and Alberi, L. (2016). Notch1 hallmarks fibrillary depositions in sporadic Alzheimer's disease. Acta Neuropathol. Commun. 4:64. doi: 10.1186/s40478-016-0327-2

Brai, E., Marathe, S., Astori, S., Fredj, N. B., Perry, E., Lamy, C., et al. (2015). Notch1 regulates hippocampal plasticity through interaction with the reelin pathway, glutamatergic transmission and CREB signaling. Front. Cell. Neurosci. 9:447. doi: 10.3389/fncel.2015.00447

Brickman, A. M. (2013). Contemplating Alzheimer's disease and the contribution of white matter hyperintensities. Curr. Neurol. Neurosci. Rep. 13:415. doi: 10.1007/s11910-013-0415-7

Brier, M. R., Thomas, J. B., and Ances, B. M. (2014a). Network dysfunction in Alzheimer's disease: refining the disconnection hypothesis. Brain Connect 4, 299-311. doi: 10.1089/brain.2014.0236

Brier, M. R., Thomas, J. B., Fagan, A. M., Hassenstab, J., Holtzman, D. M., Benzinger, T. L., et al. (2014b). Functional connectivity and graph theory in preclinical Alzheimer's disease. Neurobiol. Aging 35, 757-768. doi: 10.1016/j.neurobiolaging.2013.10.081

Broks, P., Preston, G. C., Traub, M., Poppleton, P., Ward, C., and Stahl, S. M. (1988). Modelling dementia: effects of scopolamine on memory and attention. Neuropsychologia 26, 685-700. doi: 10.1016/0028-3932(88)90004-8

Buckner, R. L., Sepulcre, J., Talukdar, T., Krienen, F. M., Liu, H., Hedden, T., et al. (2009). Cortical hubs revealed by intrinsic functional connectivity: mapping, assessment of stability, and relation to Alzheimer's disease. J. Neurosci. 29, 1860-1873. doi: 10.1523/JNEUROSCI.5062-08.2009

Bullmore, E., and Sporns, O. (2009). Complex brain networks: graph theoretical analysis of structural and functional systems. Nat. Rev. Neurosci. 10, 186-198. doi: $10.1038 / \mathrm{nrn} 2575$

Burggren, A., and Brown, J. (2014). Imaging markers of structural and functional brain changes that precede cognitive symptoms in risk for Alzheimer's disease. Brain Imaging Behav. 8, 251-261. doi: 10.1007/s11682-013-9278-4

Butchart, J., Brook, L., Hopkins, V., Teeling, J., Puntener, U., Culliford, D., et al. (2015). Etanercept in Alzheimer disease: a randomized, placebo-controlled, double-blind, phase 2 trial. Neurology 84, 2161-2168. doi: 10.1212/WNL.0000000000001617

Byun, M. S., Kim, S. E., Park, J., Yi, D., Choe, Y. M., Sohn, B. K., et al. (2015). Heterogeneity of regional brain atrophy patterns associated with distinct progression rates in Alzheimer's disease. PLOS ONE 10:e142756. doi: 10.1371/journal.pone.0142756

Callen, D. J. A., Black, S. E., Gao, F., Caldwell, C. B., and Szalai, J. P. (2001). Beyond the hippocampus. MRI volumetry confirms widespread limbic atrophy in AD. Neurology 57, 1669-1674. doi: 10.1212/WNL.57.9.1669

Cebers, G., Alexander, R. C., Haeberlein, S. B., Han, D., Goldwater, R., Ereshefsky, L., et al. (2017). AZD3293: pharmacokinetic and pharmacodynamic effects in healthy subjects and patients with Alzheimer's disease. J. Alzheimer Dis. 55, 1039-1053. doi: 10.3233/JAD-160701

Chang, Y. T., Huang, C. W., Chang, Y. H., Chen, N. C., Lin, K. J., Yan, T. C., et al. (2015). Amyloid burden in the hippocampus and default mode network: relationships with gray matter volume and cognitive performance in mild stage Alzheimer disease. Medicine 94:e763. doi: 10.1097/MD.0000000000000763

Chen, C. (2005). $\beta$-Amyloid increases dendritic Ca2+ influx by inhibiting the Atype $\mathrm{K}+$ current in hippocampal CA1 pyramidal neurons. Biochem. Biophys. Res. Commun. 338, 1913-1919. doi: 10.1016/j.bbrc.2005.10.169

Chen, G., Zhang, H.-Y., Xie, C., Chen, G., Zhang, Z.-J., Teng, G.-J., et al. (2013). Modular reorganization of brain resting state networks and its independent validation in Alzheimer's disease patients. Front. Hum. Neurosci. 7:456. doi: 10.3389/fnhum.2013.00456

Chen, Y., Yan, H., Han, Z., Bi, Y., Chen, H., Liu, J., et al. (2016). Functional activity and connectivity differences of five resting-state networks in patients with Alzheimer's disease or mild cognitive impairment. Curr. Alzheimer Res. 13, 234-242. doi: 10.2174/156720501303160217113858

Cheng, Y. W., Chen, T. F., and Chiu, M. J. (2017). From mild cognitive impairment to subjective cognitive decline: conceptual and methodological evolution. Neuropsychiatr. Dis. Treat 13, 491-498. doi: 10.2147/NDT.S123428
Cho, H., Choi, J. Y., Hwang, M. S., Lee, J. H., Kim, Y. J., Lee, H. M., et al. (2016). Tau PET in Alzheimer disease and mild cognitive impairment. Neurology 87, 375-383. doi: 10.1212/WNL.0000000000002892

Chou, R. C., Kane, M., Ghimire, S., Gautam, S., and Gui, J. (2016). Treatment for rheumatoid arthritis and risk of Alzheimer's disease: a nested case-control analysis. CNS Drugs 30, 1111-1120. doi: 10.1007/s40263-016-0374-z

Çiftçi, K. (2011). Minimum spanning tree reflects the alterations of the default mode network during Alzheimer's disease. Ann. Biomed. Eng. 39, 1493-504. doi: 10.1007/s10439-011-0258-9

Clark, C. M., Schneider, J. A., Bedell, B. J., Beach, T. G., Bilker, W. B., Mintun, M. A., et al. (2011). Use of florbetapir-pet for imaging $\beta$-amyloid pathology. JAMA 305, 275-283. doi: 10.1001/jama.2010.2008

Cope, T. E., Rittman, T., Borchert, R. J., Jones, P. S., Vatansever, D. Allinson, K., et al. (2018). Tau burden and the functional connectome in Alzheimer's disease and progressive supranuclear palsy. Brain 141, 550-567. doi: 10.1093/brain/awx347

Coric, V., van Dyck, C. H., Salloway, S., Andreasen, N., Brody, M., Richter, R. W., et al. (2012). Safety and tolerability of the gamma-secretase inhibitor avagacestat in a phase 2 study of mild to moderate Alzheimer disease. Arch. Neurol. 69, 1430-1440. doi: 10.1001/archneurol.2012.2194

Craft, S., Baker, L. D., Montine, T. J., Minoshima, S., Watson, G. S., Claxton, A., et al. (2012). Intranasal insulin therapy for Alzheimer disease and amnestic mild cognitive impairment: a pilot clinical trial. Arch. Neurol. 69, 29-38. doi: 10.1001/archneurol.2011.233

Crow, T. J., and Grove-White, I. G. (1973). An analysis of the learning deficit following hyoscine administration to man. Br. J. Pharmacol. 49, 322-327. doi: 10.1111/j.1476-5381.1973.tb08379.x

Csernansky, J. G., Hamstra, J., Wang, L., McKeel, D., Price, J. L., Gado, M., et al. (2004). Correlations between antemortem hippocampal volume and postmortem neuropathology in AD subjects. Alzheimer Dis. Associated Disord. $18,190-195$

Cure, S., Abrams, K., Belger, M., Dell'agnello, G., and Happich, M. (2014). Systematic literature review and meta-analysis of diagnostic test accuracy in Alzheimer's disease and other dementia using autopsy as standard of truth. J. Alzheimer Dis. 42, 169-182. doi: 10.3233/JAD-131559

Cuyvers, E., and Sleegers, K. (2016). Genetic variations underlying Alzheimer's disease: evidence from genome-wide association studies and beyond. Lancet Neurol. 15, 857-868. doi: 10.1016/S1474-4422(16)00127-7

Dai, Z., Lin, Q., Li, T., Wang, X., Yuan, H., Yu, X., et al. (2019). Disrupted structural and functional brain networks in Alzheimer's disease. Neurobiol. Aging 75, 71-82. doi: 10.1016/j.neurobiolaging.2018.11.005

Dai, Z., Yan, C., Li, K., Wang, Z., Wang, J., Cao, M., et al. (2014). Identifying and mapping connectivity patterns of brain network hubs in Alzheimer's disease. Cereb. Cortex 25, 3723-3742. doi: 10.1093/cercor/bhu246

Daianu, M., Jahanshad, N., Nir, T. M., Jack C. R. Jr., Weiner, M. W., Bernstein, M. A., et al. (2015). Rich club analysis in the Alzheimer's disease connectome reveals a relatively undisturbed structural core network. Human Brain Mapp. 36, 3087-3103. doi: 10.1002/hbm.22830

Day, G. S. (2019). Reversible dementias. Continuum 25, 234-253. doi: 10.1212/CON.0000000000000688

De Caluwé, J., and Dupont, G. (2013). The progression towards Alzheimer's disease described as a bistable switch arising from the positive loop between amyloids and Ca2+. J. Theor. Biol. 331, 12-18. doi: 10.1016/j.jtbi.2013.04.015

de Haan, W., Mott, K., van Straaten, E. C., Scheltens, P., and Stam, C. J. (2012). Activity dependent degeneration explains hub vulnerability in Alzheimer's disease. PLoS Comput. Biol. 8:e1002582. doi: 10.1371/journal.pcbi.1002582

de Haan, W., Pijnenburg, Y. A. L., Strijers, R. L. M., van der Made, Y., van der Flier, W. M., Scheltens, P., et al. (2009). Functional neural network analysis in frontotemporal dementia and Alzheimer's disease using EEG and graph theory. BMC Neurosci. 10:101. doi: 10.1186/1471-2202-10-101

de Haan, W., van Straaten, E. C. W., Gouw, A. A., and Stam, C. J. (2017). Altering neuronal excitability to preserve network connectivity in a computational model of Alzheimer's disease. PLoS Comput. Biol. 13:e1005707. doi: 10.1371/journal.pcbi.1005707

de Vos, F., Koini, M., Schouten, T. M., Seiler, S., van der Grond, J., Lechner, A., et al. (2018). A comprehensive analysis of resting state fMRI measures to classify individual patients with Alzheimer's disease. Neuroimage 167, 62-72. doi: 10.1016/j.neuroimage.2017.11.025

de Wilde, A., van der Flier, W. M., Pelkmans, W., Bouwman, F., Verwer, J., Groot, C., et al. (2018). Association of amyloid positron emission 
tomography with changes in diagnosis and patient treatment in an unselected memory clinic cohort: the ABIDE project. JAMA Neurol. 75, 1062-1070. doi: 10.1001/jamaneurol.2018.1346

Deco, G., Jirsa, V. K., Robinson, P. A., Breakspear, M., and Friston, K. (2008). The dynamic brain: from spiking neurons to neural masses and cortical fields. PLoS Comput. Biol. 4:e1000092. doi: 10.1371/journal.pcbi.1000092

Degerman Gunnarsson, M., Lannfelt, L., Ingelsson, M., Basun, H., and Kilander, L. (2014). High tau levels in cerebrospinal fluid predict rapid decline and increased dementia mortality in Alzheimer's disease. Dement. Geriatr. Cogn. Disord. 37, 196-206. doi: 10.1159/000355556

Delbeuck, X., Van der Linden, M., and Collette, F. (2003). Alzheimer' disease as a disconnection syndrome? Neuropsychol. Rev. 13, 79-92. doi: 10.1023/A:1023832305702

Demirtaş, M., Falcon, C., Tucholka, A., Gispert, J. D., Molinuevo, J. L., and Deco, G. (2017). A whole-brain computational modeling approach to explain the alterations in resting-state functional connectivity during progression of Alzheimer's disease. NeuroImage Clin. 16, 343-354. doi: 10.1016/j.nicl.2017.08.006

Dennis, E. L., and Thompson, P. M. (2014). Functional brain connectivity using fMRI in aging and Alzheimer's disease. Neuropsychol. Rev. 24, 49-62. doi: 10.1007/s11065-014-9249-6

Dickerson, B. C., Goncharova, I., Sullivan, M. P., Forchetti, C., Wilson, R. S., Bennett, D. A., et al. (2001). MRI-derived entorhinal and hippocampal atrophy in incipient and very mild Alzheimer's disease. Neurobiol. Aging 22, 747-754. doi: 10.1016/S0197-4580(01)00271-8

Dickerson, B. C., McGinnis, S. M., Xia, C., Price, B. H., Atri, A., Murray, M. E., et al. (2017). Approach to atypical Alzheimer's disease and case studies of the major subtypes. CNS Spectr. 22, 439-449. doi: 10.1017/S109285291600047X

Dickerson, B. C., Salat, D. H., Bates, J. F., Atiya, M., Killiany, R. J., Greve, D. N., et al. (2004). Medial temporal lobe function and structure in mild cognitive impairment. Ann. Neurol. 56, 27-35. doi: 10.1002/ana.20163

Dipasquale, O., and Cercignani, M. (2016). Network functional connectivity and whole-brain functional connectomics to investigate cognitive decline in neurodegenerative conditions. Funct. Neurol. 31, 191-203. doi: 10.11138/FNeur/2016.31.4.191

Domingo-Fernández, D., Kodamullil, A. T., Iyappan, A., Naz, M., Emon, M. A., Raschka, T., et al. (2017). Multimodal mechanistic signatures for neurodegenerative diseases (NeuroMMSig): a web server for mechanism enrichment. Bioinformatics 33, 3679-3681. doi: 10.1093/bioinformatics/btx399

Ertekin-Taner, N. (2007). Genetics of Alzheimer's disease: a centennial review. Neurol. Clin. 25, 611-667. doi: 10.1016/j.ncl.2007.03.009

Eyjolfsdottir, H., Eriksdotter, M., Linderoth, B., Lind, G., Juliusson, B., Kusk, P., et al. (2016). Targeted delivery of nerve growth factor to the cholinergic basal forebrain of Alzheimer's disease patients: application of a secondgeneration encapsulated cell biodelivery device. Alzheimer Res. Ther. 8:30. doi: 10.1186/s13195-016-0195-9

Falcon, M. I., Riley, J. D., Jirsa, V., McIntosh, A. R., Elinor Chen, E., and Solodkin, A. (2016). Functional mechanisms of recovery after chronic stroke: modeling with the virtual brain. eNeuro 3, 1-14. doi: 10.1523/ENEURO.0158-1 5.2016

Falcon, M. I., Riley, J. D., Jirsa, V., McIntosh, A. R., Shereen, A. D., Chen, E. E., et al. (2015). The virtual brain: modeling biological correlates of recovery after chronic stroke. Front. Neurol. 6:228. doi: 10.3389/fneur.2015.00228

Farlow, M. R., Andreasen, N., Riviere, M. E., Vostiar, I., Vitaliti, A., Sovago, J., et al. (2015). Long-term treatment with active Abeta immunotherapy with CAD106 in mild Alzheimer's disease. Alzheimer Res. Ther. 7:23. doi: 10.1186/s13195-015-0108-3

Faux, N. G., Ritchie, C. W., Gunn, A., Rembach, A., Tsatsanis, A., Bedo, J., et al. (2010). PBT2 rapidly improves cognition in Alzheimer's disease: additional phase II analyses. J. Alzheimer Dis. 20, 509-516. doi: 10.3233/JAD2010-1390

Ferreira, D., Verhagen, C., Hernández-Cabrera, J. A., Cavallin, L., Guo, C.-J., Ekman, U., et al. (2017). Distinct subtypes of Alzheimer's disease based on patterns of brain atrophy: longitudinal trajectories and clinical applications. Sci. Rep. 7:46263. doi: 10.1038/srep46263

Ferreira-Vieira, T. H., Guimaraes, I. M., Silva, F. R., and Ribeiro, F. M. (2016). Alzheimer's disease: targeting the cholinergic system. Curr. Neuropharmacol. 14, 101-115. doi: 10.2174/1570159X13666150716165726
Fiest, K. M., Jette, N., Roberts, J. I., Maxwell, C. J., Smith, E. E., Black, S. E., et al. (2016). The prevalence and incidence of dementia: a systematic review and meta-analysis. Can. J. Neurol. Sci. 43(Suppl. 1), S3-S50. doi: $10.1017 /$ cjn.2016.18

Floel, A. (2014). tDCS-enhanced motor and cognitive function in neurological diseases. Neuroimage 85(Pt 3), 934-947. doi: 10.1016/j.neuroimage.2013.05.098

Folch, J., Petrov, D., Ettcheto, M., Pedros, I., Abad, S., Beas-Zarate, C., et al. (2015). Masitinib for the treatment of mild to moderate Alzheimer's disease. Expert Rev. Neurother. 15, 587-596. doi: 10.1586/14737175.2015.1045419

Forlenza, O. V., Diniz, B. S., Radanovic, M., Santos, F. S., Talib, L. L., and Gattaz, W. F. (2011). Disease-modifying properties of long-term lithium treatment for amnestic mild cognitive impairment: randomised controlled trial. $\mathrm{Br}$. J. Psychiatry 198, 351-356. doi: 10.1192/bjp.bp.110.080044

Fornito, A., Zalesky, A., and Breakspear, M. (2015). The connectomics of brain disorders. Nat. Rev. Neurosci. 16, 159-172. doi: 10.1038/nrn3901

Freitas, C., Mondragon-Llorca, H., and Pascual-Leone, A. (2011). Noninvasive brain stimulation in Alzheimer's disease: systematic review and perspectives for the future. Exp. Gerontol. 46, 611-627. doi: 10.1016/j.exger.2011.04.001

Freund-Levi, Y., Eriksdotter-Jonhagen, M., Cederholm, T., Basun, H., FaxenIrving, G., Garlind, A., et al. (2006). Omega-3 fatty acid treatment in 174 patients with mild to moderate Alzheimer disease: OmegAD study: a randomized double-blind trial. Arch. Neurol. 63, 1402-1408. doi: 10.1001/archneur.63.10.1402

Freund-Levi, Y., Hjorth, E., Lindberg, C., Cederholm, T., Faxen-Irving, G., Vedin, I., et al. (2009). Effects of omega-3 fatty acids on inflammatory markers in cerebrospinal fluid and plasma in Alzheimer's disease: the OmegAD study. Dement. Geriatr. Cogn. Disord. 27, 481-490. doi: 10.1159/000218081

Frisoni, G. B., Testa, C., Zorzan, A., Sabattoli, F., Beltramello, A., Soininen, H., et al. (2002). Detection of grey matter loss in mild Alzheimer's disease with voxel based morphometry. J. Neurol. Neurosurg. Psychiatry 73, 657-664. doi: 10.1136/jnnp.73.6.657

Fukai, M., Hirosawa, T., Kikuchi, M., Hino, S., Kitamura, T., Ouchi, Y., et al. (2018). Different patterns of glucose hypometabolism underlie functional decline in frontotemporal dementia and Alzheimer's disease: FDG-PET study. Neuropsychiatry 8, 441-447. doi: 10.4172/Neuropsychiatry.1000365

Galimberti, D., and Scarpini, E. (2017). Pioglitazone for the treatment of Alzheimer's disease. Expert Opin. Investig. Drugs 26, 97-101. doi: 10.1080/13543784.2017.1265504

Gauthier, S., Zhang, H., Ng, K. P., Pascoal, T. A., and Rosa-Neto, P. (2018). Impact of the biological definition of Alzheimer's disease using amyloid, tau and neurodegeneration (ATN): what about the role of vascular changes, inflammation, Lewy body pathology? Transl. Neurodegener. 7:12. doi: 10.1186/s40035-018-0117-9

Geldmacher, D. S., Fritsch, T., McClendon, M. J., and Landreth, G. (2011). A randomized pilot clinical trial of the safety of pioglitazone in treatment of patients with Alzheimer disease. Arch. Neurol. 68, 45-50. doi: 10.1001/archneurol.2010.229

George, A., and Howlett, D. (1999). Computationally derived structural models of the $\beta$-amyloid found in Alzheimer's disease plaques and the interaction with possible aggregation inhibitors. Biopolymers 50, 733-741. doi: 10.1002/ (SICI) 1097-0282(199912)50:7<733::AID-BIP6>3.0.CO;2-7

Ghosh, A., Rho, Y., McIntosh, A. R., Kotter, R., and Jirsa, V. K. (2008). Noise during rest enables the exploration of the brain's dynamic repertoire. PLoS Comput. Biol. 4:e1000196. doi: 10.1371/journal.pcbi.1000196

Gilman, S., Koller, M., Black, R. S., Jenkins, L., Griffith, S. G., Fox, N. C., et al. (2005). Clinical effects of Abeta immunization (AN1792) in patients with $\mathrm{AD}$ in an interrupted trial. Neurology 64, 1553-1562. doi: 10.1212/01.WNL.0000159740.16984.3C

Golriz Khatami, S., Robinson, C., Birkenbihl, C., Domingo-Fernandez, D., Hoyt, C. T., and Hofmann-Apitius, M. (2019). Challenges of integrative disease modeling in Alzheimer's disease. Front. Mol. Biosci. 6:158. doi: 10.3389/fmolb.2019.00158

Gonneaud, J., Baria, A. T., Binette, A. P., Gordon, B. A., Chhatwal, J. P., Cruchaga, C., et al. (2020). Functional brain age prediction suggests accelerated aging in preclinical familial Alzheimer's disease, irrespective of fibrillar amyloid-beta pathology. bioRxiv. 1-24. doi: 10.1101/2020.05.06.076745

Gordon, B. A., Blazey, T. M., Christensen, J., Dincer, A., Flores, S., Keefe, S., et al. (2019). Tau PET in autosomal dominant Alzheimer's disease: relationship 
with cognition, dementia and other biomarkers. Brain 142, 1063-1076. doi: 10.1093/brain/awz019

Graff-Radford, J., Arenaza-Urquijo, E. M., Knopman, D. S., Schwarz, C. G., Brown, R. D. Jr., Rabinstein, A. A., et al. (2019). White matter hyperintensities: relationship to amyloid and tau burden. Brain 142, 2483-2491. doi: 10.1093/brain/awz162

Grant, W. B., Campbell, A., Itzhaki, R. F., and Savory, J. (2002). The significance of environmental factors in the etiology of Alzheimer's disease. J. Alzheimer Dis. 4, 179-189. doi: 10.3233/JAD-2002-4308

Green, R. C., Schneider, L. S., Amato, D. A., Beelen, A. P., Wilcock, G., Swabb, E. A., et al. (2009). Effect of tarenflurbil on cognitive decline and activities of daily living in patients with mild Alzheimer disease: a randomized controlled trial. JAMA 302, 2557-2564. doi: 10.1001/jama.2009.1866

Greicius, M. D., Srivastava, G., Reiss, A. L., and Menon, V. (2004). Defaultmode network activity distinguishes Alzheimer's disease from healthy aging: evidence from functional MRI. Proc. Natl. Acad. Sci. U.S.A. 101, 4637-4642. doi: 10.1073/pnas.0308627101

Guillon, J., Chavez, M., Battiston, F., Attal, Y., La Corte, V., Thiebaut de Schotten, M., et al. (2019). Disrupted core-periphery structure of multimodal brain networks in Alzheimer's disease. Netw. Neurosci. 3, 635-652. doi: 10.1162/netn_a_00087

Guo, T., Noble, W., and Hanger, D. P. (2017). Roles of tau protein in health and disease. Acta Neuropathol. 133, 665-704. doi: 10.1007/s00401-017-1707-9

Hahn, K., Myers, N., Prigarin, S., Rodenacker, K., Kurz, A., Förstl, H., et al. (2013). Selectively and progressively disrupted structural connectivity of functional brain networks in Alzheimer's disease-revealed by a novel framework to analyze edge distributions of networks detecting disruptions with strong statistical evidence. Neuroimage 81, 96-109. doi: 10.1016/j.neuroimage.2013.05.011

Hampel, H., Ewers, M., Burger, K., Annas, P., Mortberg, A., Bogstedt, A., et al. (2009). Lithium trial in Alzheimer's disease: a randomized, single-blind, placebo-controlled, multicenter 10-week study. J. Clin. Psychiatry 70, 922-931. doi: 10.4088/JCP.08m04606

Hardenacke, K., Shubina, E., Buhrle, C. P., Zapf, A., Lenartz, D., Klosterkotter, J., et al. (2013). Deep brain stimulation as a tool for improving cognitive functioning in Alzheimer's dementia: a systematic review. Front. Psychiatry 4:159. doi: 10.3389/fpsyt.2013.00159

Hardy, J., and Selkoe, D. J. (2002). The amyloid hypothesis of Alzheimer's disease: progress and problems on the road to therapeutics. Science 297, 353-356. doi: 10.1126/science.1072994

Harrison, T. M., La Joie, R., Maass, A., Baker, S. L., Swinnerton, K., Fenton, L., et al. (2019). Longitudinal tau accumulation and atrophy in aging and Alzheimer disease. Ann. Neurol. 85, 229-240. doi: 10.1002/ana.25406

Hasselmo, M. E. (1994). Runaway synaptic modification in models of cortex: implications for Alzheimer's disease. Neural Netw. 7, 13-40. doi: 10.1016/0893-6080(94)90053-1

Hasselmo, M. E. (2006). The role of acetylcholine in learning and memory. Curr. Opin. Neurobiol. 16, 710-715. doi: 10.1016/j.conb.2006.09.002

Hasselmo, M. E., and Bower, J. M. (1992). Cholinergic suppression specific to intrinsic not afferent fiber synapses in rat piriform (olfactory) cortex. $J$. Neurophysiol. 67, 1222-1229. doi: 10.1152/jn.1992.67.5.1222

Hasselmo, M. E., and Schnell, E. (1994). Laminar selectivity of the cholinergic suppression of synaptic transmission in rat hippocampal region CA1: computational modeling and brain slice physiology. J. Neurosci. 14, 3898-3914. doi: 10.1523/JNEUROSCI.14-06-03898.1994

Hasselmo, M. E., and Stern, C. E. (2006). Mechanisms underlying working memory for novel information. Trends Cogn. Sci 10, 487-493. doi: 10.1016/j.tics.2006.09.005

He, Y., Chen, Z., and Evans, A. (2008). Structural insights into aberrant topological patterns of large-scale cortical networks in Alzheimer's disease. J. Neurosci. 28, 4756-4766. doi: 10.1523/JNEUROSCI.0141-08.2008

Heneka, M. T., Carson, M. J., Khoury, J. E., Landreth, G. E., Brosseron, F., Feinstein, D. L., et al. (2015a). Neuroinflammation in Alzheimer's disease. Lancet Neurol. 14, 388-405. doi: 10.1016/S1474-4422(15) 70016-5

Heneka, M. T., Fink, A., and Doblhammer, G. (2015b). Effect of pioglitazone medication on the incidence of dementia. Ann. Neurol 78, 284-294. doi: 10.1002/ana.24439
Heneka, M. T., Golenbock, D. T., and Latz, E. (2015c). Innate immunity in Alzheimer's disease. Nat. Immunol. 16:229. doi: 10.1038/ni.3102

Hindmarsh, J., and Rose, R. (1984). A model of neuronal bursting using three coupled first order differential equations. Proc. R. Soc. London B Biol. Sci. 221, 87-102. doi: 10.1098/rspb.1984.0024

Hodgkin, A. L., and Huxley, A. F. (1952). A quantitative description of membrane current and its application to conduction and excitation in nerve. J. Physiol. 117, 500-544. doi: 10.1113/jphysiol.1952.sp004764

Hofmann-Apitius, M., Alarcon-Riquelme, M. E., Chamberlain, C., and McHale, D. (2015). Towards the taxonomy of human disease. Nat. Rev. Drug Discov. 14, 75-76. doi: 10.1038/nrd4537

Honey, C. J., Kotter, R., Breakspear, M., and Sporns, O. (2007). Network structure of cerebral cortex shapes functional connectivity on multiple time scales. Proc. Natl. Acad. Sci. U.S.A. 104, 10240-10245. doi: 10.1073/pnas.0701519104

Honig, L. S., Vellas, B., Woodward, M., Boada, M., Bullock, R., Borrie, M., et al. (2018). Trial of solanezumab for mild dementia due to Alzheimer's disease. $N$. Engl. J. Med. 378, 321-330. doi: 10.1056/NEJMoa1705971

Hsiao, C. C., Rombouts, F., and Gijsen, H. J. M. (2019). New evolutions in the BACE1 inhibitor field from 2014 to 2018. Bioorg. Med. Chem. Lett. doi: 10.1016/j.bmcl.2018.12.049

Hwang, J., Kim, C. M., Jeon, S., Lee, J. M., Hong, Y. J., Roh, J. H., et al. (2016). Prediction of Alzheimer's disease pathophysiology based on cortical thickness patterns. Alzheimer Dement. 2, 58-67. doi: 10.1016/j.dadm.2015.11.008

Hyman, B. T., Phelps, C. H., Beach, T. G., Bigio, E. H., Cairns, N. J., Carrillo, M. C., et al. (2012). National Institute on Aging-Alzheimer's Association guidelines for the neuropathologic assessment of Alzheimer's disease. Alzheimer Dement. 8, 1-13. doi: 10.1016/j.jalz.2011.10.007

Hyman, B. T., Van Hoesen, G. W., Damasio, A. R., and Barnes, C. L. (1984). Alzheimer's disease: cell-specific pathology isolates the hippocampal formation. Science 225, 1168-1170. doi: 10.1126/science.6474172

Hynd, M. R., Scott, H. L., and Dodd, P. R. (2004). Glutamate-mediated excitotoxicity and neurodegeneration in Alzheimer's disease. Neurochem. Int. 45, 583-595. doi: 10.1016/j.neuint.2004.03.007

Iturria-Medina, Y., Carbonell, F. M., and Evans, A. C. (2018). Multimodal imaging-based therapeutic fingerprints for optimizing personalized interventions: application to neurodegeneration. Neuroimage. 179, 40-50. doi: 10.1016/j.neuroimage.2018.06.028

Iyappan, A., Gundel, M., Shahid, M., Wang, J., Li, H., Mevissen, H. T., et al. (2016). Towards a pathway inventory of the human brain for modeling disease mechanisms underlying neurodegeneration. J. Alzheimer Dis. 52, 1343-1360. doi: 10.3233/JAD-151178

Izhikevich, E. M. (2003). Simple model of spiking neurons. IEEE Trans. Neural Netw. 14, 1569-1572. doi: 10.1109/TNN.2003.820440

Izhikevich, E. M. (2004). Which model to use for cortical spiking neurons? IEEE Trans. Neural Netw. 15, 1063-1070. doi: 10.1109/TNN.2004.832719

Jack, C. R., Wiste, H. J., Weigand, S. D., Rocca, W. A., Knopman, D. S., Mielke, M. M., et al. (2014). Age-specific population frequencies of amyloidosis and neurodegeneration among cognitively normal people age 50-89 years: a cross-sectional study. Lancet Neurol. 13, 997-1005. doi: 10.1016/S1474-4422(14)70194-2

Jack, C. R. Jr., Bennett, D. A., Blennow, K., Carrillo, M. C., Dunn, B., Haeberlein, S. B., et al. (2018). NIA-AA research framework: toward a biological definitionAlzheimer dement of Alzheimer's disease. Alzheimer Dement. 14, 535-562. doi: 10.1016/j.jalz.2018.02.018

Jack, C. R. Jr., and Holtzman, D. M. (2013). Biomarker modeling of Alzheimer's disease. Neuron 80, 1347-1358. doi: 10.1016/j.neuron.2013.12.003

Jack, C. R. Jr., Lowe, V. J., Weigand, S. D., Wiste, H. J., Senjem, M. L., Knopman, D. S., et al. (2009). Serial PIB and MRI in normal, mild cognitive impairment and Alzheimer's disease: implications for sequence of pathological events in Alzheimer's disease. Brain 132(Pt 5), 1355-1365. doi: 10.1093/brain/awp062

Jadhav, S., Avila, J., Scholl, M., Kovacs, G. G., Kovari, E., Skrabana, R., et al. (2019). A walk through tau therapeutic strategies. Acta Neuropathol. Commun. 7:22. doi: 10.1186/s40478-019-0664-z

Jansen, B. H., and Rit, V. G. (1995). Electroencephalogram and visual evoked potential generation in a mathematical model of coupled cortical columns. Biol. Cybern. 73, 357-366. doi: 10.1007/BF00199471

Jansen, I. E., Savage, J. E., Watanabe, K., Bryois, J., Williams, D. M., Steinberg, S., et al. (2019). Genome-wide meta-analysis identifies new loci and functional 
pathways influencing Alzheimer's disease risk. Nat. Genet. 51, 404-413. doi: 10.1038/s41588-018-0311-9

Jansen, W. J., Ossenkoppele, R., Knol, D. L., Tijms, B. M., Scheltens, P., Verhey, F. R., et al. (2015). Prevalence of cerebral amyloid pathology in persons without dementia: a meta-analysis. JAMA 313, 1924-1938. doi: 10.1001/jama.2015.4668

Jarrett, J. T., Berger, E. P., and Lansbury, P. T. (1993). The carboxy terminus of the.beta. amyloid protein is critical for the seeding of amyloid formation: implications for the pathogenesis of Alzheimer's disease. Biochemistry 32, 4693-4697. doi: 10.1021/bi00069a001

Jaturapatporn, D., Isaac, M. G., McCleery, J., and Tabet, N. (2012). Aspirin, steroidal and non-steroidal anti-inflammatory drugs for the treatment of Alzheimer's disease. Cochrane Database Syst. Rev. 2, 128-135. doi: 10.1002/14651858.CD006378.pub2

Jellinger, K. A. (1997). Neuropathological staging of Alzheimer-related lesions: the challenge of establishing relations to age. Neurobiol. Aging 18, 369-375; 89-92. doi: 10.1016/S0197-4580(97)00048-1

Jirsa, V. K., Proix, T., Perdikis, D., Woodman, M. M., Wang, H., GonzalezMartinez, J., et al. (2017). The virtual epileptic patient: individualized whole-brain models of epilepsy spread. Neuroimage 145(Pt B), 377-388. doi: 10.1016/j.neuroimage.2016.04.049

Jirsa, V. K., Sporns, O., Breakspear, M., Deco, G., and McIntosh, A. R. (2010). Towards the virtual brain: network modeling of the intact and the damaged brain. Arch. Ital. Biol. 148, 189-205. doi: 10.4449/aib.v148i3.1223

Karas, G. B., Scheltens, P., Rombouts, S. A. R. B., Visser, P. J., van Schijndel, R. A., Fox, N. C., et al. (2004). Global and local gray matter loss in mild cognitive impairment and Alzheimer's disease. NeuroImage 23, 708-716. doi: 10.1016/j.neuroimage.2004.07.006

Kendler, K. S. (2009). An historical framework for psychiatric nosology. Psychol. Med. 39, 1935-1941. doi: 10.1017/S0033291709005753

Khanna, S., Domingo-Fernández, D., Iyappan, A., Emon, M. A., Hofmann-Apitius, M., and Fröhlich, H. (2018). Using multi-scale genetic, neuroimaging and clinical data for predicting alzheimer's disease and reconstruction of relevant biological mechanisms. Sci. Rep. 8, 1-13. doi: 10.1038/s41598-018-29433-3

Kitamura, S., Shimada, H., Niwa, F., Endo, H., Shinotoh, H., Takahata, K., et al. (2018). Tau-induced focal neurotoxicity and network disruption related to apathy in Alzheimer's disease. J. Neurol. Neurosurg. Psychiatry 89, 1208-1214. doi: 10.1136/jnnp-2018-317970

Klunk, W. E., Price, J. C., Mathis, C. A., Tsopelas, N. D., Lopresti, B. J., Ziolko, S. K., et al. (2007). Amyloid deposition begins in the striatum of presenilin1 mutation carriers from two unrelated pedigrees. J. Neurosci. 27, 6174-6184. doi: 10.1523/JNEUROSCI.0730-07.2007

Koedam, E. L. G. E., Lauffer, V., van der Vlies, A. E., van der Flier, W. M., Scheltens, P., and Pijnenburg, Y. A. L. (2010). Early-versus late-onset Alzheimer's disease: more than age alone. J. Alzheimer's Dis. 19, 1401-1408. doi: 10.3233/JAD-2010-1337

Korte, M. (2019). Neuronal function of Alzheimer's protein. Science 363, 123-124. doi: $10.1126 /$ science.aaw0636

Kovacs, G. G. (2015). Invited review: neuropathology of tauopathies: principles and practice. Neuropathol. Appl. Neurobiol. 41, 3-23. doi: 10.1111/nan.12208

Koval, I., Bône, A., Louis, M., Bottani, S., Marcoux, A., Samper-Gonzalez, J., et al. (2018). AD course map charts Alzheimer's disease progression. HAL-Inria [Preprint].

Kunkle, B. W., Grenier-Boley, B., Sims, R., Bis, J. C., Damotte, V., Naj, A. C., et al. (2019). Genetic meta-analysis of diagnosed Alzheimer's disease identifies new risk loci and implicates $\mathrm{A} \beta$, tau, immunity and lipid processing. Nat. Genet. 51, 414-430. doi: 10.1038/s41588-019-0358-2

Kunze, T., Hunold, A., Haueisen, J., Jirsa, V., and Spiegler, A. (2016). Transcranial direct current stimulation changes resting state functional connectivity: a large-scale brain network modeling study. NeuroImage 140, 174-187. doi: 10.1016/j.neuroimage.2016.02.015

Kyrtsos, C. R., and Baras, J. S. (2013). Studying the role of ApoE in Alzheimer's disease pathogenesis using a systems biology model. J. Bioinform. Comput. Biol. 11:1342003. doi: 10.1142/S0219720013420031

Langbaum, J. B. S., Chen, K., Caselli, R. J., Lee, W., Reschke, C., Bandy, D., et al. (2010). Hypometabolism in Alzheimer-affected brain regions in cognitively healthy latino individuals carrying the apolipoprotein E $\varepsilon 4$ allele. Arch. Neurol. 67, 462-468. doi: 10.1001/archneurol.2010.30
Lannfelt, L., Blennow, K., Zetterberg, H., Batsman, S., Ames, D., Harrison, J., et al. (2008). Safety, efficacy, and biomarker findings of PBT2 in targeting Abeta as a modifying therapy for Alzheimer's disease: a phase IIa, doubleblind, randomised, placebo-controlled trial. Lancet Neurol. 7, 779-786. doi: 10.1016/S1474-4422(08)70167-4

Lanoiselée, H.-M., Nicolas, G., Wallon, D., Rovelet-Lecrux, A., Lacour, M., Rousseau, S., et al. (2017). APP, PSEN1, and PSEN2 mutations in early-onset Alzheimer disease: a genetic screening study of familial and sporadic cases. PLoS Med. 14:e1002270. doi: 10.1371/journal.pmed.1002270

Larson, E. B., Wang, L., Bowen, J. D., McCormick, W. C., Teri, L., Crane, P., et al. (2006). Exercise is associated with reduced risk for incident dementia among persons 65 years of age and older. Ann. Internal Med. 144, 73-81. doi: 10.7326/0003-4819-144-2-200601170-00004

Lee, S., Viqar, F., Zimmerman, M. E., Narkhede, A., Tosto, G., Benzinger, T. L. S., et al. (2016). White matter hyperintensities are a core feature of Alzheimer's disease: evidence from the dominantly inherited Alzheimer network. Ann. Neurol. 79, 929-939. doi: 10.1002/ana.24647

Lefaucheur, J. P., Antal, A., Ayache, S. S., Benninger, D. H., Brunelin, J., Cogiamanian, F., et al. (2017). Evidence-based guidelines on the therapeutic use of transcranial direct current stimulation (tDCS). Clin. Neurophysiol. 128, 56-92. doi: 10.1016/j.clinph.2016.10.087

Leyhe, T., Reynolds, C. F. 3rd, Melcher, T., Linnemann, C., Kloppel, S., Blennow, K., et al. (2017). A common challenge in older adults: classification, overlap, and therapy of depression and dementia. Alzheimer Dement. 13, 59-71. doi: 10.1016/j.jalz.2016.08.007

Li, G., Mayer, C. L., Morelli, D., Millard, S. P., Raskind, W. H., Petrie, E. C., et al. (2017). Effect of simvastatin on CSF Alzheimer disease biomarkers in cognitively normal adults. Neurology 89, 1251-1255. doi: 10.1212/WNL.0000000000004392

Liley, D. T., Cadusch, P. J., and Dafilis, M. P. (2002). A spatially continuous mean field theory of electrocortical activity. Netw. Comput. Neural Syst. 13, 67-113. doi: $10.1080 /$ net.13.1.67.113

Lindsay, J., Laurin, D., Verreault, R., Hebert, R., Helliwell, B., Hill, G. B., et al. (2002). Risk factors for Alzheimer's disease: a prospective analysis from the Canadian Study of Health and Aging. Am. J. Epidemiol. 156, 445-453. doi: 10.1093/aje/kwf074

Liu, Y., Paajanen, T., Zhang, Y., Westman, E., Wahlund, L.-O., Simmons, A., et al. (2010). Analysis of regional MRI volumes and thicknesses as predictors of conversion from mild cognitive impairment to Alzheimer's disease. Neurobiol. Aging 31, 1375-1385. doi: 10.1016/j.neurobiolaging.2010.01.022

Lo, C.-Y., Wang, P.-N., Chou, K.-H., Wang, J., He, Y., and Lin, C.-P. (2010). Diffusion tensor tractography reveals abnormal topological organization in structural cortical networks in Alzheimer's disease. J. Neurosci. 30, 16876-16885. doi: 10.1523/JNEUROSCI.4136-10.2010

Lomakin, A., Teplow, D. B., Kirschner, D. A., and Benedek, G. B. (1997). Kinetic theory of fibrillogenesis of amyloid beta-protein. Proc. Natl. Acad. Sci. U.S.A. 94, 7942-7947. doi: 10.1073/pnas.94.15.7942

Love, S., and Miners, J. S. (2016). Cerebrovascular disease in ageing and Alzheimer's disease. Acta Neuropathol. 131, 645-658. doi: 10.1007/s00401-015-1522-0

Lv, Q., Du, A., Wei, W., Li, Y., Liu, G., and Wang, X. P. (2018). Deep brain stimulation: a potential treatment for dementia in Alzheimer's disease (AD) and Parkinson's disease dementia (PDD). Front. Neurosci. 12:360. doi: 10.3389/fnins.2018.00360

Madan, S., Szostak, J., Komandur Elayavilli, R., Tsai, R. T.-H., Ali, M., Qian, L., et al. (2019). The extraction of complex relationships and their conversion to biological expression language (BEL) overview of the BioCreative VI (2017) BEL track. Database 2019:baz084. doi: 10.1093/database/baz084

Madsen, S. K., Ho, A. J., Hua, X., Saharan, P. S., Toga, A. W., Jack, C. R., et al. (2010). 3D maps localize caudate nucleus atrophy in 400 Alzheimer's disease, mild cognitive impairment, and healthy elderly subjects. Neurobiol. Aging 31, 1312-1325. doi: 10.1016/j.neurobiolaging.2010.05.002

Mahley, R. W. (2016). Apolipoprotein E: from cardiovascular disease to neurodegenerative disorders. J. Mol. Med. 94, 739-746. doi: 10.1007/s00109-016-1427-y

Marathe, S., and Alberi, L. (2015). Notch in memories: points to remember. Hippocampus 25, 1481-1488. doi: 10.1002/hipo.22426 
Marioni, R. E., Harris, S. E., Zhang, Q., McRae, A. F., Hagenaars, S. P., Hill, W. D., et al. (2018). GWAS on family history of Alzheimer's disease. Transl. Psychiatry 8:99. doi: 10.1038/s41398-018-0150-6

Markram, H., Meier, K., Lippert, T., Grillner, S., Frackowiak, R., Dehaene, S., et al. (2011). Introducing the human brain project. Procedia Comput. Sci. 7, 39-42. doi: 10.1016/j.procs.2011.12.015

McIntosh, A. R., and Jirsa, V. K. (2019). The hidden repertoire of brain dynamics and dysfunction. Netw. Neurosci. 3, 994-1008. doi: 10.1162/netn_a_00107

McKhann, G., Drachman, D., Folstein, M., Katzman, R., Price, D., and Stadlan, E. M. (1984). Clinical diagnosis of Alzheimer's disease. Report of the NINCDS-ADRDA Work Group under the auspices of Department of Health and Human Services Task Force on Alzheimer's disease. Neurology 34:939. doi: 10.1212/WNL.34.7.939

McKhann, G. M., Knopman, D. S., Chertkow, H., Hyman, B. T., Jack, C. R. Jr., Kawas, C. H., et al. (2011). The diagnosis of dementia due to Alzheimer's disease: recommendations from the National Institute on Aging-Alzheimer's Association workgroups on diagnostic guidelines for Alzheimer's disease. Alzheimer Dement. 7, 263-269. doi: 10.1016/j.jalz.2011.03.005

Melozzi, F., Woodman, M. M., Jirsa, V. K., and Bernard, C. (2017). The virtual mouse brain: a computational neuroinformatics platform to study whole mouse brain dynamics. eNeuro 4, 1-14. doi: 10.1523/ENEURO.0111-17.2017

Meltzer, C. C., Zubieta, J. K., Brandt, J., Tune, L. E., Mayberg, H. S., and Frost, J. J. (1996). Regional hypometabolism in Alzheimer's disease as measured by positron emission tomography after correction for effects of partial volume averaging. Neurology 47, 454-461. doi: 10.1212/WNL.47.2.454

Mesulam, M. M. (2000). A plasticity-based theory of the pathogenesis of Alzheimer's disease. Ann. N. Y. Acad. Sci. 924, 42-52. doi: 10.1111/j.1749-6632.2000.tb05559.x

Minati, L., Chan, D., Mastropasqua, C., Serra, L., Spanò, B., Marra, C., et al. (2014). Widespread alterations in functional brain network architecture in amnestic mild cognitive impairment. J. Alzheimer Dis. 40, 213-220. doi: 10.3233/JAD-131766

Mo, J. J., Li, J.-y, Yang, Z., Liu, Z., and Feng, J. S. (2017). Efficacy and safety of anti-amyloid- $\beta$ immunotherapy for Alzheimer's disease: a systematic review and network meta-analysis. Ann. Clin. Transl. Neurol. 4, 931-942. doi: $10.1002 / \operatorname{acn} 3.469$

Montine, T. J., Phelps, C. H., Beach, T. G., Bigio, E. H., Cairns, N. J., Dickson, D. W., et al. (2012). National Institute on AgingAlzheimer's Association guidelines for the neuropathologic assessment of Alzheimer's disease: a practical approach. Acta Neuropathol. 123, 1-11. doi: 10.1007/s00401-011-0910-3

Moradi, E., Pepe, A., Gaser, C., Huttunen, H., Tohka, J., and Alzheimer's Disease Neuroimaging Initiative (2015). Machine learning framework for early MRIbased Alzheimer's conversion prediction in MCI subjects. Neuroimage 104, 398-412. doi: 10.1016/j.neuroimage.2014.10.002

Morbelli, S., Piccardo, A., Villavecchia, G., Dessi, B., Brugnolo, A., Piccini, A., et al. (2010). Mapping brain morphological and functional conversion patterns in amnestic MCI: a voxel-based MRI and FDG-PET study. Eur. J. Nucl. Med. Mol. Imaging 37, 36-45. doi: 10.1007/s00259-009-1218-6

Morimoto, B. (2010). Drug Development for Neurodegenerative Diseases-Second Annual marcus evans Conference. Advances in drug development for NDD and expediting discovery through novel compounds and sound clinical trials. IDrugs 13, 440-443.

Morimoto, B. H., Schmechel, D., Hirman, J., Blackwell, A., Keith, J., and Gold, M. (2013). A double-blind, placebo-controlled, ascending-dose, randomized study to evaluate the safety, tolerability and effects on cognition of AL-108 after 12 weeks of intranasal administration in subjects with mild cognitive impairment. Dement Geriatr. Cogn. Disord. 35, 325-336. doi: 10.1159/000348347

Morris, C., and Lecar, H. (1981). Voltage oscillations in the barnacle giant muscle fiber. Biophys. J. 35, 193-213. doi: 10.1016/S0006-3495(81)84782-0

Morris, R. G. (1999). D.O. Hebb: The Organization of Behavior, Wiley: New York; 1949. Brain Res. Bull. 50:437. doi: 10.1016/S0361-9230(99)00182-3

Morse, T. M., Carnevale, N. T., Mutalik, P. G., Migliore, M., and Shepherd, G. M. (2010). Abnormal excitability of oblique dendrites implicated in early Alzheimer's: a computational study. Front. Neural Circuits 4:16. doi: $10.3389 /$ fncir. 2010.00016
Müller, U., Winter, P., and Graeber, M. B. (2013). A presenilin 1 mutation in the first case of Alzheimer's disease. Lancet Neurol. 12, 129-130. doi: 10.1016/S1474-4422(12)70307-1

Murray, M. E., Graff-Radford, N. R., Ross, O. A., Petersen, R. C., Duara, R., and Dickson, D. W. (2011). Neuropathologically defined subtypes of Alzheimer's disease with distinct clinical characteristics: a retrospective study. Lancet Neurol. 10, 785-796. doi: 10.1016/S1474-4422(11)70156-9

Murray, M. E., Lowe, V. J., Graff-Radford, N. R., Liesinger, A. M., Cannon, A., Przybelski, S. A., et al. (2015). Clinicopathologic and (11)C-Pittsburgh compound B implications of Thal amyloid phase across the Alzheimer's disease spectrum. Brain 138, 1370-1381. doi: 10.1093/brain/awv050

Nardone, R., Holler, Y., Tezzon, F., Christova, M., Schwenker, K., Golaszewski, S., et al. (2015). Neurostimulation in Alzheimer's disease: from basic research to clinical applications. Neurol. Sci. 36, 689-700. doi: 10.1007/s10072-015-2120-6

Nardone, R., Tezzon, F., Holler, Y., Golaszewski, S., Trinka, E., and Brigo, F. (2014). Transcranial magnetic stimulation (TMS)/repetitive TMS in mild cognitive impairment and Alzheimer's disease. Acta Neurol. Scand. 129, 351-366. doi: 10.1111/ane.12223

Nelson, P. T., Alafuzoff, I., Bigio, E. H., Bouras, C., Braak, H., Cairns, N. J., et al. (2012). Correlation of Alzheimer disease neuropathologic changes with cognitive status: a review of the literature. J. Neuropathol. Exp. Neurol. 71, 362-381. doi: 10.1097/NEN.0b013e31825018f7

Norton, S., Matthews, F. E., Barnes, D. E., Yaffe, K., and Brayne, C. (2014). Potential for primary prevention of Alzheimer's disease: an analysis of population-based data. Lancet Neurol. 13, 788-794. doi: 10.1016/S1474-4422(14)70136-X

Oertel, W. H. (2017). Recent advances in treating Parkinson's disease. F1000Research 6:260. doi: 10.12688/f1000research.10100.1

Olsson, B., Lautner, R., Andreasson, U., Ohrfelt, A., Portelius, E., Bjerke, M., et al. (2016). CSF and blood biomarkers for the diagnosis of Alzheimer's disease: a systematic review and meta-analysis. Lancet Neurol. 15, 673-684. doi: 10.1016/S1474-4422(16)00070-3

Ortega, F., Stott, J., Visser, S. A. G., and Bendtsen, C. (2013). Interplay between $\alpha-, \beta$-, and $\gamma$-secretases determines biphasic amyloid- $\beta$ protein level in the presence of a $\gamma$-secretase inhibitor. J. Biol. Chem. 288, 785-792. doi: $10.1074 /$ jbc.M112.419135

Ossenkoppele, R., Mattsson, N., Teunissen, C. E., Barkhof, F., Pijnenburg, Y., Scheltens, P., et al. (2015). Cerebrospinal fluid biomarkers and cerebral atrophy in distinct clinical variants of probable Alzheimer's disease. Neurobiol. Aging 36, 2340-2347. doi: 10.1016/j.neurobiolaging.2015.04.011

Ou, Y.-N., Xu, W., Li, J.-Q., Guo, Y., Cui, M., Chen, K.-L., et al. (2019). FDG-PET as an independent biomarker for Alzheimer's biological diagnosis: a longitudinal study. Alzheimer Res. Ther. 11:57. doi: 10.1186/s13195-019-0512-1

Pallitto, M. M., and Murphy, R. M. (2001). A mathematical model of the kinetics of beta-amyloid fibril growth from the denatured state. Biophys. J. 81, 1805-1822. doi: 10.1016/S0006-3495(01)75831-6

Palomero-Gallagher, N., and Zilles, K. (2018). Cyto-and receptor architectonic mapping of the human brain. Handb. Clin. Neurol. 150, 355-387. doi: 10.1016/B978-0-444-63639-3.00024-4

Panza, F., Lozupone, M., Dibello, V., Greco, A., Daniele, A., Seripa, D., et al. (2019). Are antibodies directed against amyloid-beta (Abeta) oligomers the last call for the Abeta hypothesis of Alzheimer's disease? Immunotherapy 11, 3-6. doi: 10.2217/imt-2018-0119

Pasquier, F., Boulogne, A., Leys, D., and Fontaine, P. (2006). Diabetes mellitus and dementia. Diabetes Metab. 32(5 Pt 1), 403-414. doi: 10.1016/S1262-3636(07)70298-7

Pedersen, N. L., Gatz, M., Berg, S., and Johansson, B. (2004). How heritable is Alzheimer's disease late in life? Findings from Swedish twins. Ann. Neurol. 55, 180-185. doi: 10.1002/ana.10999

Pellegrini, E., Ballerini, L., Hernandez, M., Chappell, F. M., Gonzalez-Castro, V., Anblagan, D., et al. (2018). Machine learning of neuroimaging for assisted diagnosis of cognitive impairment and dementia: a systematic review. Alzheimer Dement 10, 519-535. doi: 10.1016/j.dadm.2018.07.004

Pereira, J. B., Mijalkov, M., Kakaei, E., Mecocci, P., Vellas, B., Tsolaki, M., et al. (2016). Disrupted network topology in patients with stable and progressive mild cognitive impairment and Alzheimer's disease. Cereb. Cortex 26, 3476-3493. doi: 10.1093/cercor/bhw128 
Perez, C., Ziburkus, J., and Ullah, G. (2016). Analyzing and modeling the dysfunction of inhibitory neurons in Alzheimer's disease. PLOS ONE 11:e0168800. doi: 10.1371/journal.pone. 0168800

Perry, A., Wen, W., Lord, A., Thalamuthu, A., Roberts, G., Mitchell, P. B., et al. (2015). The organisation of the elderly connectome. Neuroimage 114, 414-426. doi: 10.1016/j.neuroimage.2015.04.009

Persson, K., Eldholm, R. S., Barca, M. L., Cavallin, L., Ferreira, D., Knapskog, A.-B., et al. (2017). MRI-assessed atrophy subtypes in Alzheimer's disease and the cognitive reserve hypothesis. PLoS ONE 12:e0186595. doi: 10.1371/journal.pone. 0186595

Petersen, R. C., Caracciolo, B., Brayne, C., Gauthier, S., Jelic, V., and Fratiglioni, L. (2014). Mild cognitive impairment: a concept in evolution. J. Internal Med. 275, 214-228. doi: 10.1111/joim.12190

Phelps, M. E. (2000). Positron emission tomography provides molecular imaging of biological processes. Proc. Natl. Acad. Sci. U.S.A. 97, 9226-9233. doi: $10.1073 /$ pnas. 97.16 .9226

Phillips, D. J., McGlaughlin, A., Ruth, D., Jager, L. R., Soldan, A., and Alzheimer's Disease Neuroimaging Initiative (2015). Graph theoretic analysis of structural connectivity across the spectrum of Alzheimer's disease: the importance of graph creation methods. NeuroImage Clin. 7, 377-390. doi: 10.1016/j.nicl.2015.01.007

Pierfelice, T., Alberi, L., and Gaiano, N. (2011). Notch in the vertebrate nervous system: an old dog with new tricks. Neuron 69, 840-855. doi: $10.1016 /$ j.neuron.2011.02.031

Poil, S.-S., De Haan, W., van der Flier, W. M., Mansvelder, H. D., Scheltens, P., and Linkenkaer-Hansen, K. (2013). Integrative EEG biomarkers predict progression to Alzheimer's disease at the MCI stage. Front. Aging Neurosci. 5:58. doi: $10.3389 /$ fnagi.2013.00058

Pons, A. J., Cantero, J. L., Atienza, M., and Garcia-Ojalvo, J. (2010). Relating structural and functional anomalous connectivity in the aging brain via neural mass modeling. Neuroimage 52, 848-861. doi: 10.1016/j.neuroimage.2009.12.105

Pontecorvo, M. J., Devous, M. D., Kennedy, I., Navitsky, M., Lu, M., Galante, N., et al. (2019). A multicentre longitudinal study of flortaucipir (18F) in normal ageing, mild cognitive impairment and Alzheimer's disease dementia. Brain 142, 1723-1735. doi: 10.1093/brain/awz090

Proctor, C. J., Boche, D., Gray, D. A., and Nicoll, J. A. R. (2013). Investigating interventions in Alzheimer's disease with computer simulation models. PLoS ONE 8:e73631. doi: 10.1371/journal.pone.0073631

Proctor, C. J., and Gray, D. A. (2010). GSK3 and p53 - is there a link in Alzheimer's disease? Mol. Neurodegener. 5:7. doi: 10.1186/1750-1326-5-7

Proix, T., Bartolomei, F., Guye, M., and Jirsa, V. K. (2017). Individual brain structure and modelling predict seizure propagation. Brain 140, 641-654. doi: 10.1093/brain/awx004

Pruss, H., and Lennox, B. R. (2016). Emerging psychiatric syndromes associated with antivoltage-gated potassium channel complex antibodies. J. Neurol. Neurosurg. Psychiatry 87, 1242-1247. doi: 10.1136/jnnp-2015-313000

Quinn, J. F., Raman, R., Thomas, R. G., Yurko-Mauro, K., Nelson, E. B., Van Dyck, C., et al. (2010). Docosahexaenoic acid supplementation and cognitive decline in Alzheimer disease: a randomized trial. JAMA 304, 1903-1911. doi: 10.1001/jama.2010.1510

Quiroz, Y. T., Budson, A. E., Celone, K., Ruiz, A., Newmark, R., Castrillón, G., et al. (2010). Hippocampal hyperactivation in presymptomatic familial Alzheimer's disease. Ann. Neurol. 68, 865-875. doi: 10.1002/ana.22105

Rabin, L. A., Smart, C. M., Crane, P. K., Amariglio, R. E., Berman, L. M., Boada, M., et al. (2015). Subjective cognitive decline in older adults: an overview of self-report measures used across 19 international research studies. J. Alzheimer Dis. 48(Suppl. 1):S63-S86. doi: 10.3233/JAD-150154

Read, S., Wu, P., and Biscow, M. (2014). Sustained 4-year cognitive and functional response in early Alzheimer's disease with pioglitazone. J. Am. Geriatr. Soc. 62, 584-586. doi: 10.1111/jgs.12722

Reijmer, Y. D., Leemans, A., Caeyenberghs, K., Heringa, S. M., Koek, H. L., and Biessels, G. J. (2013). Disruption of cerebral networks and cognitive impairment in Alzheimer disease. Neurology 80, 1370-1377. doi: 10.1212/WNL.0b013e31828c2ee5

Reitz, C., Brayne, C., and Mayeux, R. (2011). Epidemiology of Alzheimer disease. Nat. Rev. Neurol. 7, 137-152. doi: 10.1038/nrneurol.2011.2
Ridge, P. G., Hoyt, K. B., Boehme, K., Mukherjee, S., Crane, P. K., Haines, J. L., et al. (2016). Assessment of the genetic variance of late-onset Alzheimer's disease. Neurobiol. Aging 41, 200.e13-e20. doi: 10.1016/j.neurobiolaging.2016.02.024

Riley, K. P., Snowdon, D. A., and Markesbery, W. R. (2002). Alzheimer's neurofibrillary pathology and the spectrum of cognitive function: findings from the Nun Study. Ann. Neurol. 51, 567-577. doi: 10.1002/ana.10161

Ritter, P., Schirner, M., McIntosh, A. R., and Jirsa, V. K. (2013). The virtual brain integrates computational modeling and multimodal neuroimaging. Brain Connect 3, 121-145. doi: 10.1089/brain.2012.0120

Robinson, J. L., Corrada, M. M., Kovacs, G. G., Dominique, M., Caswell, C., Xie, S. X., et al. (2018a). Non-Alzheimer's contributions to dementia and cognitive resilience in the $90+$ study. Acta Neuropathol. 136, 377-388. doi: 10.1007/s00401-018-1872-5

Robinson, J. L., Lee, E. B., Xie, S. X., Rennert, L., Suh, E., Bredenberg, C., et al. (2018b). Neurodegenerative disease concomitant proteinopathies are prevalent, age-related and APOE4-associated. Brain 141, 2181-2193. doi: 10.1093/brain/awy146

Rohn, T. T. (2014). Is apolipoprotein E4 an important risk factor for vascular dementia? Int. J. Clin. Exp. Pathol. 7, 3504-3511.

Romani, A., Marchetti, C., Bianchi, D., Leinekugel, X., Poirazi, P., Migliore, M., et al. (2013). Computational modeling of the effects of amyloid-beta on release probability at hippocampal synapses. Front. Comput. Neurosci. 7:1. doi: 10.3389 /fncom.2013.00001

Rombouts, S. A. R. B., Barkhof, F., Witter, M. P., and Scheltens, P. (2000). Unbiased whole-brain analysis of gray matter loss in Alzheimer's disease. Neurosci. Lett. 285, 231-233. doi: 10.1016/S0304-3940(00)01067-3

Rose, R., and Hindmarsh, J. (1989). The assembly of ionic currents in a thalamic neuron I. The three-dimensional model. Proc. R. Soc. London B Biol. Sci. 237, 267-288. doi: 10.1098/rspb.1989.0049

Rosenbloom, M. H., Alkalay, A., Agarwal, N., Baker, S. L., O'Neil, J. P., Janabi, M., et al. (2011). Distinct clinical and metabolic deficits in PCA and $\mathrm{AD}$ are not related to amyloid distribution. Neurology 76, 1789-1796. doi: 10.1212/WNL.0b013e31821cccad

Rowan, M. S., Neymotin, S. A., and Lytton, W. W. (2014). Electrostimulation to reduce synaptic scaling driven progression of Alzheimer's disease. Front. Comput. Neurosci. 8:39. doi: 10.3389/fncom.2014.00039

Roy, D., Sigala, R., Breakspear, M., McIntosh, A. R., Jirsa, V. K., Deco, G., et al. (2014). Using the virtual brain to reveal the role of oscillations and plasticity in shaping brain's dynamical landscape. Brain Connect. 4, 791-811. doi: 10.1089/brain.2014.0252

Saito, T., Matsuba, Y., Mihira, N., Takano, J., Nilsson, P., Itohara, S., et al. (2014). Single App knock-in mouse models of Alzheimer's disease. Nat. Neurosci. 17, 661-663. doi: 10.1038/nn.3697

Salma, A., Vasilakis, M., and Tracy, P. T. (2014). Deep brain stimulation for cognitive disorders: insights into targeting nucleus basalis of meynert in Alzheimer dementia. World Neurosurg. 81, e4-5. doi: 10.1016/j.wneu.2013.08.011

Sannerud, R., Esselens, C., Ejsmont, P., Mattera, R., Rochin, L., Tharkeshwar, A. K., et al. (2016). Restricted location of PSEN $2 / \gamma$-secretase determines substrate specificity and generates an intracellular A $\beta$ pool. Cell 166, 193-208. doi: $10.1016 /$ j.cell.2016.05.020

Sano, M., Bell, K. L., Galasko, D., Galvin, J. E., Thomas, R. G., van Dyck, C. H., et al. (2011). A randomized, double-blind, placebo-controlled trial of simvastatin to treat Alzheimer disease. Neurology 77, 556-563. doi: 10.1212/WNL.0b013e318228bf11

Santos, C. Y., Snyder, P. J., Wu, W.-C., Zhang, M., Echeverria, A., and Alber, J. (2017). Pathophysiologic relationship between Alzheimer's disease, cerebrovascular disease, and cardiovascular risk: a review and synthesis. Alzheimer Dement. 7, 69-87. doi: 10.1016/j.dadm.2017.01.005

Sanz Leon, P., Knock, S. A., Woodman, M. M., Domide, L., Mersmann, J., McIntosh, A. R., et al. (2013). The virtual brain: a simulator of primate brain network dynamics. Front. Neuroinform. 7:10. doi: 10.3389/fninf.2013. 00010

Sanz-Arigita, E. J., Schoonheim, M. M., Damoiseaux, J. S., Rombouts, S. A., Maris, E., Barkhof, F., et al. (2010). Loss of 'small-world' networks in Alzheimer's disease: graph analysis of FMRI resting-state functional connectivity. PLoS ONE 5:e13788. doi: 10.1371/journal.pone.0013788 
Sanz-Leon, P., Knock, S. A., Spiegler, A., and Jirsa, V. K. (2015). Mathematical framework for large-scale brain network modeling in the virtual brain. NeuroImage 111, 385-430. doi: 10.1016/j.neuroimage.2015.01.002

Schirner, M., McIntosh, A. R., Jirsa, V., Deco, G., and Ritter, P. (2018). Inferring multi-scale neural mechanisms with brain network modelling. Elife 7:e28927. doi: 10.7554/eLife.28927

Schneider, L. S., Mangialasche, F., Andreasen, N., Feldman, H., Giacobini, E., Jones, R., et al. (2014). Clinical trials and late-stage drug development for Alzheimer's disease: an appraisal from 1984 to 2014. J. Internal Med. 275, 251-283. doi: 10.1111/joim.12191

Schöll, M., Lockhart Samuel, N., Schonhaut Daniel, R., O’Neil James, P., Janabi, M., Ossenkoppele, R., et al. (2016). PET imaging of tau deposition in the aging human brain. Neuron 89, 971-982. doi: 10.1016/j.neuron.2016.01.028

Schorer, C. E. (1985). Historical essay: Kraepelin's description of Alzheimer's disease. Int. J. Aging Human Dev. 21, 235-238. doi: 10.2190/GNQ1-GDUX-EPTL-0F2L

Selkoe, D. J. (2004). Alzheimer disease: mechanistic understanding predicts novel therapies. Ann. Internal Med. 140, 627-638. doi: 10.7326/0003-4819-140-8-200404200-00047

Selkoe, D. J., and Hardy, J. (2016). The amyloid hypothesis of Alzheimer's disease at 25 years. EMBO Mol. Med. 8, 595-608. doi: 10.15252/emmm.201606210

Sevigny, J., Chiao, P., Bussiere, T., Weinreb, P. H., Williams, L., Maier, M., et al. (2016). The antibody aducanumab reduces Abeta plaques in Alzheimer's disease. Nature 537, 50-56. doi: 10.1038/nature19323

Sevush, S., Peruyera, G., Bertran, A., and Cisneros, W. (2003). A three-factor model of cognition in Alzheimer disease. Cogn. Behav. Neurol. 16, 110-117. doi: 10.1097/00146965-200306000-00004

Shepardson, N. E., Shankar, G. M., and Selkoe, D. J. (2011a). Cholesterol level and statin use in Alzheimer disease: I. Review of epidemiological and preclinical studies. Arch. Neurol. 68, 1239-1244. doi: 10.1001/archneurol.2011.203

Shepardson, N. E., Shankar, G. M., and Selkoe, D. J. (2011b). Cholesterol level and statin use in Alzheimer disease: II. Review of human trials and recommendations. Arch. Neurol. 68, 1385-1392. doi: 10.1001/archneurol.2011.242

Shi, F., Liu, B., Zhou, Y., Yu, C., and Jiang, T. (2009). Hippocampal volume and asymmetry in mild cognitive impairment and Alzheimer's disease: metaanalyses of MRI studies. Hippocampus 19, 1055-1064. doi: 10.1002/hipo.20573

Shiino, A., Watanabe, T., Maeda, K., Kotani, E., Akiguchi, I., and Matsuda, M. (2006). Four subgroups of Alzheimer's disease based on patterns of atrophy using VBM and a unique pattern for early onset disease. NeuroImage 33, 17-26. doi: 10.1016/j.neuroimage.2006.06.010

Siegerink, B., and Rohmann, J. L. (2018). Impact of your results: beyond the relative risk. Res. Pract. Thromb. Haemost. 2, 653-657. doi: 10.1002/rth2.12148

Siemers, E. R., Sundell, K. L., Carlson, C., Case, M., Sethuraman, G., LiuSeifert, H., et al. (2016). Phase 3 solanezumab trials: secondary outcomes in mild Alzheimer's disease patients. Alzheimer Dement. 12, 110-120. doi: 10.1016/j.jalz.2015.06.1893

Sintini, I., Martin, P. R., Graff-Radford, J., Senjem, M. L., Schwarz, C. G., Machulda, M. M., et al. (2019). Longitudinal tau-PET uptake and atrophy in atypical Alzheimer's disease. NeuroImage Clin. 23:101823. doi: 10.1016/j.nicl.2019.101823

Smailagic, N., Vacante, M., Hyde, C., Martin, S., Ukoumunne, O., and Sachpekidis, C. (2015). 18F-FDG PET for the early diagnosis of Alzheimer's disease dementia and other dementias in people with mild cognitive impairment (MCI). Cochrane Database Syst. Rev. 1:Cd010632. doi: 10.1002/14651858.CD010632.pub2

Smith, G. D., Cox, C. L., Sherman, S. M., and Rinzel, J. (2000). Fourier analysis of sinusoidally driven thalamocortical relay neurons and a minimal integrate-andfire-or-burst model. J. Neurophysiol. 83, 588-610. doi: 10.1152/jn.2000.83.1.588

Solodkin, A., Chen, E. E., Van Hoesen, G. W., Heimer, L., Shereen, A., Kruggel, F., et al. (2013). In vivo parahippocampal white matter pathology as a biomarker of disease progression to Alzheimer's disease. J. Compar. Neurol. 521, 4300-4317. doi: $10.1002 / \mathrm{cne} .23418$

Solodkin, A., Zimmermann, J., McIntosh, A. R., Stefanovski, L., and Ritter, P. (2018). "Neurological biomarkers and neuroinformatics: the role of the virtual brain," in Molecular-Genetic and Statistical Techniques for Behavioral and Neural Research, ed R. T. Gerlai (San Diego, CA: Academic Press), 3-30. doi: 10.1016/B978-0-12-804078-2.00001-5
Song, Z., Insel, P. S., Buckley, S., Yohannes, S., Mezher, A., Simonson, A., et al. (2015). Brain amyloid-beta burden is associated with disruption of intrinsic functional connectivity within the medial temporal lobe in cognitively normal elderly. J. Neurosci. 35, 3240-3247. doi: 10.1523/JNEUROSCI.2092-14.2015

Sotero, R. C., and Trujillo-Barreto, N. J. (2008). Biophysical model for integrating neuronal activity, EEG, fMRI and metabolism. NeuroImage 39, 290-309. doi: 10.1016/j.neuroimage.2007.08.001

Speed, D., Cai, N., Consortium, U., Johnson, M. R., Nejentsev, S., and Balding, D. J. (2017). Reevaluation of SNP heritability in complex human traits. Nat. Genet. 49, 986-992. doi: 10.1038/ng.3865

Spiegler, A., and Jirsa, V. (2013). Systematic approximations of neural fields through networks of neural masses in the virtual brain. NeuroImage 83, 704-725. doi: 10.1016/j.neuroimage.2013.06.018

Spiegler, A., Knösche, T. R., Schwab, K., Haueisen, J., and Atay, F. M. (2011). Modeling brain resonance phenomena using a neural mass model. PLoS Comput. Biol. 7:e1002298. doi: 10.1371/journal.pcbi.1002298

Spires-Jones, T. L., Attems, J., and Thal, D. R. (2017). Interactions of pathological proteins in neurodegenerative diseases. Acta Neuropathol. 134, 187-205. doi: 10.1007/s00401-017-1709-7

Stam, C. J. (2014). Modern network science of neurological disorders. Nat. Rev. Neurosci. 15, 683-695. doi: 10.1038/nrn3801

Stam, C. J., de Haan, W., Daffertshofer, A., Jones, B. F., Manshanden, I., van Cappellen van Walsum, A. M., et al. (2009). Graph theoretical analysis of magnetoencephalographic functional connectivity in Alzheimer's disease. Brain 132(Pt 1), 213-224. doi: 10.1093/brain/awn262

Stam, C. J., Jones, B. F., Nolte, G., Breakspear, M., and Scheltens, P. (2007). Smallworld networks and functional connectivity in Alzheimer's disease. Cereb. Cortex 17, 92-99. doi: 10.1093/cercor/bhj127

Stefanescu, R. A., and Jirsa, V. K. (2008). A low dimensional description of globally coupled heterogeneous neural networks of excitatory and inhibitory neurons. PLoS Comput. Biol. 4:e1000219. doi: 10.1371/journal.pcbi.1000219

Stefanovski, L., Ghani, A., McIntosh, A. R., and Ritter, P. (2016). Linking connectomics and dynamics in the human brain. Neuroforum 22, 64-70. doi: 10.1007/s13295-016-0027-1

Stefanovski, L., Triebkorn, P., Spiegler, A., Diaz-Cortes, M.-A., Solodkin, A., Jirsa, V., et al. (2019). Linking molecular pathways and large-scale computational modeling to assess candidate disease mechanisms and pharmacodynamics in Alzheimer's disease. Front. Comput. Neurosci. 13:54. doi: 10.3389/fncom.2019.00054

Stern, Y. (2012). Cognitive reserve in ageing and Alzheimer's disease. Lancet Neurol. 11, 1006-1012. doi: 10.1016/S1474-4422(12)70191-6

Sun, L., Zhou, R., Yang, G., and Shi, Y. (2017). Analysis of 138 pathogenic mutations in presenilin-1 on the in vitro production of $A \beta 42$ and $A \beta 40$ peptides by $\gamma$-secretase. Proc. Natl. Acad. Sci. U.S.A. 114, E476-E485. doi: 10.1073/pnas.1618657114

Supekar, K., Menon, V., Rubin, D., Musen, M., and Greicius, M. D. (2008). Network analysis of intrinsic functional brain connectivity in Alzheimer's disease. PLoS Comput. Biol. 4:e1000100. doi: 10.1371/journal.pcbi. 1000100

Suri, S., Heise, V., Trachtenberg, A. J., and Mackay, C. E. (2013). The forgotten APOE allele: a review of the evidence and suggested mechanisms for the protective effect of APOE varepsilon2. Neurosci. Biobehav. Rev. 37(10 Pt 2), 2878-2886. doi: 10.1016/j.neubiorev.2013.10.010

Sweeney, M. D., Sagare, A. P., and Zlokovic, B. V. (2018). Blood-brain barrier breakdown in Alzheimer disease and other neurodegenerative disorders. Nat. Rev. Neurol. 14, 133-150. doi: 10.1038/nrneurol.2017.188

Taylor, K. I., and Probst, A. (2008). Anatomic localization of the transentorhinal region of the perirhinal cortex. Neurobiol. Aging 29, 1591-1596. doi: 10.1016/j.neurobiolaging.2007.03.024

Teipel, S. J., Pruessner, J. C., Faltraco, F., Born, C., Rocha-Unold, M., Evans, A., et al. (2006). Comprehensive dissection of the medial temporal lobe in $\mathrm{AD}$ : measurement of hippocampus, amygdala, entorhinal, perirhinal and parahippocampal cortices using MRI. J. Neurol. 253, 794-800. doi: 10.1007/s00415-006-0120-4

Tijms, B. M., Wink, A. M., de Haan, W., van der Flier, W. M., Stam, C. J., Scheltens, P., et al. (2013). Alzheimer's disease: connecting findings from graph theoretical studies of brain networks. Neurobiol. Aging 34, 2023-2036. doi: 10.1016/j.neurobiolaging.2013.02.020 
Tomski, S. J., and Murphy, R. M. (1992). Kinetics of aggregation of synthetic $\beta$-amyloid peptide. Arch. Biochem. Biophys. 294, 630-638. doi: 10.1016/0003-9861(92)90735-F

Tong, G., Wang, J. S., Sverdlov, O., Huang, S. P., Slemmon, R., Croop, R., et al. (2012). Multicenter, randomized, double-blind, placebocontrolled, single-ascending dose study of the oral gamma-secretase inhibitor BMS-708163 (Avagacestat): tolerability profile, pharmacokinetic parameters, and pharmacodynamic markers. Clin. Ther. 34, 654-667. doi: 10.1016/j.clinthera.2012.01.022

Tuszynski, M. H., Yang, J. H., Barba, D., U. H. S., Bakay, R. A., Pay, M. M., et al. (2015). Nerve growth factor gene therapy: activation of neuronal responses in Alzheimer disease. JAMA Neurol. 72, 1139-1147. doi: 10.1001/jamaneurol.2015.1807

van den Heuvel, M. P., de Lange, S. C., Zalesky, A., Seguin, C., Yeo, B. T. T., and Schmidt, R. (2017). Proportional thresholding in resting-state fMRI functional connectivity networks and consequences for patient-control connectome studies: issues and recommendations. Neuroimage 152, 437-449. doi: 10.1016/j.neuroimage.2017.02.005

van der Flier, W. M., van Straaten, E. C. W., Barkhof, F., Ferro, J. M., Pantoni, L., Basile, A. M., et al. (2005). Medial temporal lobe atrophy and white matter hyperintensities are associated with mild cognitive deficits in non-disabled elderly people: the LADIS study. J. Neurol. Neurosurg. Psychiatry 76, 1497-1500. doi: 10.1136/jnnp.2005.064998

Van der Zee, E. A., Platt, B., and Riedel, G. (2011). Acetylcholine: future research and perspectives. Behav. Brain Res. 221, 583-586. doi: 10.1016/j.bbr.2011.01.050

Van Hoesen, G. W., and Solodkin, A. (1994). Cellular and systems neuroanatomical changes in Alzheimer's disease. Ann. N. Y. Acad. Sci. 747, 12-35. doi: 10.1111/j.1749-6632.1994.tb44399.x

van Wijk, B. C. M., Stam, C. J., and Daffertshofer, A. (2010). Comparing brain networks of different size and connectivity density using graph theory. PLoS ONE 5:e13701. doi: 10.1371/journal.pone.0013701

Vandenberghe, R., Riviere, M. E., Caputo, A., Sovago, J., Maguire, R. P., Farlow, M., et al. (2017). Active Abeta immunotherapy CAD106 in Alzheimer's disease: a phase 2b study. Alzheimer Dement. 3, 10-22. doi: 10.1016/j.trci.2016.12.003

Velayudhan, L., Proitsi, P., Westman, E., Muehlboeck, J. S., Mecocci, P., Vellas, B., et al. (2013). Entorhinal cortex thickness predicts cognitive decline in Alzheimer's disease. J. Alzheimer Dis. 33, 755-766. doi: 10.3233/JAD-2012-121408

Vellas, B., Sol, O., Snyder, P. J., Ousset, P. J., Haddad, R., Maurin, M., et al. (2011). EHT0202 in Alzheimer's disease: a 3-month, randomized, placebo-controlled, double-blind study. Curr. Alzheimer Res. 8, 203-212. doi: 10.2174/156720511795256053

Villemagne, V. L., Ataka, S., Mizuno, T., Brooks, W. S., Wada, Y., Kondo, M., et al. (2009). High striatal amyloid beta-peptide deposition across different autosomal Alzheimer disease mutation types. Arch. Neurol. 66, 1537-1544. doi: 10.1001/archneurol.2009.285

Visscher, P. M., Wray, N. R., Zhang, Q., Sklar, P., McCarthy, M. I., Brown, M. A., et al. (2017). 10 years of GWAS discovery: biology, function, and translation. Am. J. Hum. Genet. 101, 5-22. doi: 10.1016/j.ajhg.2017.06.005

Wahlberg, L. U., Lind, G., Almqvist, P. M., Kusk, P., Tornoe, J., Juliusson, B., et al. (2012). Targeted delivery of nerve growth factor via encapsulated cell biodelivery in Alzheimer disease: a technology platform for restorative neurosurgery. J. Neurosurg. 117, 340-347. doi: 10.3171/2012.2.JNS11714

Wainaina, M. N., Chen, Z., and Zhong, C. (2014). Environmental factors in the development and progression of late-onset Alzheimer's disease. Neurosci. Bull. 30, 253-270. doi: 10.1007/s12264-013-1425-9

Wallesch, C. W., and Förstl, H. (2012). "Klinische diagnostic," in Demenzen, 2nd Edn. (Stuttgart, NY: Georg Thieme Verlag), 128-135. doi: 10.1055/b-002-21524

Walsh, D. M., and Selkoe, D. J. (2007). A $\beta$ oligomers - a decade of discovery. J. Neurochem 101, 1172-1184. doi: 10.1111/j.1471-4159.2006.04426.x

Wang, J., Tan, L., Wang, H. F., Tan, C. C., Meng, X. F., Wang, C., et al. (2015). Anti-inflammatory drugs and risk of Alzheimer's disease: an updated systematic review and meta-analysis. J. Alzheimer Dis. 44, 385-396. doi: 10.3233/JAD-141506

Wang, Z., Zhang, M., Han, Y., Song, H., Guo, R., and Li, K. (2016). Differentially disrupted functional connectivity of the subregions of the amygdala in Alzheimer's disease. J. X-ray Sci. Technol. 24, 329-342. doi: 10.3233/XST-160556

Weintraub, M. K., Kranjac, D., Eimerbrink, M. J., Pearson, S. J., Vinson, B. T., Patel, J., et al. (2014). Peripheral administration of poly I:C leads to increased hippocampal amyloid-beta and cognitive deficits in a non-transgenic mouse. Behav. Brain Res. 266, 183-187. doi: 10.1016/j.bbr.2014.03.009

Whitwell, J. L., Dickson, D. W., Murray, M. E., Weigand, S. D., Tosakulwong, N., Senjem, M. L., et al. (2012). Neuroimaging correlates of pathologically defined subtypes of Alzheimer's disease: a case-control study. Lancet Neurol. 11, 868-877. doi: 10.1016/S1474-4422(12)70200-4

Whitwell, J. L., Josephs, K. A., Murray, M. E., Kantarci, K., Przybelski, S. A., Weigand, S. D., et al. (2008). MRI correlates of neurofibrillary tangle pathology at autopsy. A voxel-based morphometry study. Neurology 71, 743-749. doi: 10.1212/01.wnl.0000324924.91351.7d

Whitwell, J. L., Sampson, E. L., Watt, H. C., Harvey, R. J., Rossor, M. N., and Fox, N. C. (2005). A volumetric magnetic resonance imaging study of the amygdala in frontotemporal lobar degeneration and Alzheimer's disease. Dement. Geriatric Cogn. Disord. 20, 238-244. doi: 10.1159/000087343

Wilson, H. R. (1999). Simplified dynamics of human and mammalian neocortical neurons. J. Theor. Biol. 200, 375-388. doi: 10.1006/jtbi.1999.1002

Wilson, H. R., and Cowan, J. D. (1972). Excitatory and inhibitory interactions in localized populations of model neurons. Biophys. J. 12, 1-24. doi: 10.1016/S0006-3495(72)86068-5

Winblad, B., Andreasen, N., Minthon, L., Floesser, A., Imbert, G., Dumortier, T., et al. (2012). Safety, tolerability, and antibody response of active Abeta immunotherapy with CAD106 in patients with Alzheimer's disease: randomised, double-blind, placebo-controlled, first-in-human study. Lancet Neurol. 11, 597-604. doi: 10.1016/S1474-4422(12)70140-0

Wong, K.-F., and Wang, X.-J. (2006). A recurrent network mechanism of time integration in perceptual decisions. J. Neurosci. 26, 1314-1328. doi: 10.1523/JNEUROSCI.3733-05.2006

Wright, J. J., and Liley, D. T. J. (2010). Dynamics of the brain at global and microscopic scales: neural networks and the EEG. Behav. Brain Sci. 19, 285-295. doi: 10.1017/S0140525X00042679

Xia, M., Wang, Z., Dai, Z., Liang, X., Song, H., Shu, N., et al. (2014). Differentially disrupted functional connectivity in posteromedial cortical subregions in Alzheimer's disease. J. Alzheimer Dis. 39, 527-543. doi: 10.3233/JAD-131583

Xia, W. (2019). $\gamma$-Secretase and its modulators: twenty years and beyond. Neurosci. Lett. 701, 162-169. doi: 10.1016/j.neulet.2019.02.011

Yan, T., Wang, W., Yang, L., Chen, K., Chen, R., and Han, Y. (2018). Rich club disturbances of the human connectome from subjective cognitive decline to Alzheimer's disease. Theranostics 8:3237. doi: 10.7150/thno.23772

Yanamandra, K., Jiang, H., Mahan, T. E., Maloney, S. E., Wozniak, D. F., Diamond, M. I., et al. (2015). Anti-tau antibody reduces insoluble tau and decreases brain atrophy. Ann. Clin. Transl. Neurol. 2, 278-288. doi: 10.1002/ acn 3.176

Yao, H., Liu, Y., Zhou, B., Zhang, Z., An, N., Wang, P., et al. (2013). Decreased functional connectivity of the amygdala in Alzheimer's disease revealed by resting-state fMRI. Eur. J. Radiol. 82, 1531-1538. doi: 10.1016/j.ejrad.2013.03.019

Yao, Z., Zhang, Y., Lin, L., Zhou, Y., Xu, C., Jiang, T., et al. (2010). Abnormal cortical networks in mild cognitive impairment and Alzheimer's disease. PLoS Comput. Biol. 6:e1001006. doi: 10.1371/journal.pcbi.1001006

Ye, C., Mori, S., Chan, P., and Ma, T. (2019). Connectome-wide network analysis of white matter connectivity in Alzheimer's disease. NeuroImage Clin. 22:101690. doi: 10.1016/j.nicl.2019.101690

Yetman, M. J., Lillehaug, S., Bjaalie, J. G., Leergaard, T. B., and Jankowsky, J. L. (2016). Transgene expression in the Nop-tTA driver line is not inherently restricted to the entorhinal cortex. Brain Struct. Funct. 221, 2231-2249. doi: 10.1007/s00429-015-1040-9

Yi, H.-A., Möller, C., Dieleman, N., Bouwman, F. H., Barkhof, F., Scheltens, P., et al. (2016). Relation between subcortical grey matter atrophy and conversion from mild cognitive impairment to Alzheimer's disease. J. Neurol. Neurosurg. Psychiatry 87, 425-432. doi: 10.1136/jnnp-2014-309105

Younesi, E., and Hofmann-Apitius, M. (2013). From integrative disease modeling to predictive, preventive, personalized and participatory (P4) medicine. EPMA J. 4:23. doi: 10.1186/1878-5085-4-23 
Young, J. J., Lavakumar, M., Tampi, D., Balachandran, S., and Tampi, R. R. (2018). Frontotemporal dementia: latest evidence and clinical implications. Ther. Adv. Psychopharmacol. 8, 33-48. doi: 10.1177/2045125317739818

Zetterberg, L. H., Kristiansson, L., and Mossberg, K. (1978). Performance of a model for a local neuron population. Biol.. Cyber. 31, 15-26. doi: $10.1007 /$ BF00337367

Zhao, T., Sheng, C., Bi, Q., Niu, W., Shu, N., and Han, Y. (2017). Age-related differences in the topological efficiency of the brain structural connectome in amnestic mild cognitive impairment. Neurobiol. Aging 59, 144-155. doi: 10.1016/j.neurobiolaging.2017.08.005

Zhao, X., Liu, Y., Wang, X., Liu, B., Xi, Q., Guo, Q., et al. (2012). Disrupted smallworld brain networks in moderate Alzheimer's disease: a resting-state fMRI study. PLoS ONE 7:e33540. doi: 10.1371/journal.pone.0033540

Zimmermann, J., Perry, A., Breakspear, M., Schirner, M., Sachdev, P., Wen, W., et al. (2018). Differentiation of Alzheimer's disease based on local and global parameters in personalized Virtual Brain models. NeuroImage Clin. 19, 240-251. doi: 10.1016/j.nicl.2018.04.017
Zou, X., Coyle, D., Wong-Lin, K., and Maguire, L. (2011). Computational study of hippocampal-septal theta rhythm changes due to beta-amyloidaltered ionic channels. PLOS ONE 6:e21579. doi: 10.1371/journal.pone. 0021579

Conflict of Interest: The authors declare that the research was conducted in the absence of any commercial or financial relationships that could be construed as a potential conflict of interest.

Copyright $\odot 2021$ Stefanovski, Meier, Pai, Triebkorn, Lett, Martin, Bülau, HofmannApitius, Solodkin, McIntosh and Ritter. This is an open-access article distributed under the terms of the Creative Commons Attribution License (CC BY). The use, distribution or reproduction in other forums is permitted, provided the original author(s) and the copyright owner(s) are credited and that the original publication in this journal is cited, in accordance with accepted academic practice. No use, distribution or reproduction is permitted which does not comply with these terms. 